\title{
Beyond Trade
}

\section{The Impact of Preferential Trade Agreements on Foreign Direct Investment Inflows}

\author{
Denis Medvedev*
}

\begin{abstract}
This paper investigates the effects of preferential trade agreements (PTAs) on the net foreign direct investment (FDI) inflows of member countries using a comprehensive database of PTAs in a panel setting. We find that PTA membership is associated with a positive change in net FDI inflows, and the FDI gains are increasing in the market size of the PTA partners and their proximity to the host country. We identify several different channels through which preferential trade liberalization may affect FDI, and confirm that both threshold effects (signing the agreement) and market size effects (joining a larger and faster-growing common market) are important determinants of net FDI inflows, although the latter seem to dominate. The estimated relationship is largely driven by North-South PTAs, and is most pronounced in the late 1990s and early 2000s, which is a period when the majority of "deep integration" PTAs have been advanced.
\end{abstract}

JEL classification: F15, F21, F53.

World Bank Policy Research Working Paper 4065, November 2006

The Policy Research Working Paper Series disseminates the findings of work in progress to encourage the exchange of ideas about development issues. An objective of the series is to get the findings out quickly, even if the presentations are less than fully polished. The papers carry the names of the authors and should be cited accordingly. The findings, interpretations, and conclusions expressed in this paper are entirely those of the authors. They do not necessarily represent the view of the World Bank, its Executive Directors, or the countries they represent. Policy Research Working Papers are available online at http://econ.worldbank.org.

*Development Prospects Group, World Bank and Department of Economics, American University. I am deeply grateful to Robert Blecker, Jeffrey Lewis, Kara Reynolds, and Hans Timmer for valuable comments and suggestions. 


\section{Contents}

1 Introduction $\quad 1$

2 The theory of preferential liberalization and FDI 2

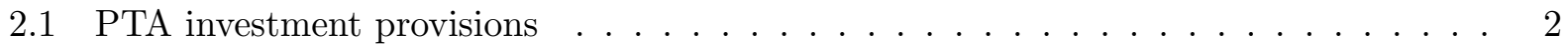

2.2 Investment climate . . . . . . . . . . . . . . . . . . . . . 4

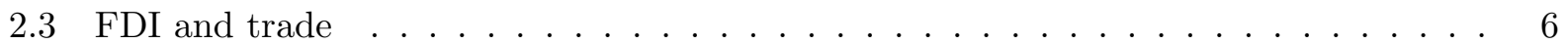

2.4 FDI and market size $\ldots \ldots \ldots \ldots \ldots \ldots \ldots$

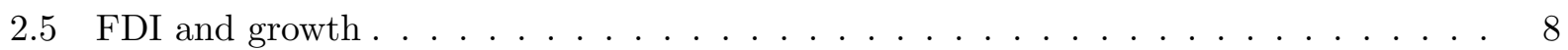

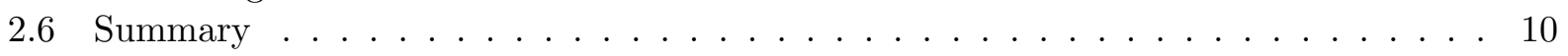

3 Empirical evidence on the effects of PTAs on FDI 10

4 Model setup and estimation results $\quad 14$

4.1 Replication of previous studies . . . . . . . . . . . . . . . . 15

4.2 Baseline model . . . . . . . . . . . . . . . . . . . 26

4.3 Model extensions: alternative specifications of the PTA variable . . . . . . . . . 31

4.4 Decomposition by income level and time period . . . . . . . . . . . . . . 38

5 Conclusion $\quad 42$

A Data details $\quad \mathbf{4 5}$

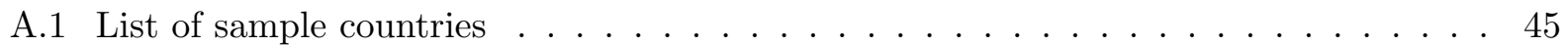

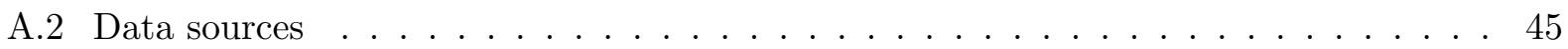

A.3 Data transformation . . . . . . . . . . . . . . . . 46

B Additional estimation results $\quad 5$

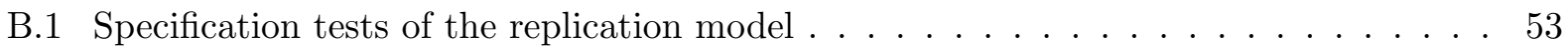

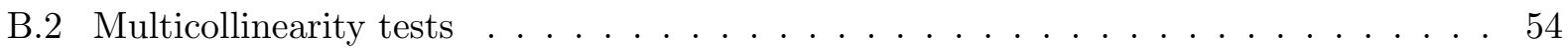

B.3 Granger causality tests . . . . . . . . . . . . . . . . . 54

B.4 Specification tests of the baseline model . . . . . . . . . . . . . . 55

B.5 Decomposing model results by geographic region and income level . . . . . . . . 57

\section{List of Tables}

1 "Deep integration" provisions of various PTAs . . . . . . . . . . . 3

2 Potential effects of preferential trade liberalization on FDI . . . . . . . . . . . 10

$3 \quad$ Fixed effects estimation results: net FDI inflows f . . . . . . . . . . . . 22

$4 \quad$ FGLS estimation results: net FDI inflows . . . . . . . . . . . . . . 28

$5 \quad$ FGLS estimation results with alternative definitions of distance: net FDI inflows . . 32

6 Alternative PTA specification estimation results: net FDI inflows . . . . . . . . . 34

$7 \quad$ Estimation results by income level: net FDI inflows . . . . . . . . . . . . . 38

8 Estimation results by time period: net FDI inflows . . . . . . . . . . . . . 40

9 Regional definitions and country membership . . . . . . . . . . . . . 45

10 Variable names and codes . . . . . . . . . . . . . . . . . . 46

11 Fixed effects and FGLS estimation results: net FDI inflows . . . . . . . . . . . . 53 


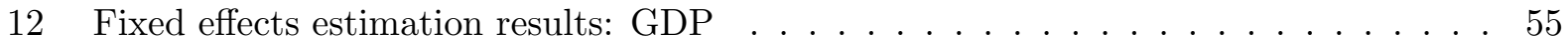

13 Granger causality estimation results . . . . . . . . . . . . . . . 55

14 Fixed effects and FGLS estimation results: net FDI inflows . . . . . . . . . . . 56

15 Estimation results by income level and region: net FDI inflows . . . . . . . . . . 58 


\section{Introduction}

The unprecedented surge in the number of preferential trade agreements signed during the last decade and a half has reinvigorated the policy and research debate in this area. Medvedev (2006) has documented that PTAs signed since 1990 account for over three quarters of all PTAs in force; however, this new wave of PTAs differs from the previous agreements not only in the sheer number, but, more importantly, in content. One of the distinguishing features of the more recent PTAs, sometimes referred to as the "third wave of regionalism" (e.g. Adams et al., 2003), is that the negotiations are no longer dominated by the subject of merchandise trade alone; instead, these PTAs feature a much more intensive pursuit of other areas of integration, such as investment, trade in services, setting and harmonization of standards, competition disciplines, customs cooperation, intellectual property rights (IPR), and dispute settlement.

The emergence of these "deep integration" issues (i.e. areas that go beyond the "shallow integration" of lowering tariff barriers) as major components of many PTAs suggests that preferential agreements are increasingly about much more than trade. Medvedev (2006) has shown that less than half of all trade flows between PTA partners take place in tariff lines where the margin of tariff preference is high enough to justify the costs of satisfying the relevant rules of origin. At the global level, between one-sixth and one-tenth of world trade can be meaningfully considered "preferential"; and the continued progress of multilateral and unilateral liberalization is likely to further erode preference margins due to the growing incidence of zero and low MFN duty lines. More and more PTAs are being signed between countries that are far away from each other and may not be each other's major trading partners, therefore prompting our choice of terminology as preferential trade agreements rather than regional trade agreements - a term that has been often used in the literature discussing preferential liberalization. ${ }^{1}$ Therefore, among the many reasons for the continued pursuit of PTAs mentioned in Medvedev (2006), the incentive of greater market access has become a smaller part of the story. In order to understand the motives behind the drive toward more PTAs, we need to consider areas of integration other than trade - e.g. the "deep integration" issues mentioned earlier.

One of the most often mentioned aspects of "deep integration" is foreign direct investment (FDI). Next to the market access benefits of PTAs, investment provisions are generally afforded the most attention, recognizing the key role of FDI as a source of financing as well as the growthenhancing technology spillovers it is hoped to generate. The interest in FDI is also motivated by its potential ability to create new industries and shift production toward higher value-added activities. Although larger FDI inflows do not automatically translate into benefits for the host economy (for example, the emergence of a dual or enclave economy is a major concern), the potential gains from greater access to financing, job creation, and possible knowledge and technology spillovers can be very enticing for policymakers. For example, many observers viewed the expected post-NAFTA increase in cross-border investment inflows as the main motivation of the agreement for Mexico (see Lederman et al., 2005, chapter 4). A number of other recent PTAs, particularly the North-South agreements, have heavily emphasized specific commitments in the area of investment liberalization and have carried great expectations with regard to increased FDI. Thus, the potential of greater FDI has become an important motivating factor in the pursuit of PTAs.

Although the trade outcomes of PTAs have received extensive attention in the theoretical

\footnotetext{
${ }^{1}$ This choice of terminology saves us from using terms such as "inter-regional regional agreements" to describe PTAs that span multiple regions. Of course, this does not change the fact that the largest and most well-known PTAs, as well as those that account for the bulk of preferential trade, are all between contiguous partners (e.g. NAFTA alone is 37 percent of all trade between PTA partners).
} 
and empirical literature, the FDI consequences of these agreements have generated less academic interest. This knowledge gap is particularly striking given the growing importance of FDI in PTA negotiations. Theoretical models identify both investment-creating and investment-diverting effects of PTAs and leave the question of which ones dominate to empirical studies. The empirical literature on FDI and PTAs has traditionally focused on case studies of large and well-known agreements such as the EU, NAFTA, or MERCOSUR; it is only in the last few years that crosscountry regression estimates of the effects of PTAs on FDI began to appear in the literature. However, despite sampling a large number of countries, these recent studies continue to focus on a small subset of all PTAs in force. This paper aims to add to this emerging literature by combining an extensive sample of PTAs with a set of FDI determinants in a panel framework. Our first contribution is a concise review of the existing theoretical arguments and the empirical evidence on the relationship between PTAs and FDI. The empirical section of this paper tests for a significant relationship between preferential liberalization and net FDI inflows by country in a large panel of high income and developing nations over the last two decades. We conduct extensive specification analysis in order to arrive at a baseline model that adequately explains the variation in the data and establishes a positive relationship between preferential liberalization and net FDI. We then check the robustness of this relationship to different specifications of the PTA variable and decompose the FDI effect by time period, geographic region, and income level of the host country. The rest of the paper is organized as follows: section 2 summarizes the theory of the effects of preferential liberalization on FDI, while section 3 highlights the previous empirical findings. Section 4 presents the model and discusses the estimation results. Section 5 offers concluding remarks.

\section{The theory of preferential liberalization and FDI}

There are a number of ways in which PTAs can affect FDI flows. In this section, we identify five major channels through which preferential liberalization can influence FDI: the direct effects of investment provisions, the indirect effects of changes in trade flows, improvements in the investment climate, creation of an extended market, and long-term growth effects. The following discussion examines each of these mechanisms in some detail; however, the purpose is not to add to the already vast literature on the determinants of FDI, but rather to draw on the existing studies to delineate some general links between PTAs and FDI without specifying a formal model.

\subsection{PTA investment provisions}

The most immediate impact of PTAs on foreign investment is the direct response of FDI to the implementation of various investment provisions in an agreement. We use the term "investment provisions" to refer to the removal of regulatory and legal barriers to international capital flows and the participation of foreign investors in domestic firms and financial markets. If present, the implementation of these provisions will generally work to bring in more FDI as the agreement opens up new sectors, relaxes foreign ownership restrictions, and changes or abolishes local content requirements. However, while the transition mechanism is straightforward, significant increases in FDI flows can materialize only if the most important sectors are not left out of the liberalization schedules and the relevant provisions are successfully implemented. In addition, investment provisions alone are not a guarantee of increased FDI - higher levels of investment are only possible with the implementation of complementary policies that serve to improve the overall investment climate. 
FDI provisions have become more common in recent agreements, which make up the "third wave" of PTAs that began in the 1990s (see Table 1 for a partial list of PTAs whose texts include the liberalization of cross-border financial flows). At the same time, while the incidence of inclusion of FDI disciplines in PTAs is increasing, most of the active PTAs still do not contain any explicit investment provisions, and the majority of those that do fail to make specific commitments, delineate timelines for implementation, and ensure compliance. Notable exceptions include many US free trade agreements, several EU agreements, and a few South-South PTAs.

Table 1: "Deep integration" provisions of various PTAs

\begin{tabular}{|c|c|c|c|c|c|c|c|}
\hline & $\begin{array}{l}\text { Invest- } \\
\text { ment }\end{array}$ & Services & S"Standards & $\begin{array}{l}\text { Compe- } \\
\text { tition }\end{array}$ & $\begin{array}{l}\text { Customs } \\
\text { cooperation }\end{array}$ & 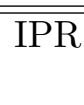 & $\begin{array}{l}\text { Dispute } \\
\text { settlement }\end{array}$ \\
\hline \multicolumn{8}{|l|}{ North-South } \\
\hline US-Jordan & Yes & Yes & No & Yes & Yes & Yes & Yes \\
\hline US-Chile & Yes & Yes & Yes & Yes & Yes & Yes & Yes \\
\hline US-Singapore & Yes & Yes & Yes & Yes & Yes & Yes & Yes \\
\hline US-Australia & Yes & Yes & Yes & Yes & Yes & Yes & Yes \\
\hline US-CAFTA & Yes & Yes & Yes & No & Yes & Yes & Yes \\
\hline US-Morocco & Yes & Yes & Yes & No & Yes & Yes & Yes \\
\hline NAFTA & Yes & Yes & Yes & Yes & Yes & Yes & Yes \\
\hline EU-South Africa & No & No & No & Yes & No & Yes & Yes \\
\hline EU-Mexico & Yes & Yes & Yes* & Yes & Yes* & Yes & Yes \\
\hline EU-Chile & Yes & Yes & Yes* & Yes & Yes & Yes & Yes \\
\hline Euro-Med. & No & No & No & Yes* & No & Yes & Yes \\
\hline Japan-Singapore & Yes & Yes & Yes & Yes & Yes & Yes & Yes \\
\hline Canada-Chile & Yes & Yes & No & Yes & Yes & No & Yes \\
\hline \multicolumn{8}{|l|}{ South-South } \\
\hline MERCOSUR & Yes & Yes & Yes & Yes & Yes & No & Yes \\
\hline Andean Comm. & Yes & Yes & Yes & Yes & Yes & No & Yes \\
\hline CARICOM & Yes & Yes & Yes & Yes & Yes & No & Yes \\
\hline AFTA & Yes & Yes & Yes & No & Yes & No & No \\
\hline SADC & No & n.a. & n.a. & n.a. & Yes & Yes & Yes \\
\hline COMESA & Yes & Yes & Yes & Yes & Yes & No & Yes \\
\hline Chile-Mexico & Yes & Yes & Yes & Yes & Yes & Yes & Yes \\
\hline
\end{tabular}

Source: World Bank (2004).

Note: While EU agreements mention cooperation in most of the subject areas, only those in which specific commitments are undertaken receive a "Yes" rating. $\left(^{*}\right)$ denotes areas where implementation steps are to be agreed on at a later date. Euro-Med. agreements include bilateral PTAs between the EU and developing countries in the Mediterranean basin-EU-Algeria, EU-Tunisia, etc. - that serve as predecessors to a unified EU-Mediterranean Free Trade Area to be implemented by 2010.

It is important to emphasize that Table 1 is not representative of all the 229 active PTAs, and relying on it to make any generalizations about the content and relative strength of investment provisions for all agreements in force is likely to be misleading. There are several reasons why obtaining information on the investment provisions of many PTAs is a challenging task. First, the texts of many agreements are not easily available, and therefore it is difficult to estimate how many PTAs even mention investment as a potential area of cooperation and integration. Second, PTAs 
that do discuss investment often rely on additional schedules to delineate specific details; different agreements focus on different sectors, have varying domestic ownership requirements, and allow for diverse mechanisms of transferring ownership and resolving investor disputes. For example, the US-led agreements commonly emphasize the liberalization of telecommunications and financial services, while the EU-led agreements focus on the lock-in of existing reforms and tend to be more vague on future liberalization commitments. ${ }^{2}$ Among South-South PTAs, the incidence of investment provisions is much more rare. However, when present, these provisions tend to be quite broad and usually rely on the negative list approach. ${ }^{3}$ Some examples of sectors excluded from the investment liberalization provisions in South-South PTAs are automobiles (MERCOSUR) and telecommunications (COMESA).

Despite the wide-ranging differences in the content of investment provisions of PTAs, we can identify several features that are common to most agreements. These include the MFN and national treatment provisions, which ensure that no third party investor is afforded benefits that are not available to investors from within the preferential area, and that investors from within the PTA are treated equally without regard to their national origin. Together, the two provisions can significantly boost investor confidence and the transparency of the policy environment, as their combination implies that investors who are residents of the PTA member countries are entitled to the best available treatment in any of the PTA countries.

Overall, PTAs that include specific investment provisions are likely to generate additional FDI inflows for the member countries, although the magnitude of the impact will vary with the relative strength of the provisions, the sectors they include, and the speed and efficiency with which they are implemented. In addition, complementary policies aimed at strengthening the overall investment climate are generally regarded as a necessary condition for any boost in incoming FDI. We turn to examining the effects of these policies in the next section.

\section{$2.2 \quad$ Investment climate}

In addition to explicit investment provisions, the "third wave" agreements cover a number of other subjects that can influence FDI: trade in services, setting and harmonization of standards, competition policy, customs cooperation, IPR, and dispute settlement (see Table 1 for some examples of PTAs that contain these provisions). Although not directly related to merchandise trade or investment, these features improve the host economy's investment climate and are thus likely to result in increased FDI inflows. The liberalization of service sectors is a difficult fit in the investment climate category, although it provides perhaps the most clear-cut link to increased investment. This is due to the fact that the provision of most services (with the exception of back-office products and remote customer service) requires establishing a presence in the source country, which in turn necessitates new foreign investment.

\footnotetext{
${ }^{2}$ It should be noted that there two qualitatively different categories of EU-led PTAs: those with the ultimate goal of joining the EU (accession agreements), and all others. The accession countries are required to gradually adopt all existing EU rules and regulations with respect to investment flows, and the details of this process are extensively specified and carefully monitored. Other EU-led PTAs devote much less attention to "deep integration" issues, although EU tends to heavily emphasize competition disciplines in both multilateral and PTA forums.

${ }^{3}$ The negative list approach involves specifying only those sectors that are excluded from liberalization, while all others are subject to opening. On the other hand, a positive list approach specifies only the sectors to be liberalized, with all others remaining protected. Although in theory both vehicles can yield a similar degree of reduction in the level of external protection, in practice PTAs utilizing negative lists tend to result in broader and more aggressive liberalization.
} 
Other provisions that tend to encourage foreign investors include clear procedures for dispute settlement and effective protection of one of the key advantages of multinational enterprises (MNEs) - intellectual property. ${ }^{4}$ Taken together, these policies are likely to generate an "investment creation" effect - an FDI parallel to the classic trade creation example. However, although the theoretical links between these provisions and greater incentives for foreign investment are relatively simple, none of them guarantee increased FDI or, conversely, that FDI will not increase even if these disciplines are not strengthened following the signing of a PTA. In other words, improved dispute settlement mechanisms and more IPR protection are neither necessary nor sufficient conditions for increased FDI, although both are capable of creating additional investment at the margin. The empirical literature confirms this observation, since the relationship between, for example, IPR provisions and FDI is difficult to establish and, if found, tends to be quite weak. Thus, in a review of the literature on the relationship between the strength of the IPR regime and FDI, Maskus (2000) cites Mansfield (1993), Maskus and Eby-Konan (1994), and Primo Braga and Fink (1998), who could not establish a link between measures of IPR protection and the distribution of FDI. Other studies, such as Lee and Mansfield (1996) and Maskus (1998), manage to isolate a relationship between US-sourced FDI and IPR, but the results are tentative and, for the latter paper, limited to developing countries.

Even if a particular agreement does not go very far in terms of "deep integration," its provisions could still inspire investor confidence by locking in the existing reforms. Krueger (1999) mentions this possibility in an argument for PTAs as "building blocks" toward global free trade. This hypothesis is also supported by Burfisher et al. (2001), who, while analyzing the effects of NAFTA on its member countries, argue that one of the agreement's main impacts on Mexico has been to lock in the country's commitment to reforms and open policy stance, which in turn helped to buttress investor confidence during the peso crisis and improve the aggregate trade balance. A related transmission channel is that PTAs may stimulate FDI to the extent that greater outward orientation contributes to an overall lowering of country political risk (the reform lock-in phenomenon is just one example of this). In this case, the results of Kolstad and Tondel (2002), who note a positive association between low political risk and larger FDI per capita in a cross-sectional study of 120 developing and industrialized countries, may be relevant for the link between preferential liberalization and FDI.

At the same time, other "third wave" provisions such as mutual recognition of standards and enforcement of competition rules could result in increased or decreased FDI. To the extent that these represent non-tariff barriers to trade, the removal of such barriers may encourage MNEs to export rather than defer production to a local affiliate. Alternatively, since the goods produced in a host country can now be sold in a larger market, the above provisions could motivate increased investment in foreign subsidiaries. Overall, the observations in this and previous paragraphs show that the relationship between FDI and PTA investment climate provisions is difficult to predict ex ante. At the same time, while most of the existing empirical evidence points to a positive association between the two, the relationship is not robust to changes in specification and varied samples.

\footnotetext{
${ }^{4}$ See, for example, chapter 4 of Maskus (2000), which suggests that FDI, particularly when it represents complex but easily copied technologies, is likely to respond positively to stronger protection of IPRs, since such protection increases the value of MNEs' knowledge-based assets.
} 


\section{3 $\quad$ FDI and trade}

Despite the increased attention devoted to "third wave" / "deep integration" issues in recent PTAs, reduction of barriers to merchandise trade remains the focal point of any preferential agreement. Therefore, one of the main PTA-FDI interaction effects is the response of foreign investment to the PTA-induced changes in trade flows. The key determinant of the sign and magnitude of this effect is whether, at the margin, FDI and trade are substitutes or complements. Since intra- and extraPTA trade is affected differently by preferential liberalization (the famous issue of trade creation vs. trade diversion), we can expect the impact on incoming FDI to vary by source country. In line with standard trade theory, the following discussion will assume that intra-PTA trade increases following liberalization, and that extra-PTA trade does not. ${ }^{5}$

The early literature on the interactions between investment and trade, as noted by Blomström and Kokko (1997), conceptualized the two as different modes of reaching foreign markets. According to this view, FDI is attracted to protected markets, where it is cheaper to set up a subsidiary than pay the tariffs required to serve the market through exports (a practice referred to as "tariffjumping" FDI). This type of FDI has a long history, going back to the industrialization of Canada and Australia (Caves, 1996). Chapter 3 of World Bank (2002) cites studies that confirm that high tariff rates on imported goods induced FDI inflows into the United Kingdom (Dunning, 1958), Canada (Horst, 1972), and Australia (Brash, 1966). By lowering or eliminating tariffs between PTA members, preferential liberalization removes incentives for this type of investment, and we therefore expect tariff-jumping FDI to respond negatively to increased intra-PTA trade (which takes place as a result of lower tariff levels - the well-known trade creation result). On the other hand, as long as some trade diversion takes place following the PTA's entry into force, the reduction in trade flows with non-PTA trading partners may be accompanied by increases in investment flows. However, in line with intuition, empirical evidence suggests that tariff-jumping FDI is "transient, lasting as long as the artificial policy-induced incentives" (Balasubramanyam, 2001).

More recently, studies have proposed that FDI need not be undertaken simply to circumvent trade barriers. Instead, the literature has focused on the role of intangible assets of MNEs as a major motivation for FDI (see, for example, Caves (1996) for review). Dunning (1977) provides a conceptual framework where a MNE's decision to undertake foreign investment is guided by one or more of the following motivations: ownership advantage, where a firm's ownership of a product or production process gives it market power in a foreign country, location advantage, where a firm enjoys benefits from relocating production abroad that exceed its plant-level economies of scale at home, or internalization advantage, where a firm gains more by internalizing production rather than licensing it to a foreign associate. Embedding these ideas in a general equilibrium model with endogenous MNEs, Markusen (2002) argues that "trade and investment are complements when the countries differ in relative endowments and investment is vertical, while trade and investment are substitutes when the countries are similar and investment is horizontal." Contrary to conclusions of the earlier paragraph, this framework suggests that the relationship between preferential trade liberalization and FDI can be positive or negative, regardless of whether trade flows are intra- or extra-PTA.

Globerman (2002) develops an argument that FDI is likely to respond positively to preferential

\footnotetext{
${ }^{5}$ We assume that at least some trade creation takes place within a PTA: that is, no matter how little, some reduction in overall protection takes place between PTA partners. With regard to extra-PTA trade, there is no reason to expect increased trade between PTA partners and other countries as a result of the agreement - therefore we assume that the change in extra-PTA trade is non-positive. We make no assumptions about the relative magnitudes of the two effects - i.e. whether a PTA is net trade creating or diverting.
} 
trade liberalization regardless of whether the MNE production structure is vertical or horizontal. This view is grounded in the growing importance of intra-industry and intra-firm trade, as opposed to inter-industry trade based on differential endowments (see, for example, Chapter 2 of World Bank, 2002). Regardless of whether an MNE is vertical (taking advantage of production process economies of scale) or horizontal (benefiting from product economies of scale), the reduction of trade barriers between PTA members makes it less costly for affiliates to ship intermediate and final products to each other. Thus, since MNEs' production structure is highly integrated, intraPTA FDI is likely to respond positively to preferential trade liberalization. At the same time, as long as external protection does not increase, extra-PTA FDI should not decline. This view has received some support from the recent empirical literature, which points to the importance of openness in attracting FDI and the decline of tariff jumping as a primary motivation for FDI flows. ${ }^{6}$ In reviewing cross-country regressions on the determinants of FDI, Chakrabarti (2001) argues that after market size, openness to trade has been the most reliable indicator of the attractiveness of a location for FDI (see also Kolstad and Tondel (2002) for a recent literature review). Thus, there are reasons to believe that FDI and trade may be complements.

Clearly, the existing theoretical and empirical evidence does not provide an unambiguous answer to the direction of the relationship between trade and FDI. Furthermore, the above discussion is limited by the simplifying assumption that there are no constraints on a MNE's ability to generate FDI. Blomström and Kokko (1997) point out that "a firm's capacity to undertake new FDI projects [may be] restricted by its administrative capability or the availability of investment capital." This implies that, in addition to the possibility that intra- and extra-PTA FDI can be substitutes (an investment parallel to the standard trade creation/diversion argument), it could also be the case that within a PTA, investment will be attracted to some markets at the expense of others (including the home/source country market). In particular, a more liberal intra-PTA environment may encourage a MNE to reorganize its production structure by concentrating investment in affiliates with the greatest location advantages - leading to greater FDI inflows in some PTA partners but also to outflows from others. Thus, the net change in FDI flows as a result of preferential trade liberalization could be either positive or negative, depending on the type of FDI, individual country characteristics, and MNEs' capacity to undertake new investment projects.

\subsection{FDI and market size}

While the above discussion illustrates that the aggregate relationship between trade and FDI remains unclear, the connection between host market size and FDI is well established. In a review of literature, Lim (2001) cites both survey and econometric evidence that confirms market size as the most robust determinant of FDI. In fact, virtually all studies of FDI find a highly significant positive effect of the size of the host market on FDI inflows (see also Kolstad and Tondel, 2002; Chakrabarti, 2001). To the extent that a PTA creates an extended market through closer integration of PTA partners, this channel suggests a positive relationship between PTAs and FDI. Blomström and Kokko (1997) argue that this effect works through increased firm size - a larger market may allow some firms to grow beyond what they would have been able to achieve in segmented national markets, or the competitive pressures of a larger marketplace may force some firms to expand through mergers and acquisitions of former competitors. In either case, larger firms are likely to have greater R\&D expenditures, leading to creation of new intangible assets that motivate more FDI.

\footnotetext{
${ }^{6}$ This transition away from tariff-jumping FDI could be attributed to the steady decline of average tariff rates over the past two decades, since FDI of this type is less likely to be found in more open economies.
} 
Furthermore, larger firms may simply have more capacity to participate in new FDI projects due to scale economies. Since the market size of countries not party to a PTA remains unchanged, the extended market FDI effect is first and foremost an intra-PTA phenomenon; however, additional extra-PTA FDI could also be generated if MNEs' capacity to undertake FDI increases. Thus, in contrast to the previous sub-section, the positive relationship between preferential liberalization and FDI could hold not only for host, but also for source countries.

One issue with the extended common market hypothesis of the relationship between PTAs and FDI is that its validity relies on a certain geographic and economic proximity between PTA members. This paper has argued that one of the distinguishing characteristics of the "third wave" of PTAs is that more agreements are being signed between distant countries who are not each other's major trading partners. In this case, it is difficult to build a theoretical argument for the firms' need to expand in order to serve geographically, economically, and culturally distant markets. For instance, even after the full implementation of the US-Morocco and US-Jordan free trade agreements, it would not be appropriate to view the partners' economies as an extended common market, at least not in the same sense as NAFTA or MERCOSUR. On the other hand, to the extent that there is a certain level of demand for Middle Eastern products in the US, we would expect to see a concentration of production of these goods in the FTA beneficiaries following the phase-in of preferences. ${ }^{7}$ In other words, production would be reallocated to Morocco and Jordan from neighboring countries without preferential access to the US, and the former would receive additional FDI.

The above discussion shows that the PTA extended common market effect on FDI is not automatic, and its magnitude depends on the economic and geographic proximity of the partners. Although preferential liberalization can potentially bring some FDI benefits even for distant countries, the impact is likely to be much stronger for closer-positioned partners with established economic ties. Therefore, while the sign of this effect is almost certainly positive, its relative size is likely to vary considerably across different PTAs.

\subsection{FDI and growth}

The links between PTAs and FDI discussed in the previous sub-sections are all likely to be of short- or medium-term nature (the time frame during which relevant provisions are implemented and trade flows adjust). However, PTAs may also affect FDI through more dynamic means by generating additional economic growth. The complementarities between FDI and growth have been well documented in the empirical literature. A number of studies, including World Bank (2001) and UNCTAD (1998) have shown that, controlling for other factors, FDI flows are positively associated with economic growth. Unfortunately, the direction of causation is not clear: while a large literature documents the growth-enhancing knowledge and efficiency spillovers from FDI (see, for example, the review in Lim, 2001), other studies, most notably Rodrik (1999), have suggested that FDI tends to be located in more productive and faster-growing economies. ${ }^{8}$ One solution to the question

\footnotetext{
${ }^{7}$ This assumes that the preferences granted to Moroccan and Jordanian exporters represent a significant cost advantage vs. exporting the same goods under the MFN regime. For many products, this may not be the case- see the discussion in Medvedev (2006), which noted that more than half of all trade between PTA partners takes place in goods with very low or zero MFN tariffs; furthermore, more than 35 percent of all US tariff lines carry a zero percent MFN duty.

${ }^{8}$ This line of reasoning is similar to the critique of trade and growth literature by Rodriguez and Rodrik (2001), who suggest that most of the trade policy variables used in previous studies are endogenous and serve mainly as proxies for macroeconomic stability. They argue that more successful and faster growing economies tend to trade more and have a better trade policy environment, while exogenous changes in trade policy are not a significant
} 
of causality may be the "virtuous circle" hypothesis, where new investment generates additional growth, which in turn brings in more investment through both supply and demand mechanisms (i.e. a faster-growing economy demands a larger quantity of investment, including foreign, while foreign investors are more likely to channel funds toward countries with higher growth rates and consequently greater expected profits). ${ }^{9}$ However, regardless of the direction of the relationship, there is considerable support in both theoretical and empirical literature for the positive association between FDI and growth.

While the positive FDI-growth link is well established, the connection between PTAs and growth is much more ambiguous. There are several channels through which preferential trade liberalization may increase economic growth, although the validity of each pathway must be heavily qualified. For example, if a PTA is trade-creating and improves the overall trade policy environment, we may expect the positive trade liberalization-growth link to be applicable. However, there are important caveats to this channel: first, PTAs do not necessarily result in a more liberal trade environment, ${ }^{10}$ and second, the ability of trade liberalization to contribute to improved growth performance has been subject to much criticism since the early studies by Sachs and Warner (1995) and Dollar (1992) proposing this hypothesis. The main problem, as argued most notably by Rodriguez and Rodrik (2001), is that the direction of causation is not clear and the data only support the conclusion that richer countries tend to have lower trade barriers. The more recent literature on the relationship between trade and growth has focused on the role of institutions in determining both overall trade openness and the economy's growth potential. For example, Rodrik et al. (2004) show that institutional quality is the main determinant of growth in incomes, and that the effect of trade on growth is insignificant once institutional controls are added to the regression equation. Furthermore, while trade does not seem to affect institutions, the converse relationship is positive, large, and statistically significant. On the other hand, Frankel and Rose (2002) find that the trade-growth hypothesis remains valid in the presence of institutional and geographic variables. Dollar and Kraay (2003) show that, despite the very high correlation between trade and institutions, trade explains a larger share of growth in the short and medium run. To complicate matters further, the definition of openness appears to matter for conclusions: Yanikkaya (2003) finds a positive association between trade volumes and growth, but also a positive relationship between trade barriers (e.g. average tariffs) and growth in incomes. Therefore, the trade-growth hypothesis is far from certain, although in a review of the literature, Winters (2004) concludes that "[d]espite the econometric difficulties of establishing beyond doubt from cross-sections that openness enhances growth, the weight of the evidence is quite clearly in that direction."

Another potential PTA-growth link may work through increased efficiency and productivity gains brought about by the higher degree of economic integration in a PTA. However, productivity and efficiency gains are notoriously difficult to measure, and attributing them mainly to PTArelated integration requires a certain leap of faith. Therefore, the validity of the PTA-growth-FDI hypothesis is uncertain. Berthelon (2004) provides some evidence in favor of this relationship: using a panel of both high income and developing countries between 1960 and 1999, he finds a positive correlation between regional integration and growth, but the relationship is significant only for the larger countries in the sample.

determinant of economic growth.

${ }^{9}$ The unfortunate converse to this hypothesis is a downward spiral, where a slow-growing economy is unable to attract new FDI or possibly even retain the existing projects, and its growth rate suffers further.

${ }^{10}$ For a recent example, consider the EAC agreement between Kenya, Tanzania, and Uganda. It has been a wellpublicized fact that, following the implementation of the customs union and common external tariff, Uganda's average level of protection would increase relative to the pre-EAC levels. 
Another possibility bypasses the PTA-growth link and considers instead the additional FDI generated through one of the channels discussed in the earlier sub-sections. As long as preferential liberalization results in a net increase in FDI inflows, we can rely on the FDI-growth linkages discussed earlier to generate additional growth and potentially give rise to the "virtuous circle" hypothesis. This possibility comes with many qualifications, since the suggested relationship is complicated and in any case requires an initial positive change in FDI to jump-start the dynamic PTA-FDI link. The direction of causality is also unclear, since larger and faster-growing economies may be better positioned to take advantage of regional integration and preferential liberalization may thus be an effect rather than a cause. At best, the "virtuous circle" may have many entry points. These could include PTAs, but other factors (e.g. institutions and geography) are likely to be more important. Therefore, although we may expect to see a positive long-run association between preferential trade liberalization and FDI through higher rates of economic growth, the relationship requires a number of rather restrictive initial conditions and is thus tentative at best.

\subsection{Summary}

The above discussion shows that the possible interactions between PTAs and FDI are multifaceted and can act in opposite directions (see Table 2). In fact, even the signs of some individual effects are far from certain. To the extent that multiple transmission channels are present, theory does not establish their relative magnitudes and therefore provides no ready answer for the direction of the net effect. In addition, if there are budget constraints on an MNE's ability to undertake additional FDI, preferential liberalization may result in reallocation of investment from some PTA members to others. Even if no such constraints are present, certain countries within PTAs are likely to benefit more than others because of stronger locational or other advantages. Due to these ambiguities, the sign and magnitude of the overall PTA-induced change in FDI inflows becomes a question for empirical analysis.

Table 2: Potential effects of preferential trade liberalization on FDI

\begin{tabular}{ll}
\hline \hline Transmission channel & Expected change in FDI \\
\hline PTA investment provisions & Positive \\
Other "deep integration" provisions & Mostly positive \\
Trade-FDI elasticity & Ambiguous \\
Market size (both host and source) & Positive \\
Dynamic/growth effects & Positive, but highly uncertain \\
\hline
\end{tabular}

\section{Empirical evidence on the effects of PTAs on FDI}

Most empirical work dealing with the relationship between PTAs and FDI has until recently been limited to case studies of large, well-known agreements such as the EU, NAFTA, or MERCOSUR. Therefore, much of the evidence is largely descriptive. For example, Lim (2001) collects data on FDI as a percentage of GDP for Portugal, Spain, Mexico, Argentina, and Brazil, and notes that the post-PTA FDI share is more than double the pre-PTA share for all countries but Argentina, where the increase is 70 percent. ${ }^{11}$ Lederman et al. (2005) show similar results for Spain and Portugal,

\footnotetext{
${ }^{11}$ Pre- and post-PTA time periods are defined as 1981-1985 and 1986-1990 for EU accession, 1989-1993 and 19941998 for NAFTA, and 1990-1994 and 1995-1998 for MERCOSUR.
} 
but note that FDI inflows for Greece (as a percentage of GDP) remained relatively unchanged following its accession to the EU in 1981 - a phenomenon attributed mainly to its distorted policy environment at the time. Furthermore, the authors argue that the additional FDI in Spain and Portugal represented a one-time portfolio adjustment by investors in favor of these countries, and that the share of FDI to GDP returned to its pre-accession levels in the longer term. World Bank (2000) documents an interesting experience for countries outside the EU: FDI declined in EFTA members following the phase-in of the EU Internal Market Program (IMP) and did not recover until the establishment of the EEA. ${ }^{12}$

Other studies present results based on more formal models. For instance, Pain (1997) uses data on the stock of British FDI in seven sectors in the EU and the US over the 1981-1992 time period to isolate a sharp increase in intra-EU FDI following the implementation of the IMP in 1986. Pain and Lansbury (1997) present similar evidence for German investment into the rest of the EU. On the other hand, Dunning (2000) argues that while the IMP resulted in a substantial net FDI increase in Europe, the majority of that increase came from countries outside the EU. Furthermore, the direct impact of the IMP on FDI is small compared to the response of investment to greater market size and higher income levels generated by European integration.

The evidence on FDI flows into Canada and the US as a result of the Canada-USA FTA (CUFTA) and NAFTA largely parallels the EU findings. For the former agreement, Blomström and Kokko (1997) show that while intra-PTA FDI into Canada declined, extra-PTA FDI increased just enough to offset the decrease. In the US, net FDI rose as a result of CUFTA, but this was achieved through a large increase in FDI from outside the PTA, which more than made up for the decreased investment from Canada. Globerman (2002) echoes these findings by showing that following CUFTA, and, subsequently, NAFTA, FDI flows to Canada from Europe increased much more than those from the US. Thus, there is some support for the tariff-jumping hypothesis: since the consecutive PTAs provided Canada with secure market access to the US, they encouraged new FDI inflows from outside the PTA. At the same time, Canada's outgoing FDI to Europe grew faster than its FDI to the US. Globerman (2002) interprets this finding as indicative of the fact that increased trade intensity is not necessarily coincident with increased FDI intensity," which could be due the existing infrastructure allowing for increased intra-industry CUFTA trade without any significant demand for new FDI. On the other hand, Buckley et al. (2000) find that US FDI into Canada was encouraged by CUFTA and NAFTA; however, exchange rate changes over the same period also supported new FDI.

Turning to PTAs involving developing countries, Lederman et al. (2005) note that FDI into Mexico increased in the first two years following the agreement, but leveled off soon afterwards. In this sense, the pattern of North-South FDI under NAFTA is similar to the stock adjustment experienced by the new EU entrants. Lederman et al. (2005) also show that this increase in FDI to Mexico was dominated by North American sources, while inflows from other regions rose to a more limited extent. The former is consistent with Monge-Naranjo (2002), who finds a positive effect of NAFTA on US-sourced FDI in Mexico only during the first two-three years of the agreement. In addition, Lederman et al. (2005) provide evidence that NAFTA resulted in diversion of FDI from other countries in Latin America, as Mexico's share of US-sourced investment remained stable throughout the 1990s while the share of other countries declined. Blomström and Kokko (1997) and Burfisher et al. (2001) argue that one of the main contributions of NAFTA was an improvement in Mexico's investment climate, achieved largely through its lock-in of policy reforms.

\footnotetext{
${ }^{12} \mathrm{EEA}$ is a free trade agreement between the EU and three of the EFTA countries (Iceland, Liechtenstein, Norway). See Appendix E of Medvedev (2006) for more details.
} 
This argument is consistent with the fingings of Graham and Wada (2000), who show that US FDI to Mexico began to grow rapidly in the late 1980s, much earlier than the implementation of NAFTA, and attribute the increase to Mexico's unilateral policy reforms. In the case of MERCOSUR, Blomström and Kokko (1997) show that extra-PTA FDI responded more strongly to the macroeconomic stabilization programs than the early stages of the Southern Cone project. However, subsequent deeper integration with the establishment of the customs union seemed to result in significant increases in the US investment position in the region. Chudnovsky and López (2001) confirm this result by finding that most of new FDI in MERCOSUR came from outside the PTA. In addition, the benefits of greater FDI were not shared equally across PTA members: due to stronger location advantages, Argentina and Brazil seemed to reap the bulk of the gains.

The evidence on the above agreements seems to suggest that most of the new FDI received by members of these PTAs is tariff-jumping and/or attracted to larger markets. However, these features cannot be characteristic of all PTAs in existence, since the large number of agreements in force would preclude the incentive for such behavior. For instance, the growing number of overlapping PTAs (documented in Medvedev (2006)) is likely to lower the marginal effect of new agreements on FDI through the extended common market channel. Consider the example of the East African Community (EAC) of Kenya, Tanzania, and Uganda, where all three countries are also members of the Cross-Border Initiative (CBI) agreement with several other African nations. Clearly, the extended common market FDI benefits that Kenya may experience from integrating with its EAC partners are not going to be seen again when it joins the CBI (although it may realize additional FDI gains from gaining new access to non-EAC member countries). At the same time, section 2.3 has noted that average MFN tariffs have declined significantly over the past two decades, ${ }^{13}$ which is likely to significantly reduce incentives for tariff-jumping FDI. Finally, the preceding discussion shows that the size of net FDI inflows varies significantly by the host country, ${ }^{14}$ and it is often difficult to separate the PTA effects from the consequences of unilateral liberalization or stabilization policies. Thus, in order to assess the nature of the relationship between preferential liberalization and FDI, cross-country panel estimates covering large numbers of PTAs are needed to complement the case studies of individual agreements.

It is only in the course of the last few years that cross-country analyses of the interactions between PTAs and FDI began to appear. Some of these studies have concentrated on bilateral investment, using a methodology similar to the gravity model of international trade, while others have chosen to focus on the net FDI position of sample countries. As an example of the former, Levy Yeyati et al. (2003) use 1982-1999 data on bilateral outward FDI stocks for 20 source and 60 host countries and find a positive relationship between FDI and membership in the same PTA. They estimate that, on average, joining a PTA increases bilateral FDI between members by 27 percent while a larger common market ${ }^{15}$ affects host's FDI with an elasticity of just over 0.1 . However, their data does not cover FDI between developing countries and their PTA sample is limited to thirteen agreements, including the EU. In addition, although the authors do not impose the same functional relationship for North-South and North-North FDI, their model does not explicitly distinguish between the two by sweeping any potential differences into a country-pair specific intercept term. Finally, although the model in Levy Yeyati et al. (2003) is useful in determining that regional integration matters for bilateral FDI, its specification does not yield any predictions about the direction of the net effect on a country's FDI position.

\footnotetext{
${ }^{13}$ More detailed evidence of this has been presented in Medvedev (2006).

${ }^{14}$ This variation could be related to the economic and geographic proximity of the partners.

${ }^{15}$ This variable is equal to the total GDP of all PTA members.
} 
The last difficulty is addressed in a study of bilateral FDI by Adams et al. (2003), who improve on the simple gravity specification by including three separate PTA variables ${ }^{16}$ to account for intra-PTA FDI creation and extra-PTA FDI diversion, both from PTA members to outsiders and from non-member countries to PTA partners. The authors consider stocks of outward FDI for a panel of high-income and developing countries over 1988-1997 and find six of the nine sample PTAs (including the EU) to be investment-creating, one investment-diverting, and two to have no observable impact. Furthermore, Adams et al. (2003) argue that while tariff-jumping and large market-seeking incentives for FDI appear to matter for some agreements, the majority of the investment impact comes from non-trade provisions.

Although studies like Adams et al. (2003) are useful in determining the net FDI effect of a particular PTA, they cannot establish the impact of preferential liberalization on a net FDI position of a particular country. This question is addressed by Lederman et al. (2005), who focus on aggregate FDI flows to 45 countries over the 1980-2000 period and find a positive relationship between PTAs and FDI. Their sample includes seven PTAs, four of which are in Latin America, and the model assumes that FDI effects are the same across North-North, North-South, and SouthSouth PTAs. Although the coefficient on the PTA membership dummy is insignificant, both the expectation of joining a $\mathrm{PTA}^{17}$ and the size of common market created remain significant across various specifications. The variable coefficients suggest that the expectation of joining a PTA can increase FDI flows by more than one-third, while joining a common market twice as large as the host country can raise FDI flows by twenty percent or more. In another study, Jaumotte (2004) uses a larger sample of 71 developing countries over 1980-1999. Sub-dividing the sample into fiveyear periods, she finds a significant positive effect of the beginning-of-period extended market size on end-of-period FDI stocks. She considers fifteen PTAs - those that had been established prior to 1995-but her model disregards much of time-series variation in the data by using only four observation points over the above period.

In addition to the criticisms mentioned above, the main shortcoming of the existing studies lies in their small sample size, both in terms of country coverage and the number of PTAs considered. The latter is a particular handicap, since the coefficient on the extended market variable will be significantly biased if only some PTAs of which a particular country is a member are included. For example, if the sample PTAs are mainly agreements known to generate large FDI flows, the results could easily be affected in an upward direction. Another difficulty is the lack of differentiation between the effects of North-North vs. North-South vs. South-South agreements, since the determinants of FDI are likely to differ across these types of PTAs. Many of the existing studies are also subject to criticism on econometric grounds, since they do not carefully investigate the time-series properties of FDI flows, which tend to be heavily autocorrelated. Finally, all large panel estimates share the same limitation-by imposing homogeneity restrictions on model coefficients, they disregard much of the cross-country and across-time variation that enrich the analysis of individual PTAs. Therefore, panel results should be viewed as a complement to careful country-level studies rather than a substitute.

\footnotetext{
${ }^{16}$ This follows Soloaga and Winters (2001), who pioneered the three dummy variable specification in a gravity model of trade.

${ }^{17}$ This variable is equal to 1 for two years prior to the PTA coming into existence and 0 otherwise.
} 


\section{Model setup and estimation results}

In this section, we investigate the empirical relationship between preferential trade liberalization and net FDI inflows using a panel of 143 countries over the 1980-2003 period. Given the weaknesses in earlier studies (identified in section 3), this essay distinguishes itself from previous efforts by considering the broadest sample of PTAs available, rather than a handful of the most well-known agreements. In addition, we employ estimation methods that remain consistent in the presence of panel-level heteroscedasticity and autocorrelation. However, due to data limitations, we do not consider the differential impacts of various types of agreements, leaving this as an area for future research. The main contribution of this study lies in determining the links between preferential liberalization and FDI for the largest possible sample of countries and PTAs.

The choice of net FDI inflows as the dependent variable ${ }^{18}$ imposes several important limitations on the direction of our analysis and we acknowledge these at the outset. First, this precludes the use of bilateral datasets, and therefore does not allow us to distinguish FDI by source. This implies, for example, that we cannot separate intra-PTA FDI from investment that comes from outside the preferential trade area, and we cannot readily differentiate between FDI from high income and developing countries. Second, our choice of the dependent variable as a net value carries an implicit acknowledgment that we cannot distinguish whether, for example, a positive change in net FDI inflows is driven by increased inflows or reduced outflows. This implies a certain difficulty in the comparison and interpretation of the results, since a similar change in the dependent variable may be driven by inflows in some countries, outflows in others, and yet other countries may experience varying combinations of the two effects. This is particularly important for the PTA-growth-FDI link proposed in section 2.5, since the technology content of new investment inflows may be different from the composition of the existing stock.

Despite these difficulties, our choice of the dependent variable has some important advantages. Unlike several studies mentioned in section 3, we consider FDI flows rather than stocks in order to improve our tracking of the variation in the data. Globerman and Shapiro (2002) point out that "to the extent that inward and outward FDI have been going on for a long time, recent and relatively large changes in FDI behavior may not be apparent if FDI stock figures are used." That is, as long as FDI stocks are relatively large, annual innovations to these stocks are likely to be marginal, causing an empirical model to have difficulty identifying the determinants of change in the dependent variable. In addition, the calculation of FDI stocks is often not homogeneous across countries (Globerman and Shapiro, 2002). Regarding the issue of bilateral FDI flows vs. net flows by country, the bilateral data are quite scarce and are usually limited to high income countries as the source of foreign investment. Focusing on total net FDI inflows of each country allows us to significantly increase the sample size and also to include South-South FDI flows, albeit implicitly. Furthermore, the exact origin of FDI may not be as important as the type of investment, which is not country-specific. For example, it is not clear that US- and EU-sourced FDI is qualitatively

\footnotetext{
${ }^{18}$ The full series name is "foreign direct investment, net inflows" (see Appendix A for more details). This corresponds to the increase in holdings of foreign enterprises inside a country less the decreases in domestic asset holdings by the same enterprises. It is important to distinguish our dependent variable from net FDI, which is the difference between net FDI inflows and net FDI outflows (the net increase in home country MNE assets abroad). Using the net inflows definition would imply, for example, that FDI would increase in both the US and Canada if the two countries began investing more into each other after the implementation of CUFTA. Contrast this with the net FDI definition, which under the same circumstances could show little or no change in the FDI position of either country (if the bilateral flows would be of the same magnitude and thus cancel out). It is our belief that the former definition represents a more intuitive way of capturing cross-country changes in FDI flows, and also reflects the policy goals of most countries in seeking PTAs as a way to attract net FDI inflows.
} 
different if both are of the same type (e.g. vertical FDI) and destined for the same country and sector. Therefore, looking at aggregate (rather than bilateral) FDI may not be a large cost in terms of the richness of the data while allowing us the significant benefit of considering a much broader sample of countries. ${ }^{19}$ Finally, while our lack of ability to identify the source countries behind changes in net FDI inflows may represent an analytical shortcoming, the policy relevance of this may not be as critical. This is because policymakers are much more likely to care about the overall change in the country's investment position rather than changes in the FDI decisions of individual investment partners. For example, Mexico's decision to join NAFTA was likely motivated by the desire to attract increased FDI not only from the US but from other sources (Europe, Asia) as well. In addition, although definite proof has yet to be supplied, Globerman and Shapiro (1999) argue that FDI inflows and outflows are symmetrical. Therefore, the choice of net FDI inflows as the dependent variable appears to be defensible due to both data and policy considerations.

Our analysis of the relationship between preferential trade liberalization and net FDI inflows focuses on three broad sets of questions. The first question is whether the positive relationship between PTAs and FDI described in the earlier literature holds in our sample. Here, we will rely on a similar methodology as in the previous studies since the objective is to determine if the same PTA-FDI transmission channels can be identified in our dataset. ${ }^{20}$ The second question is whether we can identify alternative (better) ways to measure the association between preferential trade liberalization and FDI. In particular, we will consider several specifications of the extended common market variable to determine which one yields better estimation results. Furthermore, we will investigate whether the number of PTAs signed or the expectation of joining a PTA can offer additional insights into the PTA-FDI relationship. The third and final set of questions will be answered by decomposition analysis: can we extract additional information from decomposing the sample into sub-groups by time period, geographic region, and income level? In particular, we will attempt to identify important trends in the sub-samples that may be driving the overall results.

\subsection{Replication of previous studies}

The starting point for our empirical analysis is the model of Lederman et al. (2005). The main reason for choosing this model is the fact that it is the only existing study that models net FDI inflows by country, which offers two important advantages. First, the set of independent variables in Lederman et al. (2005) is a good initial point for determining the specification of our model (i.e. at least some of the more robust determinants of FDI in their study are likely to be significant in our sample as well). Second, since the main objective of this section is to attempt to identify a similar PTA-FDI relationship as earlier studies, the work of Lederman et al. (2005) is an appropriate point of reference given their choice of the dependent variable. The following discussion will present the model used in the study by Lederman et al. (2005), apply it to our data, offer some critiques of the model specification and econometric methods, and introduce an alternative approach that will become the baseline specification of this paper.

The vector of independent variables in Lederman et al. (2005) can be broadly separated into four main categories:

\footnotetext{
${ }^{19}$ Note that our inability to distinguish intra-PTA FDI from extra-PTA FDI remains a major disadvantage in this case.

${ }^{20}$ In this step, we will generally follow the Lederman et al. (2005) study, since it is the only paper in the existing literature that considers net FDI inflows as the dependent variable. We will, however, make several modifications to their model - see section 4.2 for more details.
} 
1. PTA effects, including a PTA membership dummy, an expected PTA dummy, a measure of the size of the extended common market, and an investment diversion variable; ${ }^{21}$

2. Global effects, including world GDP growth, world FDI, and global interest rates (proxied by the return on a one-year US treasury bill);

3. Local effects, including the level of GDP and its growth rate, outward orientation of the economy, per capita income relative to the US, inflation, and current account balance;

4. Institutional effects, including indices of government stability, rule of law, and quality of bureaucracy.

In attempting to replicate the results of the Lederman et al. (2005) study, we will consider only a subset of the explanatory variables above in order to maximize efficiency and data coverage. The data for all series have been collected from the World Development Indicators (WDI) database of the World Bank. Our criteria for variable choice include ease of data collection, sound theoretical justifications, and the variable's robustness in the estimates presented by the authors. For example, among the variables listed under item 1, we will only consider the extended common market variable and the expected PTA dummy. We will not use the investment diversion variable due to the difficulties involved in its construction and the fact that its coefficient was never significantly different from zero in any of the specifications presented by Lederman et al. (2005). Similarly, we will not use the PTA dummy to capture the potential FDI gains from preferential liberalization. This is because the dummy offers no additional information in the presence of an extended market variable (which, like a dummy, carries a value of zero for countries that are not members of any PTAs, and a positive value for PTA members) and may lead to a violation of the full rank assumption. In fact, Lederman et al. (2005) include the PTA dummy in only half of their specifications and always find the variable insignificantly different from zero, confirming our suspicions. We therefore choose to drop the insignificant variable (PTA dummy), a decision that is also more defensible on theoretical grounds. This is because the PTA common market variable, despite its potential problems, is likely to explain more of the variation in net FDI inflows than a simple dummy since the former allows the model to differentiate across PTAs by the cumulative size of their country members. ${ }^{22}$ We are thus left with an expected PTA dummy and the extended common market size as variables that will be used to capture the potential $\operatorname{link}(\mathrm{s})$ between preferential liberalization and FDI.

In order to construct both of the above variables, data on PTA membership by country have been obtained from the PTA database of Medvedev (2006), which provides comprehensive coverage of PTAs in force. ${ }^{23}$ Overall, our panel takes into account 196 preferential agreements (both regional and bilateral), many of which overlap and which encompass the vast majority of sample countries. For countries that are members of at least one PTA, the PTAGDP variable is defined so that it is equal to zero for all years prior to the PTA entering into force, and the log of the combined GDP

\footnotetext{
${ }^{21}$ Lederman et al. (2005) describe the investment diversion variable as a "weighted sum of the GDP of all the sample countries participating in FTAs, with the weight of each countrys GDP given by the fraction of worldwide GDP covered by its FTA arrangements."

${ }^{22}$ Recall that the simple version of this variable does not take into account the geographic and economic distance between PTA partners. We will consider these issues in more detail during specification tests in section 4.3, where, for example, we will investigate the effects of using the dummy variable alone, as well as the appropriateness of alternative versions of the PTA extended common market variable.

${ }^{23}$ This dataset improves upon previous sources by including agreements that have not been notified to the WTO as well as PTAs found in the WTO database. This addition is important since the PTAs that have not been notified to the WTO account for more than $45 \%$ of the total number of PTAs in force.
} 
of PTA partners thereafter. If a country is a member of multiple PTAs, we sum over the GDP of all of its PTA partners so that $P T A G D P_{i}=\ln \left(\sum_{j}^{N} G D P_{i j}\right) \forall i \neq j$, where $j$ ranges over all of the PTA partners of country $i$; in a time-series context, we add the GDP of new PTA partners to the PTAGDP value in the year in which a country enters into a new agreement. In the case of overlapping agreements (i.e. when the same country pair appears in more than one PTA) ${ }^{24}$ we add a given partner's GDP to the PTAGDP variable in the year in which the earlier of the two (or more) agreements enters into force. Finally, for countries that are not members of a single PTA in a given year, $P T A G D P$ is equal to zero. It is important to acknowledge in advance that this is only one of a number of potential measures of the size of the PTA extended common market, and we construct the PTAGDP variable in the above fashion mainly to be consistent with the model of Lederman et al. (2005). Both this section and section 2.4 have mentioned several shortcomings of this specification, and we will consider alternative measures later in the paper.

Among the global effects in the model of Lederman et al. (2005), we retain the global FDI and global growth variables but drop the international interest rate variable. This decision is driven by two reasons. First, it is not clear that the one-year return on the US Treasury bills is a good measure of the global interest rate environment. Second, the coefficient on this variable is never significantly different from zero in any of the specifications attempted by the authors. Both the global FDI and the global growth variables are calculated using the "world" aggregate of the WDI rather than the sum (or average) of the relevant values for each of the sample countries; this is done because the "world" aggregate is already adjusted for missing observations. Note that the two global variables - world growth and world FDI - are potentially collinear since growth and FDI are positively correlated. Lederman et al. (2005) do not discuss this possibility, but we believe it is not a serious problem. This is because the theoretical relationship between the two, although valid in both directions, allows only for forward-looking causation. Since the equation to be estimated includes only the contemporaneous values of these variables, collinearity is likely to be a problem only to the extent that the current levels of the variables are determined by their past values. ${ }^{25}$ Another potential problem is the endogeneity of the global FDI variable, since a higher average value of the dependent variable implies greater global FDI. Although this problem is likely to be significant only if an individual country contributes to a large share of the variation in the global variable, we believe this possibility should be addressed nonetheless since it implies a direct correlation between one of the independent variables and the error term. Since the authors do not consider this in their discussion, we will estimate the replication model as they specified it and address this issue when we present our own baseline model in the following section.

We keep all of the local factors considered by Lederman et al. (2005) with the exception of the current account balance. In contrast to the variables we excluded in the earlier discussion, the trade deficit enters as a significant FDI determinant (with a negative coefficient) in all of the specifications presented by the authors. However, their a priori justifications for including this variable are not clear - the authors mention that it could take on a positive or a negative sign, depending on whether it captures the overall financing need or macro instability. In the broader

\footnotetext{
${ }^{24}$ The instances of the same country pair appearing in multiple PTAs are quite common-see the discussion in Medvedev (2006), which shows that more than $43 \%$ of all country pairs in PTAs are members of more than one preferential agreement. For example, Kenya and Uganda are both members of the EAC and COMESA, and Georgia and Armenia are both members of the CIS agreement but also have a bilateral FTA.

${ }^{25}$ This possibility is not trivial, since both growth and FDI time series are strongly serially correlated. However, regressing one of the variables on the other yields an insignificant $t$-statistic and an $R^{2}$ of close to zero, showing that the statistical relationship between the two is very weak. Furthermore, analysis using variance inflation factors (VIF) shows that most of the variation in each of these variables is independent of the other variable.
} 
FDI literature, this variable appears with both signs, and its interpretation varies with the sign of the estimated coefficient (see Chakrabarti (2001) for a more detailed discussion). Since it is not clear beforehand what this variable is measuring, we choose to exclude it and instead keep inflation, which was not significant in any estimates presented by Lederman et al. (2005). If the trade deficit mainly reflects macro instability (as indicated by the estimated negative coefficient in the authors' results), then the inflation variable should pick up that effect once the collinearity between inflation and current account balance is removed by dropping the latter. Furthermore, there are potential endogeneity problems with including the current account variable, since FDI is part of the balance of payments and therefore related to the current account. The inflation rate is calculated as the annual percentage change in the consumer price index of each country, where the CPI base year is 2000 (i.e. $C P I_{i, 2000}=100$ ). The level of per capita income relative to the US is calculated as a ratio of GNI per capita, i.e. GNIpc $c_{i, t} / G N I p c_{U S A, t}$.

We keep the GDP variable in the replication model even though Lederman et al. (2005) find that GDP level has an insignificant effect on net FDI inflows. ${ }^{26}$ This finding is a stark contrast to the existing literature on FDI determinants. For example, Chakrabarti (2001) cites over a dozen papers that have found a positive effect of market size (defined as absolute GDP, GDP per capita, GNI, or GNI per capita) on FDI and concludes that "market size has, by far, been the single most widely accepted ... significant determinant of FDI flows." Therefore, it is very difficult to justify dropping this variable on theoretical grounds, and we choose to retain it in the replication model. We use the trade-to-GDP ratio as a measure of the economy's openness and outward orientation, and calculate it as $\left(X_{i t}+M_{i t}\right) / G D P_{i t}$, where $X_{i t}$ and $M_{i t}$ are merchandise exports and imports, respectively, of country $i$ in time period $t$. It should be acknowledged at the outset that the tradeto-GDP ratio does not necessarily reflect the extent of an economy's outward orientation - among other things, it could be measuring country size (inversely) - and it could reflect either free trade or interventionist export promotion policies. An alternative measure for openness is tariff levels, but data is more scarce and there is also less time-series variability, both of which make estimation more difficult. In addition, according to the ranking of the most robust determinants of FDI by Chakrabarti (2001), the trade-to-GDP ratio places five positions above tariff levels. Furthermore, low tariffs do not always indicate a more open economy due to the presence of non-tariff barriers, which are notoriously difficult to measure.

Endogeneity is a likely problem for both of the above variables. There are many potential channels through which FDI may affect GDP, the simplest one being that any host country investment financed by FDI is included in the national accounts definition of GDP. Similarly, there are various ways in which FDI and trade may be complements or substitutes - many of which have been discussed in section 2.3. However, Lederman et al. (2005) do not discuss the potential endogeneity of either of these variables specifically and therefore we estimate the replication model without any corrections. ${ }^{27}$ We will, however, return to these issues during the discussion of the estimation results and the motivation for our baseline model in the following section.

The GDP growth rates of individual countries have been calculated as annual percentage changes, i.e. $\left(x_{t}-x_{t-1}\right) / x_{t-1}$. One potential difficulty with using GDP growth rates in a model of FDI is the probable endogeneity of the two variables. Section 2.5 has noted that there is no certainty regarding the directions of causation - some studies argue that FDI generates growth while

\footnotetext{
${ }^{26}$ The authors, surprisingly, offer no explanation for this result.

${ }^{27}$ The authors do mention endogeneity as a general problem and report that specification testing could not reject the exogeneity of regressors. However, the comment on specification testing appears to refer solely to the GDP growth variable.
} 
others suggest that FDI tends to be located in faster-growing economies. However, this endogeneity problem is unlikely to arise in our analysis since we model FDI in the current time period as a function of GDP growth in the previous period. Therefore, we allow previous growth to affect FDI ${ }^{28}$ but the reverse causality is only possible if we accept that current levels of FDI may affect growth rates in the earlier period. Since the theory only allows for the forward-looking growth-FDI relationship, it is doubtful that our estimates will suffer from this endogeneity problem. ${ }^{29}$ Another reason to be optimistic is that the causal links from FDI to growth are usually envisioned as a long-run phenomenon, and therefore are less likely to be problematic in annual data.

Finally, the institutional quality variables are not included in the replication model because they are likely to significantly limit the sample size due to data availability. In addition, Blonigen (2005) highlights two other potential difficulties in using these variables for empirical FDI analysis. First, since the indices are usually computed using survey responses, cross-country comparability is questionable when the composition of respondents varies across countries. Second, since institutions are quite static, the amount of information that can be extracted from time-series variation in these variables is likely to be negligible. Furthermore, fixed effects estimation allows us to control for a number of country-specific characteristics that display a lot of inertia-such as the quality of institutions.

Taking into account the above modifications to the model of Lederman et al. (2005), we are left with a specification in which a country's net FDI inflows are a function of its income level and growth, per capita income relative to the US, openness, rate of inflation, global growth and FDI, membership in a PTA, and the expectation of joining a preferential agreement. With the exception of inflation, all country-specific variables are identified by Chakrabarti (2001) as the most robust empirical determinants of FDI. The equation to be estimated is:

$$
\begin{aligned}
F D I_{i t} & =\alpha+\gamma_{i}+\beta_{1} G D P_{i t}+\beta_{2} O P E N_{i t}+\beta_{3} G N I R E L_{i t}+\beta_{4} G D P G R O_{i t}+\beta_{5} C P I G R O_{i t} \\
& +\beta_{6} W L D F D I_{t}+\beta_{7} W L D G R O_{t}+\beta_{8} P T A G D P_{i t}+\beta_{9} P T A E X P_{i t}+\epsilon_{i t}
\end{aligned}
$$

where

$F D I_{i t} \quad$ is the log of net FDI inflows to country $i$ in time period $t$

$\alpha, \gamma_{i} \quad$ are the constant and country fixed effects

$G D P_{i t} \quad$ is the log of GDP of country $i$ in $t$

$O P E N_{i t} \quad$ is the trade-to-GDP ratio of $i$ in $t$

$G N I R E L_{i t}$ is the ratio of per capita GNI of country $i$ to per capita GNI of the US in $t$

$G D P G R O_{i t}$ is the GDP growth rate of $i$ between $t$ and $(t-1)$

$C P I G R O_{i t}$ is the rate of inflation in $i$ between $t$ and $(t-1)^{30}$

$W L D F D I_{t} \quad$ is the log of net world FDI inflows in $t^{31}$

$W L D G R O_{t}$ is the growth rate of world GDP between $t$ and $(t-1)$

PTAGDP $i t$ is log of the sum of GDP of PTA partners of country $i$ at time $t$

$P T A E X P_{i t} \quad$ is equal to 1 for two years prior to country $i$ joining its first PTA

$\epsilon_{i t} \quad$ is the error term

\footnotetext{
${ }^{28}$ This is consistent with the arguments of Rodrik (1999).

${ }^{29}$ The problem may arise nonetheless if both series are highly autocorrelated, although an estimation approach that explicitly controls for serial correlation should minimize any adverse effects.

${ }^{30}$ This is equal to the growth rate of the Consumer Price Index (CPI).

${ }^{31}$ This is calculated using the "world" aggregate of the WDI rather than the sum of net FDI inflows in all sample countries.
} 
The dataset is an unbalanced panel of 143 high income and developing countries over the 19802003 period. ${ }^{32}$ All values are expressed in current US dollars. ${ }^{33}$ Since the dependent variable is expressed in logs, the estimated coefficients should be interpreted as elasticities and semi-elasticities. In line with the market size hypothesis, we expect the elasticity of FDI inflows with respect to GDP to be positive. The semi-elasticity of FDI with respect to openness should also be positive as long as FDI and trade are complements. On the other hand, the semi-elasticity of the relative income per capita should be negative if this variable is successful in capturing differences in labor costs across countries. In other words, if FDI is attracted to markets where real wages are relatively low (controlling for other determinants) and GNI per capita accurately reflects wage differences, ${ }^{34}$ countries with low levels of GNI per capita relative to the US should receive more net FDI inflows, after controlling for other factors. We expect the semi-elasticity of GDP growth to be positive, while the semi-elasticity of inflation (which can be interpreted more generally as a measure of macro instability) should be negative. Turning to the global effects, we expect the world FDI elasticity to be positive as this variable picks up aggregate FDI trends and globalization effects. Lederman et al. (2005) argue that the semi-elasticity of individual country FDI inflows with respect to global GDP growth is likely to have a negative value - ceteris paribus, faster growth in the rest of the world will make the host country a less appealing recipient of FDI. Following the discussion of section 2.4, we expect the elasticity of FDI with respect to the PTA common market variable $(P T A G D P)$ to be positive. Finally, the semi-elasticity of expected PTA membership should also be positive.

Given the longitudinal nature of the dataset, obtaining accurate and consistent estimates is conditional on the extent to which we are able to account for heterogeneity across countries and time periods. A standard approach to capturing cross-country variation is the fixed effects methodology, which assumes that differences across countries are systematic manifestations of unobserved country-specific characteristics. In recent panel literature, it has become common practice to estimate panel models using both country and year fixed effects to capture both the unobserved country- and year-specific variation. However, this approach is not appropriate if the vector of independent variables includes regressors that do not vary within or across countries. This is because both methods of estimating fixed-effects models - the least squares dummy variables (LSDV) estimator and the within estimator - cannot properly capture the effects of such variables. For the former estimator, the time-invariant variables are perfectly collinear with individual fixed effects, while the country-invariant variables are perfectly collinear with time fixed effects. For the within estimator, both the time- and country-invariant variables are differenced away when the model is specified with two sets of fixed effects. ${ }^{35}$ Since equation (1) includes two variables that do not

\footnotetext{
${ }^{32}$ The EU-15 is treated as a single country from the beginning of the panel. This choice is driven by several reasons. First, there are no internal barriers to investment flows within the European Union. Second, the EU negotiates all of its PTAs as a single bloc, and its PTA partners enjoy equal access to all EU members. Finally, treating the EU-15 as a single country is consistent with the methodology of Medvedev (2006), which adopted a similar treatment in the context of a gravity model of trade.

${ }^{33}$ See Appendix A for a more detailed discussion of the data sources used in this paper.

${ }^{34}$ The latter part of the statement is in fact far from certain. We will return to this subject when discussing the estimation results and their potential problems.

${ }^{35}$ Consider a simple panel with dimensions $N$ and $T$, where $N$ is the number of countries and $T$ is the number of time periods. This panel also contains a certain country-specific variable $z_{i}(i \in N)$ that, for a given country $i$, is the same in each time period $t(t \in T)$, i.e. $z_{i t}=z_{i} \forall t$. If we estimate this model using fixed effects by manually specifying $N$ dummy variables (and dropping the constant to avoid the dummy variable trap), the fixed effect for a country $i$ will be indistinguishable from the effect of the $z_{i}$ variable. To see this, note that $y_{i t}=\beta^{\prime} \mathbf{x}_{\mathbf{i t}}+\gamma z_{i}+u_{i}=\beta^{\prime} \mathbf{x}_{\mathbf{i t}}+\gamma\left(z_{i}+\gamma^{-1} u_{i}\right)$. In other words, either the $z_{i}$ variable or the fixed effect can be dropped without any loss in the explanatory power of
} 
vary across countries - world growth and world FDI - it is not appropriate to include year fixed effects in the model. This approach also implies a certain degree of imprecision in our results, since any year-specific shocks will be to some extent reflected in the coefficient estimates of our global variables. On the other hand, rather than sweeping away all country-invariant time series heterogeneity into the year fixed effects, this approach allows us to identify the impact of certain global shocks on individual country FDI inflows.

Based on the discussion above, we begin by estimating equation (1) with country fixed effects, which is also the approach of Lederman et al. (2005). The estimated coefficients, excluding the constant and individual fixed effects, are shown in Table 3. This specification appears to do a good job of explaining the variation in the dependent variable: the overall $R^{2}$ is high, ${ }^{36}$ the $F$ statistic is significant at the 1 percent level, and a Wald test $\left(F_{(141,2410)}=15.03, p=0.00\right)$ shows that the fixed effects are significant as a group. Furthermore, the coefficients on all of the model's control variables are significantly different from zero at the 5 percent level or higher, are correctly signed in accordance with our expectations, and imply reasonable elasticity values. Due to the differences in data sources, number of countries considered, and the vector of independent variables, it is not possible to make exact quantitative comparisons of coefficient values of our model with the estimates of Lederman et al. (2005). However, our results are also qualitatively different from theirs: for example, both the GDP level and inflation are highly significant. The former is consistent with a wide majority of FDI studies mentioned above, and the latter appears to confirm our earlier argument with respect to macroeconomic instability. With respect to the global variables, Lederman et al. (2005) estimate that world FDI has a much larger impact than world growth, while we find the opposite. Perhaps the most important difference, however, rests not with the model's control variables but with the two variables measuring preferential liberalization-PTAGDP and PTAEXP. Neither of these variables is significantly different from zero, while Lederman et al. (2005) find them significant at 5 and 1 percent levels, respectively.

The results in Table 3 imply that we cannot establish a statistically significant link between preferential liberalization and net FDI inflows using the specification of equation (1). One possibility is that such a relationship does not exist once we broaden our scope to most of the countries and PTAs in the world. However, it also possible that the relationship is present but the model in equation (1) is not capable of correctly capturing it due to several potential problems, including model misspecification and the use of inappropriate estimation methods. In the following discussion, we will identify some of these issues and consider how they might be addressed. This will set the stage for the next section, which will present an augmented model that takes account of these problems and becomes the baseline specification for this paper. The issues we will focus on include crosspanel heteroscedasticity and within-panel serial correlation, omitted variables, multicollinearity, and endogeneity. We address each of these in turn below.

Heteroscedasticity and autocorrelation. Empirical tests reveal that the estimates in Table 3 do not account for several important patterns in the model residuals. First, a Breusch-Pagan

the model, since the magnitude of the fixed effect can be scaled in either direction.

If we implement the fixed effects methodology using the within estimator, the outcome is essentially the same. Recall that in order to avoid the loss in degrees of freedom from specifying a large number of dummies, the within estimator relies on a simple transformation of the dependent variable $\left(y_{i t}-\bar{y}_{i}\right)$. When the same procedure is applied to the right hand side of the estimated equation, all time-invariant variables disappear, since $z_{i t}-\bar{z}_{i}=z_{i}-z_{i}=0$ (see chapter 2 of Baltagi (2001) for more details). The same reasoning applies for estimating models with country-invariant variables under time fixed effects, and panels with more than one set of fixed effects.

${ }^{36}$ Although the within $R^{2}$, arguably a better measure of model performance under the fixed effects approach, is much more modest at 37.6 precent. 
Table 3: Fixed effects estimation results: net FDI inflows

\begin{tabular}{lcc}
\hline \hline Variable & Coefficient & Std. error \\
\hline GDP & $1.209^{* *}$ & 0.094 \\
OPEN & $0.651^{* *}$ & 0.118 \\
GNIREL & $-1.904^{* *}$ & 0.472 \\
GDPGRO & $0.444^{*}$ & 0.177 \\
CPIGRO & $-0.028^{* *}$ & 0.006 \\
WLDGRO & $-1.235^{* *}$ & 0.467 \\
WLDFDI & $0.376^{* *}$ & 0.037 \\
PTAGDP & 0.002 & 0.004 \\
PTAEXP & -0.031 & 0.061 \\
\hline \multicolumn{3}{c}{2561} \\
\hline N & \multicolumn{2}{c}{0.645} \\
$\mathrm{R}^{2}$ & \multicolumn{2}{c}{${ }^{2 *}$} \\
F (150,2410) \\
\hline Significance levels : $\dagger 10 \%$ \\
Note: The dependent variable is expressed in \\
natural logarithms.
\end{tabular}

test reveals the presence of cross-panel heteroscedasticity $\left(\chi^{2}=239.38, p=0.00\right)$, which, while leaving coefficient estimates unbiased, can significantly influence standard errors and therefore affect hypothesis testing. There are a number of statistical techniques that can address this problem (e.g. weighted least squares), but their applicability and implementation are less clear in a panel context. Therefore, most panel studies rely on the Huber-White sandwich method to calculate robust standard errors, which represent consistent estimates of the variance-covariance matrix in the presence of heteroscedasticity. In the context of estimates in Table 3, however, it turns out that heteroscedasticity is not a significant problem since robust estimation does not qualitatively change the results - even though the standard errors increase by as much as 100 percent in some cases, it is not enough to push the significance level of any of the local or global coefficients below the 5 percent threshold. ${ }^{37}$

In addition to heteroscedasticity, the estimates in Table 3 are also affected by serial correlation. In particular, a Wooldridge test for autocorrelation in panel data rejects the null of no first order serial correlation $\left(F_{(1,138)}=103.032, p=0.00\right)$. The consequences of autocorrelation are similar to heteroscedasticity, but the problems caused by the latter are usually more severe. OLS coefficient estimates remain consistent and unbiased in the presence of autocorrelation, but they are no longer best linear unbiased estimators (BLUE) or asymptotically efficient. Furthermore, autocorrelation causes standard errors to be biased. Corrections for autocorrelation range from OLS estimation with Newey-West standard errors to Cochrane-Orcutt or Prais-Winsten transformations, which generalize to two-step feasible generalized least squares (FGLS) in panel data. However, the latter become incomparable with the more simple OLS-based approaches, both because coefficient signs and magnitudes can change quite drastically and because the properties of the FGLS estimators are only known asymptotically (i.e. hypothesis testing is based on the $z$ rather than $t$ statistics). In addition, if both heteroscedasticity and autocorrelation are present in the data, a three-step FGLS approach is required, further complicating comparisons with OLS/LSDV-type models. ${ }^{38}$

\footnotetext{
${ }^{37}$ See Table 11 in Appendix B for estimates of equation (1) using the Huber-White robust standard errors.

${ }^{38}$ To illustrate this, Table 11 in Appendix B presents three-step FGLS estimates of equation (1). The results
} 
Omitted variables. A notable omission from the set of regressors in equation (1) is the exchange rate, which is cited in many studies as a critical determinant of FDI (see, for example, Chakrabarti, 2001). The most basic theories of the relationship between exchange rate movements and FDI argue that a real depreciation of home currency reduces production costs for foreign investors and therefore attracts FDI inflows (see, for instance, Cushman, 1985). In addition, a real depreciation lowers foreigners' costs of acquiring domestic assets, which should also stimulate FDI. In more recent theoretical models, the link between exchange rate movements and FDI is assumed to work through capital market imperfections, since the stream of income in a weak currency is subject to greater risk and is therefore capitalized at a higher rate. For instance, Froot and Stein (1991) suggest that under information asymmetries, monitoring costs cause external financing to be more expensive than internal financing. In this situation, depreciation of the domestic currency not only increases the relative wealth of foreigners, but also increases the relative rate of return for foreign firms who can invest in domestic assets without incurring the monitoring penalty, therefore encouraging additional FDI. Blonigen (1997) also proposes a positive link between exchange rate depreciation and FDI, although his reasoning differs from that of the previous authors: even if domestic and foreign firms may have the same opportunities to purchase domestic assets, these assets can generate returns in currencies other than those used for purchase, which tends to favor foreign investors.

There are several other explanatory variables that could be added to the model specification, most notably some measure of tax policy. However, to the extent that tax codes tend to be rather static and are not revised frequently, a fixed effects methodology may effectively control for tax policy just as it should capture cross-country differences in the quality of institutions. Therefore, we focus on the exchange rate as the main omission from the set of control variables in equation (1)..$^{39}$

Turning now to the hypothesized PTA-FDI relationship, it is worth investigating whether the extended market size variable is sufficient to capture the potential links between membership in PTAs and changes in net FDI inflows. We have already mentioned that it is not appropriate to add a PTA dummy to a specification that includes the PT AGDP variable - the coefficient on the dummy is insignificant and its presence is likely to cause multicollinearity problems. However, some other PTA-related variables may be more promising. For example, section 2.4 has argued that economic and geographic proximity may be an important component of any relationship between PTAs and FDI based on the extended common market hypothesis. For example, while it is quite easy to imagine a firm benefiting from economies of scale by serving both US and Canadian markets under NAFTA, it is much more difficult to propose that the same relationship holds for the US-Chile FTA and even more so for the US-Jordan agreement. Therefore, distance may be an important factor in determining the strength of the PTA-FDI relationship, and omitting this variable from the model specification could bias the extended market size coefficient. Similar to gravity models of trade, the underlying assumption does not postulate that distance itself makes trading or investing more costly, but rather that transaction costs tend to be increasing with the distance between countries. The immediate application of this variable rests with models of bilateral FDI (see Levy Yeyati et al.

are very different from before, indicating that autocorrelation is in fact a significant problem in our sample. Note that these estimates are shown largely for illustrative purposes, since the model continues to be affected by several specification problems that will be highlighted in the following discussion. More details on the FGLS estimator will also be provided below.

${ }^{39}$ More precisely, the missing variable is the change in the exchange rate rather than its level. Some empirical studies have also used exchange rate volatility as an independent variable, but that is more indicative of macro instability than the relative wealth and capital market effects described in the previous paragraph. 
(2003) and Adams et al. (2003), both of whom find a significant negative impact of distance on outward FDI stocks). However, even in the context of net FDI inflows per country, one might expect that more FDI is likely to take place between neighboring members of a preferential agreement. On the other hand, to the extent that trade volumes are negatively related to distance and trade and FDI may be substitutes, we could see a positive relationship between distance and net FDI inflows. Therefore, while the expected sign of this variable is not clear and likely depends on the purpose of investment (i.e. whether FDI is market-seeking, tariff-jumping, etc.), in either case it could be an important determinant of net FDI inflows between PTA partners.

Multicollinearity. A high level of correlation among regressors is quite common in time-series data. However, collinearity among the model's independent variables inflates standard errors and results in overfitting, potentially over-estimating the effects of some collinear variables and underestimating the effects of others. There are few formal tests for multicollinearity, and the applicability of existing ones (such as VIF) to panel data is not entirely clear. Nonetheless, simply regressing one of the collinear variables on the other (and controlling for fixed effects in panel data) is often enough to determine the severity of the problem. We have already mentioned multicollinearity issues while discussing the potential correlation between global growth and global FDI, where we concluded that the contribution of one variable to explaining changes in the other is minimal. Other potential multicollinearity problems in the model described by equation (1) include correlation between the level of GDP and openness, as well as GDP and relative GNI per capita.

One of the reasons GDP and openness may be collinear is that smaller countries tend to have larger trade-to-GDP ratios. However, the within-panel (time-series) correlation, which is much more important for panel analysis using fixed effects, is very low. In an LSDV regression of openness on GDP the overall $R^{2}$ is just under three percent, while the within $R^{2}$ is around one percent. ${ }^{40}$ Thus, although the two variables are negatively correlated, as indicated by a significant $t$-statistic, the variation in one variable explains only a small fraction of variation in the other, and therefore multicollinearity is unlikely to pose a serious problem for estimation of partial effects of GDP and openness on net FDI inflows.

Unfortunately, the same conclusion cannot be drawn for GDP and relative GNI per capita. While Lederman et al. (2005) claim that the latter is indicative of real labor costs, it is quite likely that both variables may capture the effects of market size. ${ }^{41}$ In fact, when regressing one variable on the other (and using fixed effects) we find a significantly positive slope coefficient and an $R^{2}$ of almost 16 percent. ${ }^{42}$ Therefore, the relatively high correlation between these two variables is likely to cause estimation problems. This is evident from the results of Table 11 in Appendix B, where the relative GNI variable switches signs when we move from one estimation approach to another. While there are approaches that provide consistent estimates in the presence of multicollinearity (e.g. principal components), these have usually not been generalized to panel settings and do not control for other problems such as heteroscedasticity and autocorrelation. In such instances, the more common approach has been to drop the problematic variable or, if the theory demands its inclusion, to estimate the model as is and note that standard errors are likely to be inflated and coefficients unstable. Since equation (1) already includes a control for market size, we do not need to add another measure of size to the model. Since relative GNI is intended to capture differences in relative labor costs, it would be preferable to use real wage data in its

\footnotetext{
${ }^{40}$ See Appendix B for the estimation results.

${ }^{41}$ See, for example, an earlier reference to the discussion of market size in Chakrabarti (2001), who includes GNI per capita in the list of variables that reflect it.

${ }^{42}$ See Appendix B for the estimation results.
} 
place. However, this is problematic for several reasons: data on wages is quite scarce, reliability and cross-country comparability are highly questionable, and the level of aggregation is not clear (i.e. whether one should focus on skilled wages vs. overall, urban vs. economywide, etc.). Therefore, the best approach seems to be to drop the relative GNI per capita and rely on the fixed effects to capture some of the cross-country variation in wage levels.

Endogeneity. In the course of the previous discussion, we have already mentioned potential endogeneity problems with GDP, openness, GDP growth, and global FDI. ${ }^{43}$ Endogeneity, or twoway causality, presents problems not only for inference but also for estimation, since the right hand side variable is potentially correlated with the variation in the dependent variable that is relegated to the error term. Thus, the $\operatorname{Cov}[\epsilon, \mathbf{X}]=0$ assumption is violated, and consistent estimation requires obtaining instrument(s) that are uncorrelated with the error term. In fact, both of the commonly used endogeneity tests - the Durbin-Wu-Hausman test and the C-statistic (the difference-in-Sargan statistic) - rely on comparing regression results before and after applying the instruments. In order to test a subset of orthogonality conditions (i.e. the exogeneity of one or more instruments), both tests contrast the efficient, but potentially inconsistent estimates before the IV procedure with the consistent, but possibly inefficient IV estimates. If the pre-IV estimates are found to be inconsistent, the variables in question are deemed endogenous and instrumentation is warranted.

A common problem for this type of analysis is coming up with a set of instruments that simultaneously exhibit a high correlation with the endogenous variable(s) and no correlation with the error term. In some instances, the instrument choice is obvious. For example, consider the global FDI variable, which is problematic because it is determined by a combination of left-hand side values for all the sample countries. While it is possible to instrument world FDI with a sufficient number of its own lags, a more direct approach is to remove the endogeneity by subtracting each country's net FDI inflows from the global value. In this case, the remainder will still control for global FDI patterns but the relationship with the error term in each panel will be removed.

The choice of instruments is not so obvious for GDP and the trade-to-GDP ratio. We have already mentioned that tariff levels are not an attractive measure of openness due to data availability and the ambigious relationship between the level of tariffs and the outward orientation of the economy. ${ }^{44}$ Various openness indices, such as those constructed by Sachs and Warner (1995), have been widely criticized for capturing a whole range of policies not directly related to an economy's outward orientation. Finally, instrumenting the trade-to-GDP ratio with its own lags is problematic in annual data because this variable does not vary much through time. It is partly due to these issues that a number of FDI studies have treated the openness variable as exogenous, despite the potential two-way causality between trade and FDI (see, for example, Asiedu, 2002; Kolstad and Tondel, 2002; Addison and Heshmati, 2003).

In contrast to endogeneity tests, which require the user to pick a set of instruments a priori, Addison and Heshmati (2003) suggest the use of the Granger causality concept in order to establish the direction of causality between the model variables. ${ }^{45}$ We follow this approach and regress the

\footnotetext{
${ }^{43}$ Note that we have already established that endogeneity is unlikely to be a problem for the GDP growth variable, and we therefore will not address it in the following discussion.

${ }^{44}$ This is largely due to the presence of non-tariff barriers, which are highly distortionary yet difficult to quantify. In addition, there is no agreement in the literature on whether simple or trade-weighted average tariffs are the preferred vehicle: simple averages attach too much weight to tariff peaks and valleys, while weighted averages ignore highly protected sectors.

${ }^{45}$ This approach is a nice alternative because endogeneity tests do not actually test for endogeneity of the variables but rather for exogeneity of the instruments. In addition, the implementation of the available endogeneity tests in the presence of serial correlation is not clear.
} 
log of net FDI inflows on its three lagged values, as well as three lagged values of the trade-to-GDP ratio and a set of country fixed effects. ${ }^{46}$ The results, shown in Appendix B, indicate that openness plays a significant role in determining net FDI inflows, judging by a relatively high coefficient value and a significant $t$-statistic. In testing the Granger causality in the opposite direction, we find that FDI also causes openness, but the coefficient magnitudes are much smaller and their significance is also much lower. Therefore, although Granger causality appears to go in both directions, the link from openness to net FDI inflows is much stronger than the opposite. Taking this into account, together with a lack of good instruments and the large body of research that has treated this variable as exogenous, we believe it may be appropriate to leave this variable in the model without instrumenting while remaining aware of its potential difficulties.

Another variable thay may give rise to endogeneity problems is the level of GDP. The most direct cause for endogeneity concerns is the fact that domestic investment financed by FDI is included in the definition of GDP; other arguments note that the level of GDP is an indication of long-run growth rates that may be affected by FDI. These and other potential endogeneity problems with GDP are non-trivial, and have prompted several studies to move the GDP level to the left-hand side, estimating FDI as a share of GDP (see, for example, Asiedu, 2002; Addison and Heshmati, 2003). One problem with this approach is that the FDI-to-GDP ratio is as likely to be a measure of the host country's openness as its market size. Furthermore, the same studies also usually include the trade-to-GDP ratio as a right-hand side variable, which is likely to give rise to endogeneity concerns highlighted in the previous paragraph. IV estimation is an alternative approach, but, as with openness, the choice of instruments is not obvious (if anything, it is less so, as evidenced by the vast literature on the determinants of GDP growth). Therefore, in order to gauge the magnitude of the potential endogeneity problems, we employ the same Granger causality tests as in the earlier paragraph. The results are shown in Table 13 in Appendix B and suggest that the causality from GDP to FDI is much stronger than the causality from FDI to GDP. ${ }^{47}$ This suggests that endogeneity may not be a significant problem in our sample. Furthermore, we have made previous references to the extensive literature that has established a robust positive relationship between FDI on the left-hand side and market size (GDP) on the right. In fact, Chakrabarti (2001) concludes that market size is the only determinant of FDI that is always significant and completely robust to changes in the information set. Thus, similar to openness, we choose to leave this variable in the model without further adjustments.

\subsection{Baseline model}

Taking into account potential shortcomings and estimation issues in the replication estimates discussed in the previous section, we propose an augmented specification of equation (1). We drop the relative GNI and expected PTA dummy variables from the model, add measures of the real exchange rate and distance to PTA partners, change the definition of global FDI, and leave the expected PTA dummy for specification testing at a later point. The new model therefore has the following specification:

$$
\begin{aligned}
F D I_{i t} & =\alpha+\gamma_{i}+\beta_{1} G D P_{i t}+\beta_{2} \text { OPEN }_{i t}+\beta_{3} G D P G R O_{i t}+\beta_{4} C P I G R O_{i t}+\beta_{5} R E R G R O_{i t} \\
& +\beta_{6} \text { WLDFDIadj }_{i t}+\beta_{7} \text { WLDGRO }_{t}+\beta_{8} P T A G D P_{i t}+\beta_{9} D I S T A_{i t}+\epsilon_{i t}
\end{aligned}
$$

\footnotetext{
${ }^{46}$ The lag length was chosen after specification testing with several alternative lag structures.

${ }^{47}$ The mean and variance of both variables are very similar, therefore the difference in coefficient magnitudes across the two regressions is not due to an inappropriate choice of scale.
} 
The $R E R G R O$ variable is the annual percentage change in the real effective exchange rate (REER) index of country $i$. The REER has a base year of 2000 (i.e. $R E E R_{i, 2000}=100$ ) and is obtained from the WDI database of the World Bank. According to the WDI documentation, this variable is calculated in two steps. First, WDI computes a nominal effective exchange rate as a weighted average of a basket of foreign currencies. ${ }^{48}$ Second, the nominal rate is deflated by an indicator of manufacturing unit labor costs for high income countries and changes in consumer prices for others. Since the definition of the REER series is based on the inverse quote of the nominal exchange rate, an increase in the value of the real exchange rate (that is, a positive value for RERGRO) implies a real appreciation of the domestic currency. Therefore, based on the discussion in the previous sub-section, we expect a negative relationship between changes in the real effective exchange rate and net FDI inflows.

The $W L D F D I a d j$ variable represents an adjustment to the definition of global FDI discussed in the earlier sub-section. This new variable is calculated as $\left(W L D F D I_{t}-F D I_{i t}\right)$ to remove the two-way causality between world FDI and the dependent variable. As before, this variable should pick up aggregate trends in FDI and globalization effects, and therefore we expect its coefficient to be positive.

The third new variable, DISTA, is the log of average distance between country $i$ and all of its PTA partners at time $t$. This variable is equal to zero when a country is not a member of any PTAs, and has a time series dimension since its value is updated every time a country enters into a new preferential agreement. It is calculated as $\left[\ln \left(\frac{1}{N} \sum_{j}^{N} d i s t_{i j}\right)\right]$ for each country $i$ and every year $t$, where dist $i j$ is the great circle distance between the largest or capital cities of countries $i$ and $j$ and $N$ is the number of country $i$ 's PTA partners. ${ }^{49}$ For the reasons discussed previously, we expect to find a negative elasticity of net FDI inflows with respect to distance to PTA partners.

In order to simultaneously account for heteroscedasticity across panels and serial correlation within panels, we rely on a three-step feasible generalized least squares (FGLS) estimator. The advantage of this approach is that it allows estimation in the presence of $\mathrm{AR}(1)$ autocorrelation within panels and cross-sectional correlation and/or heteroscedasticity across panels. However, the use of this estimator is conditional on having a sufficient number of degrees of freedom, since it must generate additional estimates of the variance, covariance, and serial correlation parameters. The standard version of the FGLS estimator in the presence of both heteroscedasticity and autocorrelation is a three-step process: in the first step, the model assumes homoscedastic errors and calculates consistent estimates of the $\mathrm{AR}(1)$ parameter(s); in the second step, a groupwise heteroscedastic model is applied to the transformed data (which is now free of autocorrelation); and in the third step, the new moment matrix is used to solve the full FGLS system and obtain the correct asymptotic variance-covariance matrix for $\hat{\beta}$. The autoregressive parameters can be cross-sectionspecific or constrained to be the same across all cross-sections, with the latter increasing efficiency and improving the small sample performance of the estimator. The third step can be iterated to convergence, although Greene (2000) notes that no asymptotic gains can be expected from iteration since the estimator is efficient at every step. Furthermore, while the iterated FGLS estimator

\footnotetext{
${ }^{48}$ The WDI provides the following information on this variable: "A nominal effective exchange rate index represents the ratio (expressed on the base $2000=100$ ) of an index of a currency's period-average exchange rate to a weighted geometric average of exchange rates for currencies of selected countries and the euro area. For most high-income countries, weights are derived from trade in manufactured goods among industrial countries. For selected other countries the nominal effective exchange rate index is based on each countrys trade in both manufactured goods and primary products with its partner or competitor countries."

${ }^{49}$ The distance series has been obtained from Centre d'Etudes Prospectives et d'Informations Internationales (CEPII ). See Appendix A for more details.
} 
converges to the maximum likelihood estimator (MLE) in models without serial correlation, the same does not hold when the disturbances are assumed to follow an $\operatorname{AR}(1)$ process. Therefore, we elect to use the simpler three-step methodology; in any case, for the model in equation (2) the differences between the results generated by the two estimators are marginal and do not affect hypothesis testing or inference. ${ }^{50}$ Similarly, allowing the AR(1) coefficients to vary across countries or constraining them to be the same does not appreciably change the results, and we therefore opt for the more efficient method of imposing a common autoregressive parameter for all cross-sections.

\begin{tabular}{lcc} 
Table 4: FGLS estimation results: net FDI inflows \\
\hline \multicolumn{1}{l}{ Variable } & Coefficient & Std. error \\
\hline GDP & $0.899^{* *}$ & 0.017 \\
OPEN & $0.941^{* *}$ & 0.083 \\
GDPGRO & $0.256^{\dagger}$ & 0.142 \\
CPIGRO & $-0.008^{\dagger}$ & 0.005 \\
RERGRO & $-0.336^{*}$ & 0.146 \\
WLDGRO & $-0.677^{\dagger}$ & 0.391 \\
WLDFDIadj & $0.373^{* *}$ & 0.039 \\
PTAGDP & $0.060^{* *}$ & 0.018 \\
DISTA & $-0.155^{* *}$ & 0.058 \\
\hline \multicolumn{3}{c}{1541} \\
\hline N & \multicolumn{2}{c}{3146.643} \\
Log-likelihood & $* 5 \%$ \\
$\chi^{2}$ & $* * 1 \%$ \\
\hline Significance levels : $\dagger 10 \%$ & $* 1611$ \\
Note: The dependent variable is expressed in \\
natural logarithms.
\end{tabular}

The FGLS estimates of equation (2) are shown in Table 4. Because the REER data are not available for all sample countries and periods, the number of observations shrinks to 1541 - representing an unbalanced panel of 87 countries between 1980 and 2004. This also limits the coverage of PTAs in our sample to 180 agreements, down from the original 196. The Wald test (summarized by the $\chi^{2}$ statistic in the last row of the table) is significant at the 1 percent level and shows that the independent variables are significant as a group. The individual coefficient estimates are all significant at the ten percent level or below and imply reasonable elasticity values. The estimated elasticity of net FDI inflows with respect to market size (GDP) is slightly below unity (but significantly different from it) and is broadly consistent with estimates in the previous literature. For example, Kolstad and Tondel (2002) obtain an elasticity estimate of slightly higher than one using gross FDI per capita as a dependent variable, while Coughlin and Segev (2000) estimate a similar elasticity with gross FDI data for China. ${ }^{51}$ No such comparisons can be drawn for the semi-elasticity of trade openness, since the exact definition of this variable varies widely across studies. GDP growth has a positive effect on net FDI inflows while the impact of inflation is negative but relatively small and only borderline significant $(p=0.099)$. The estimated coefficients on the global variables-world

\footnotetext{
${ }^{50}$ The standard errors are somewhat larger for the three-step estimator, therefore presenting the three-step results allows us to err on the side of caution.

${ }^{51}$ Other studies, such as Asiedu (2002) and Addison and Heshmati (2003), impose a unitary elasticity by moving GDP to the left-hand side. Although our estimated elasticity of net FDI inflows with respect to GDP is significantly different from unity $\left(\chi^{2}=34.09, p=0.00\right)$, the absolute value of the coefficient is reasonably close to one.
} 
growth and world FDI-are consistent with our expectations and show that faster growth in the rest of the world (controlling for home country growth) makes a particular nation a less attractive location for FDI, while rising total world FDI tends to increase net FDI inflows for an average host country. ${ }^{52}$ The coefficient on world FDI is significantly less than one, which can be due to one or both of the following reasons: either our sample omits some increasingly important recipients of FDI, or the distribution of net FDI inflows across sample countries is highly unequal and biased toward a small group of large recipients. ${ }^{53}$ The coefficient on the growth rate of the real effective exchange rate is significant at the five percent level and correctly signed. The negative elasticity of net FDI inflows with respect to RERGRO implies that the appreciation of the real exchange rate leads to reduced FDI inflows, consistent with theoretical expectations. ${ }^{54}$

Turning to the variables capturing the effects of preferential liberalization, the size of the extended common market is significant at the one percent level and positively related to net FDI inflows. As mentioned earlier, this variable serves a two-fold purpose in the estimation routine. First, since it is equal to zero prior to signing a PTA and carries a positive value afterward, it measures the threshold effect of signing an agreement on FDI inflows. Furthermore, this variable also captures the effects of participating in a larger market following the signing of an agreement. This is particularly important if a country is party to more than one PTA, since PTAGDP will then be a sum of all of its partners' GDP, reflecting the fact that the country has now created a larger market. The fact that this variable is positive and significant shows that at least one of two mechanisms is present in the data: signing a PTA is associated with increased benefits in terms of greater net FDI inflows, and/or larger market size of the country's PTA partners tends to generate larger net FDI inflows. The coefficient magnitude suggests that a one percent increase in the size of an average country's extended market tends to expand net FDI inflows by 0.06 percent. This elasticity is significantly below the 0.1 value estimated by Lederman et al. (2005), but the order of magnitude is similar. Admittedly, our estimated elasticity is small; however, note that joining new PTAs will often imply much larger changes in the value of PTAGDP, especially for PTAs with multiple and/or high-income partners. To quantify this statement, consider the example of Costa Rica. By 2004, the country was a member of several PTAs, including the Central American Common Market, Association of Caribbean States, and bilateral agreements with Argentina, Chile, Dominican Republic, Mexico, Panama, Venezuela, and Canada. If Costa Rica were to join CAFTA (which includes the United States) in the same year, our model would predict an 11.5 percent increase in its net FDI inflows. ${ }^{55}$ On the other hand, were it instead to join a PTA with Ecuador, Costa Rica could only expect its net FDI inflows to rise by 0.08 percent. For Nicaragua, which has fewer PTAs (but is still a member of the CACM and CAFTA), the expected changes would be 27 and 0.8 percent, respectively. ${ }^{56}$ In addition, both countries could expect additional dynamic

\footnotetext{
${ }^{52}$ The coefficient on global growth is only significant at the nine percent level $(p=0.083)$.

${ }^{53}$ Ceteris paribus, a more unequal distribution will result in lower slope estimates with least squares. For example, in 2004 the top five recipients of FDI in our sample received 80 percent of global FDI, while the top ten received 86 percent.

${ }^{54}$ To the extent that FDI is a long-term decision to enter a particular market, it may be surprising to find a significant effect of annual movements in the real exchange rate. However, using longer-term moving averages of the REER is likely to eliminate some variation in this variable (making estimation more difficult) and is also more indicative of overall macro instability rather than relative wealth effects or short-term imperfections in the capital markets.

${ }^{55}$ This is equivalent to joining a bilateral PTA with the United States, since Costa Rica already has preferential access to all the other countries in CAFTA through its existing PTAs.

${ }^{56}$ These numbers are obtained as fitted values from the model estimates shown in Table 4 . It is important to recognize that they are not forecasts and are provided only to illustrate the relevant orders of magnitude. A number
} 
FDI gains from their partnership with the USA as the income of the latter rises over time and that change is reflected in the value of PTAGDP.

Finally, the coefficient on the average distance variable is negative and significant at the one percent level, confirming our earlier hypothesis that proximity to PTA partners is an important determinant of FDI inflows following preferential liberalization. Furthermore, this indicates that the coefficient on PTAGDP would be biased if the distance relationship were not taken into account. The negative coefficient on distance also means that, controlling for other factors, an average country receives less net FDI inflows from its more distant PTA partners. Therefore, this finding goes against the hypothesis that countries rely on FDI rather than trade to serve more distant PTA markets, although clearly it does not constitute conclusive proof. The elasticity value suggests that increasing the average distance to one's PTA partners by one percent lowers net FDI inflows by 0.16 percent. To continue with the example of Costa Rica, accounting for the fact that joining CAFTA would increase the country's average distance to PTA partners lowers the expected FDI benefit from 11.5 percent to 11.1 percent. On the other hand, if the United States were as far from Costa Rica as, say, Germany, the expected increase in net FDI inflows would be limited to 9.6 percent.

Overall, the model summarized by equation (2) appears to be not only a good predictor of net FDI inflows by country, but also a successful approach to capturing the relationship between preferential trade liberalization and FDI. The control variables are significant and correctly signed, and the PTA-related variables establish a positive link between net FDI inflows and the size of the extended common market and a negative link between net FDI inflows and the distance to PTA partners. However, in order to obtain these results we made numerous adjustments to the estimates shown in Table 3, including changing the estimation approach, reducing the sample size, redefining one independent variable, dropping two others, and adding two new regressors. In order to determine which of these changes are responsible for making the PTA-related variables statistically significant, we undertake some simple specification tests of equations (1) and (2). The detailed results are presented in Appendix B.1 and B.4, and show that reductions in the sample size do not qualitatively affect our estimates. Estimating equation (1) with FGLS instead of fixed effects yields point estimates closer to Table 4, but the coefficient on PTAGDP is five times smaller and the coefficients on distance, host country growth, and global growth are insignificantly different from zero. On the other hand, estimating equation (2) with fixed effects results in significant coefficient estimates for all variables except the REER growth rate, while using the FGLS estimator makes RERGRO significant and changes the point estimates of coefficients. Both the GDPGRO and $W L D G R O$ variables appear to be sensitive to the inclusion of the REER growth variable - they are only significant in the presence of the latter, while the point estimates and significance levels of other model variables remain largely unchanged. Excluding average distance does not affect the coefficients on the control variables or their significance, while significantly lowering the point estimate of $P T A G D P$. This is likely due to the fact that the PTAGDP variable now controls for both the positive effects of joining a PTA and having access to a larger market, and the negative effects of being located farther away from PTA partners. Overall, changes in the model specification (particularly dropping the GNIREL variable) appear to be the main reason behind the significant estimates of PTA-related variables. Using FGLS instead of fixed effects has moderate effects on the estimates by making RERGRO significant and changing coefficient magnitudes. Finally, reducing the sample size from 2561 to 1541 observations appears to have negligible effects.

of assumptions underlie these calculations, including coefficient stability, independence, and model relevance for out-of-sample predictions. 
These results provide a "two-handed" answer to the central question of this section: can the positive PTA-FDI relationship documented by earlier studies be verified in our sample? On the one hand, we do find a highly significant positive elasticity of net FDI inflows with respect to the PTAGDP variable. On the other hand, this relationship is significant only once we control for non-orthogonal errors, multicollinearity, endogeneity, and add the REER variable. The model summarized by equation (2) therefore becomes our baseline specification, and subsequent subsections will rely on it to examine some alternative measures of the PTA variable and to implement some simple decompositions by income level, geographic region, and time period.

\subsection{Model extensions: alternative specifications of the PTA variable}

In this subsection, we consider some alternative approaches to capturing the potential links between preferential trade liberalization and FDI. These will involve investigating different ways of defining some variables, as well as including additional variables that may enhance the explanatory power of the model and improve our understanding of the underlying data. The first set of experiments concerns the distance variable, which was confirmed by our previous estimates as an important determinant of the FDI-PTA relationship. Some specification tests will help to ascertain whether alternative measures of distance may improve our estimates and show the results of these explorations in Table 5. For ease of reference and comparison, the first column reports the estimated coefficients from the baseline model, as shown in Table 4. All of the estimates are obtained using the three-step FGLS estimator. As before, we omit the constant from the list of variables shown, although each model was estimated with an intercept term included.

We begin by attempting to differentiate between equidistant partners according to their relative market size. For example, consider Mexico and two of its PTAs: NAFTA and the Mexico-Israel bilateral FTA. It would seem likely that Mexico's FDI benefits are maximized by the fact that it is located closer to its larger partner, USA, as opposed to the much smaller partner, Israel. In order to reflect the importance of relative proximity to large PTA partners, we specify a new variable $D I S T W$, which is the average GDP-weighted distance between country $i$ and its PTA partners. This variable is calculated as $\left[\ln \left(\sum_{j}^{N}\left(\frac{G D P_{j}}{P T A G D P_{i}} d i s t_{i j}\right)\right)\right]$ for every country $i$ and year $t$, and, similar to its simple average counterpart, is equal to zero when a country has not entered into any PTAs and is updated dynamically when a new PTA with country $i$ enters into force.

The estimation results from substituting GDP-weighted distance for average distance in the net FDI equation are shown in column (2) of Table 5 . The coefficients on the control variables change marginally while their significance levels remain unchanged. The Wald test shows that model coefficients maintain their significance as a group $(p=0.00)$. However, neither of the PTArelated variables is significant individually. Although it is difficult to establish the exact reason for this result, the loss of significance could be due to multicollinearity problems, since the size of the extended common market is used to calculate the weighted distance.

While adding GDP-weighted distance to the estimated equation does not appear to be a useful approach to estimating the effects of proximity to PTA partners on FDI inflows, there is an alternative way to introduce this variable into the model specification. Specifically, we could use distance between different PTA partners to assign weights to the PTAGDP variable itself, so that the GDP of more distant partners is discounted relative to the more proximate countries. The new

variable $P T A G D P w$ is calculated as $\left[\ln \left(\sum_{j}^{N}\left(\frac{D I S T A_{i}}{\text { dist }_{i j}} G D P_{i j}\right)\right)\right]$ for every country $i$ and year $t$. Therefore, PTA partners that are located closer than the average for country $i$ receive weights that are greater than one, while countries further away than the average are assigned weights of less 
Table 5: FGLS estimation results with alternative definitions of distance: net FDI inflows

\begin{tabular}{|c|c|c|c|}
\hline \multirow[b]{2}{*}{ Variable } & (1) & $(2)$ & $(3)$ \\
\hline & \multicolumn{3}{|c|}{ Coefficient } \\
\hline \multirow[t]{2}{*}{ GDP } & $0.899^{* *}$ & $0.900^{* *}$ & $0.899^{* *}$ \\
\hline & $(0.017)$ & $(0.017)$ & $(0.017)$ \\
\hline \multirow[t]{2}{*}{ OPEN } & $0.941^{* *}$ & $0.922^{* *}$ & $0.909^{* *}$ \\
\hline & $(0.083)$ & $(0.081)$ & $(0.080)$ \\
\hline \multirow[t]{2}{*}{ GDPGRO } & $0.256^{\dagger}$ & $0.266^{\dagger}$ & $0.261^{\dagger}$ \\
\hline & $(0.142)$ & $(0.143)$ & $(0.143)$ \\
\hline \multirow[t]{2}{*}{ CPIGRO } & $-0.008^{\dagger}$ & $-0.008^{\dagger}$ & $-0.008^{\dagger}$ \\
\hline & $(0.005)$ & $(0.005)$ & $(0.005)$ \\
\hline \multirow[t]{2}{*}{ RERGRO } & $-0.336^{*}$ & $-0.320^{*}$ & $-0.317^{*}$ \\
\hline & $(0.146)$ & $(0.147)$ & $(0.147)$ \\
\hline \multirow[t]{2}{*}{ WLDGRO } & $-0.677^{\dagger}$ & $-0.653^{\dagger}$ & -0.636 \\
\hline & $(0.391)$ & $(0.394)$ & $(0.393)$ \\
\hline \multirow[t]{2}{*}{ WLDFDIadj } & $0.373^{* *}$ & $0.405^{* *}$ & $0.409^{* *}$ \\
\hline & $(0.039)$ & $(0.038)$ & $(0.037)$ \\
\hline \multirow[t]{2}{*}{ PTAGDP } & $0.060^{* *}$ & 0.002 & \\
\hline & $(0.018)$ & $(0.016)$ & \\
\hline \multirow[t]{2}{*}{ DISTA } & $-0.155^{* *}$ & & \\
\hline & $(0.058)$ & & \\
\hline \multirow{2}{*}{ DISTW } & & 0.042 & \\
\hline & & $(0.054)$ & \\
\hline \multirow[t]{2}{*}{ PTAGDPw } & & & $0.011^{* *}$ \\
\hline & & & $(0.004)$ \\
\hline $\mathrm{N}$ & 1541 & 1541 & 1541 \\
\hline Log-lhd & -1716.811 & -1720.753 & -1721.06 \\
\hline$\chi^{2}$ & 3146.643 & 3186.223 & 3178.957 \\
\hline
\end{tabular}

than one. In terms of the model in equation (2), the new PTAGDPw variable replaces both the PTAGDP and DISTA variables. The estimation results are shown in column (3) of Table 5.

The coefficients on the control variables are again similar to the reference specification in column (1), and the new distance-weighted PTA common market variable has the expected positive sign and is significant at the one percent level. Although the world growth variable loses its significance at conventional confidence levels, the actual change in the $p$-value is quite small, going up from 0.083 to 0.106 . In accordance with expectations, the elasticity of net FDI inflows with respect to PTAGDP $w$ is much smaller than the PTAGDP elasticity from column (1), implying that the negative effects of distance from PTA partners have been incorporated into the estimate. Therefore, the results of Table 5 confirm our earlier hypothesis that proximity to PTA partners is an important determinant of net FDI inflows following preferential liberalization. Given our earlier criticisms of the PTAGDP variable, its weighted version is better suited to capture the heterogeneity of the 
relationship between PTAs and net FDI inflows. However, using PTAGDP and DISTA together is more appealing because it allows us to decompose the total effect of PTAs on FDI into market size and distance components. Therefore, we will stick with equation (2) as the most appropriate model of the relationship between preferential trade liberalization and net FDI inflows.

The next set of experiments is presented in Table 6. First, we address the issue of how we measure the size of a PTA market area. Most gravity models of trade include a combined GDP term that is the product, not the sum, of individual members' GDP. The reasoning behind this specification is the argument that countries of like size are more likely to generate significant trade flows than a large and a small partner of equal total size. ${ }^{57}$ A similar argument can be extended to FDI, since a small country is likely to have a limited capacity to absorb investment inflows. Therefore, we would like to use an alternative specification in which the extended market size variable is defined as $\left[\ln \left(\prod_{j}^{N} G D P_{i j}\right)\right]=\sum_{j}^{N} \ln G D P_{i j}$ and $j$ ranges over all of the PTA partners of country $i$. However, this definition causes scaling problems in the model since the multiplicative term can become extremely large very quickly and the logarithmic transformation fails to condense the right tail of the distribution sufficiently. ${ }^{58}$ Therefore, we impose an additional transformation on this variable, defining PTAGDPm as $\left(\sum_{j}^{N} \ln G D P_{i j}\right)^{-1}$ and setting its value at 1 when a country does not belong to any PTAs. ${ }^{59}$ The inverse transformation, being the strongest of the three common transformations to reduce positive skewness while maintaining the relative order of data points (they are, in order, square root, logarithmic, and inverse), is successful in lengthening the left tail and compressing the right tail enough to address scaling issues in the model. However, applying this double transformation implies that the estimated coefficient will no longer have an intuitive interpretation as an elasticity, and also that the PTAGDPm variable is expected to enter the model with a negative sign. That is, an increase in the size of the PTA external common market will cause the PTAGDPm variable to become smaller in absolute value, which, if the hypothesized positive link between preferential liberalization and FDI holds in the multiplicative version of the model, should lead to an increase in the value of the dependent variable.

The estimated coefficients of the new model are shown in column (2) of Table 6 (for comparison purposes, the first column again repeats the baseline estimates). The estimated coefficients on the control variables are close to the baseline specification and largely retain their significance (the $p$-value on global growth rises from 0.083 to 0.107 ). However, neither the new multiplicative market size variable nor the average distance are significantly different from zero (the relevant $p$ values are 0.124 and 0.241 , respectively). These results are likely due to the complicated nature of the PTAGDPm variable. Furthermore, the point value of the estimated PTAGDPm coefficient suggests a very different elasticity value from the baseline specification. The implied elasticity of the multiplicative common market size (calculated at the sample mean) is 0.0003 percent compared to 0.06 percent in the baseline model. Therefore, even if we were to accept coefficient significance at the 13 percent levels, the effect of this variable on net FDI inflows is clearly negligible. One

\footnotetext{
${ }^{57}$ Another reason why a multiplicative GDP term is often used is that it is implied by the CES functional form, which underpins most gravity models. See Appendix B of Medvedev (2006) for more details on the theory behind gravity models.

${ }^{58}$ For an extreme case, consider a country like Tunisia, which is a member of several PTAs in Africa and the Middle East. When it signs a PTA with the European Union in 1998, its already considerable extended market size is now multiplied by the entire GDP of the EU, causing the common market variable (in logs!) to increase by a factor of almost ten. On the other end of the spectrum, countries that are not a member of a single PTA have the extended market size variable set at zero. As a result, the distribution of the extended market variable in multiplicative form is much wider than any of the other variables in the model, and estimation becomes problematic.

${ }^{59}$ We change the variable name to reflect its multiplicative nature.
} 
Table 6: Alternative PTA specification estimation results: net FDI inflows

\begin{tabular}{|c|c|c|c|c|c|c|}
\hline \multirow[b]{2}{*}{ Variable } & (1) & (2) & $\overline{~(3)}$ & (4) & (5) & (6) \\
\hline & \multicolumn{6}{|c|}{ Coefficient } \\
\hline \multirow[t]{2}{*}{ GDP } & $0.899^{* *}$ & $0.906^{* *}$ & $0.900^{* *}$ & $0.879^{* *}$ & $0.898^{* *}$ & $0.910^{* *}$ \\
\hline & $(0.017)$ & $(0.018)$ & $(0.017)$ & $(0.018)$ & $(0.017)$ & $(0.019)$ \\
\hline \multirow[t]{2}{*}{ OPEN } & $0.941^{* *}$ & $0.905^{* *}$ & $0.904^{* *}$ & $0.899^{* *}$ & $0.945^{* *}$ & $0.785^{* *}$ \\
\hline & $(0.083)$ & $(0.080)$ & $(0.079)$ & $(0.080)$ & $(0.083)$ & $(0.107)$ \\
\hline \multirow[t]{2}{*}{ GDPGRO } & $0.256^{\dagger}$ & $0.263^{\dagger}$ & $0.261^{\dagger}$ & $0.271^{\dagger}$ & $0.260^{\dagger}$ & $0.342^{*}$ \\
\hline & $(0.142)$ & $(0.143)$ & $(0.143)$ & $(0.142)$ & $(0.143)$ & $(0.153)$ \\
\hline \multirow[t]{2}{*}{ CPIGRO } & $-0.008^{\dagger}$ & $-0.009^{\dagger}$ & $-0.008^{\dagger}$ & $-0.008^{\dagger}$ & -0.008 & $-0.009^{\dagger}$ \\
\hline & $(0.005)$ & $(0.005)$ & $(0.005)$ & $(0.005)$ & $(0.005)$ & $(0.005)$ \\
\hline \multirow[t]{2}{*}{ RERGRO } & $-0.336^{*}$ & $-0.322^{*}$ & $-0.315^{*}$ & $-0.326^{*}$ & $-0.338^{*}$ & $-0.329^{*}$ \\
\hline & $(0.146)$ & $(0.146)$ & $(0.147)$ & $(0.147)$ & $(0.146)$ & $(0.155)$ \\
\hline \multirow[t]{2}{*}{ WLDGRO } & $-0.677^{\dagger}$ & -0.633 & -0.638 & -0.635 & -0.643 & $-0.810^{*}$ \\
\hline & $(0.391)$ & $(0.393)$ & $(0.393)$ & $(0.390)$ & $(0.391)$ & $(0.408)$ \\
\hline \multirow[t]{2}{*}{ WLDFDIadj } & $0.373^{* *}$ & $0.404^{* *}$ & $0.412^{* *}$ & $0.391^{* *}$ & $0.372^{* *}$ & $0.390^{* *}$ \\
\hline & $(0.039)$ & $(0.038)$ & $(0.037)$ & $(0.036)$ & $(0.039)$ & $(0.039)$ \\
\hline \multirow[t]{2}{*}{ DISTA } & $-0.155^{* *}$ & -0.112 & & $0.026^{\dagger}$ & $-0.156^{* *}$ & $-0.189^{*}$ \\
\hline & $(0.058)$ & $(0.095)$ & & $(0.015)$ & $(0.059)$ & $(0.093)$ \\
\hline \multirow[t]{2}{*}{ PTAGDP } & $0.060^{* *}$ & & & & $0.061^{* *}$ & $0.052^{* *}$ \\
\hline & $(0.018)$ & & & & $(0.018)$ & $(0.020)$ \\
\hline \multirow[t]{2}{*}{ PTAGDPm } & & -1.186 & & & & \\
\hline & & $(0.770)$ & & & & \\
\hline \multirow[t]{2}{*}{ PTAd } & & & $0.276^{*}$ & & & \\
\hline & & & $(0.117)$ & & & \\
\hline \multirow[t]{2}{*}{ PTAnum } & & & & $0.035^{* *}$ & & \\
\hline & & & & $(0.009)$ & & \\
\hline \multirow[t]{2}{*}{ PTAEXP } & & & & & 0.058 & \\
\hline & & & & & $(0.052)$ & \\
\hline $\mathrm{N}$ & 1541 & 1541 & 1541 & 1541 & 1541 & 1331 \\
\hline Log-lhd & -1716.811 & -1722.399 & -1721.352 & -1716.134 & -1716.007 & -1423.608 \\
\hline$\chi^{2}$ & 3146.643 & 3185.418 & 3170.289 & 3473.614 & 3141.041 & 4080.322 \\
\hline
\end{tabular}

way to interpret this result is to conclude that the positive impact of the extended market variable is mainly driven by PTAs between large and small countries, rather than partners of equal size. However, this statement must be very heavily qualified due to the complexities in construction of the multiplicative version of $P T A G D P$.

The second alternative specification focuses on estimating the threshold effect of signing a PTA. Section 4.2 has argued that the PTAGDP variable captures two effects: the initial (threshold) impact of becoming a part of a larger market, and the continued effect of expanding that market through growth and ascension to new PTAs. In order to establish the relative importance of the 
former, we introduce a dummy variable PTAd that is equal to 1 if a country is a member of one or more PTAs. We have already mentioned that using this variable in the presence of PTAGDP leads to multicollinearity problems and causes the dummy coefficient to lose significance. ${ }^{60}$ The same is true of the distance variable, since it only takes on positive values when a country has joined at least one PTA. ${ }^{61}$ This implies that we cannot estimate the threshold and expansion effects simultaneously, and we will therefore use the PTA dummy variable to capture the former and estimate the latter separately in one of the subsequent specifications.

The results of estimating the FDI model with a simple PTA dummy are shown in column (3) of Table 6 , and the estimated coefficients are again close to the original specification. ${ }^{62}$ The dummy coefficient is significant at the two percent level and its magnitude suggests that joining a PTA increases net FDI inflows of an average country by 32 percent. ${ }^{63}$ This semi-elasticity is not large when compared with the values of dummy coefficients estimated in gravity models of bilateral trade, which routinely exceed one. ${ }^{64}$ It should be acknowledged that, given the discrete nature of the dummy and its simple distribution, it is difficult to conclude what exactly this variable is capturing. For example, the estimated coefficient could be picking up the average of a range of PTA-related effects, or potentially even other shocks that are contemporaneous with joining a preferential agreement (this identification issue is common to all estimates relying on one or more dummy variables). Therefore, while the results in column (3) suggest the presence of large and significant threshold effects, the point value of their estimated semi-elasticity should be interpreted with caution.

A related sensitivity test is an investigation of whether the number of PTAs in which a given country participates has a discernible effect on net FDI. Column (4) of Table 6 shows the estimated coefficients from a model where a PTA dummy has been replaced with a variable equal to the number of PTAs a country has joined (PTAnum). This variable ranges from zero for countries that do no participate in any PTAs to 37, which is the number of PTAs signed by the European Union by the end of 2004. As before, the coefficients on the model's control variables are reasonably close to the baseline model and PTAnum is positive and significant at the one percent level. The coefficient magnitude implies that signing each additional PTA tends to increase net FDI by three and a half percent. However, the coefficient on the distance variable is of the wrong sign and significant at the ten percent level. This result does not support the validity of the current specification and is not easily explainable, although we can propose three potential justifications. The first argument is that by construction, the PTAnum variable imposes a restriction that the marginal FDI effects of each additional PTA are exactly the same. Clearly, the heterogeneity of PTAs in our sample speaks against such a restriction. For example, we would expect a much larger change in Algerian net FDI from the Algeria-EU preferential agreement than from the AlgeriaEgypt preferential agreement-yet in terms of PT Anum, both would be represented by the same incremental change in the independent variable. Furthermore, at any given level of this variable its effects are not homogeneous across countries. Suppose that the EU is the main source of FDI,

\footnotetext{
${ }^{60}$ Recall the discussion in section 4.2 , which argued that including both variables in a single regression equation will lead to a violation of the full rank assumption.

${ }^{61}$ Estimating a model with all three variables included causes the dummy and the distance variable to lose significance.

${ }^{62}$ As before, the $p$-value of global growth is right around 0.10 .

${ }^{63}$ Because the dummy implies a discrete change in the value of the dependent variable, its coefficient cannot be interpreted as an elasticity unless it is very small. However, it is always the case that $\frac{\Delta y}{y}=e^{\beta}-1$, where $\beta$ is the dummy coefficient.

${ }^{64}$ See, for example, Adams et al. (2003), Soloaga and Winters (2001), Rose and van Wincoop (2001), and others.
} 
and signing a PTA with the EU results in the largest change in net FDI for any given country. If countries sign PTAs with the EU at different times (i.e. the EU agreement may be the first PTA for one country, the third for another, and the tenth agreement for a third), the mapping of changes in PTAnum to the variation in the dependent variable is not straight-forward. These issues may offer one explanation for the unexpected coefficient on distance - since the PT Anum variable imposes both a within- and across-country homogeneity on the set of PTAs signed by a given country (neither of which are appropriate assumptions), it does not properly capture the underlying relationship between preferential liberalization and FDI and also interferes with the ability of the distance variable to account for the proximity aspect of this relationship. In other words, the size of a country's PTA partners matters, and therefore PTAGDP is a better way of capturing the PTA-FDI relationship.

The second potential explanation is related to the first, but also based on our discussion of specification (3). Earlier, we have argued that the distance variable may not be an appropriate control when we attempt to capture the effects of preferential liberalization on FDI by means of a dummy variable. Since PTAnum is more similar in its distribution to a dummy than a semi-continuous variable like $P T A G D P$, it is possible that including the distance variable is not appropriate in this specification and, given the problematic nature of PTAnum, produces perverse results. In any case, since the PTAnum variable is positive and significant, we know the results are driven by countries with a large number of agreements. These are led by the new EU accession countries, which have received growing inflows of FDI for a number of years prior to joining the EU while also having signed a plethora of bilateral accords as a precondition of EU membership. Because the distance variable is increasing in the number of PTAs for a given country and given the positive coefficient on the PTAnum variable, it may not be that surprising that we find a positive link between more FDI and distance.

Third, imagine a situation where country $i$ signs $N$ PTAs with countries $[1, N]$, while a country $j$ signs a single PTA with the same $N$ countries. A positive coefficient on the PTAnum variable implies that the effects of the former are much larger than the latter, even though both countries $i$ and $j$ have access to the exact same PTA market size. Therefore, it is our belief that this variable does not present a full and accurate description of the PTA-FDI relationship. We therefore revert to the original comment on the results of this specification - the estimated coefficients on distance and PT Anum are not intuitive and should be interpreted with caution. ${ }^{65}$

The next extension to the baseline model investigates the potential significance of the expectation of joining a PTA. Here, we return to the expected PTA dummy of the replication model, defining PTAEXP as equal to one for two years prior to a PTA coming into force, and zero before and after those dates. The estimation results are shown in column (5) of Table 6. Contrary to the findings of Lederman et al. (2005) and consistent with our replication estimates in Table 3, we cannot identify any significant effects of the expectation of joining a PTA, although the rest of the estimated coefficients are extremely similar to model (1). ${ }^{66}$ We have also attempted alternative specifications of this variable, extending its duration to three years prior to the PTA's entry into force as well as limiting it to one year. In either case, the results are virtually identical to those shown in column (5), with the expected PTA dummy never significantly different from zero.

\footnotetext{
${ }^{65}$ We have also attempted to estimate the same model with quadratic and cubic PTAnum terms to check whether there is a certain number of PTAs that tends to result in maximum gains in net FDI. The coefficient estimates on the control variables are virtually identical to those in specification (4), while the additional PTAnum terms are not significantly different from zero. Therefore, it appears that in our model net FDI inflows are strictly increasing in the number of preferential agreements - although this statement is subject to the same qualifiers as the criticisms above.

${ }^{66}$ The inflation and world growth variables have $p$-values of 0.10 .
} 
There are several reasons why we may be unsuccessful in identifying an anticipation effect of a new preferential agreement, most of them similar to the problems with PTAd and PTAnum. First, since many countries have more than one PTA and we do not rank PTAs in terms of their potential effect on FDI, it may be the case that the expectation of some agreements raises FDI but the expectation of others does not. Since the expected PTA variable is only defined for the first agreement signed by a given country, identifying a robust anticipation effect is likely to be difficult. In other words, the PTAEXP variable is constructed in such a way that the effect of the expectation of joining a PTA can only be captured in the sub-sample of first agreements for each country. Therefore, it may be the case that the expectation effect exists but we are not able to identify it due to the implicit selection bias. In addition, there are some methodological issues with including this variable in the model. The PTAEXP variable will be statistically significant if, controlling for all other factors, FDI is higher in the two years prior to a first PTA's signing than either before or after that period. ${ }^{67}$ However, to the extent that the PTA-FDI relationship is driven by the FDI's response to the investment or investment climate provisions of a PTA, no expectation effect is possible until the PTA comes into force and the existing barriers are actually dismantled. Similarly, if FDI is a complement to trade and trade flows do not change until the tariffs are actually lowered, the expectation effect may also be lessened. ${ }^{68}$ Therefore, the PTA anticipation effect is likely to work through only a subset of channels that link preferential liberalization to FDI and its empirical contribution to the PTA-FDI relationship is more difficult to capture.

The last sensitivity test comes back to the question originally posed during the discussion of specification (3): does the PTAGDP variable capture the threshold effect of signing a PTA, the expansion effect of belonging to a growing common market, or a combination of the two? In estimating specification (3), we found that the threshold effect is large and significant. Therefore, an appropriate question is whether the PTAGDP variable helps to account for any additional variation in the dependent variable once the threshold effect has been captured. As mentioned earlier, it is not possible to include both the extended common market variable and a PTA dummy in a single equation due to collinearity problems. However, it is possible to address this question by limiting our sample to countries that participate in one or more PTAs and estimating equation (2) for this reduced sample. Since all countries in this reduced sample belong to a PTA, there should be no threshold effect and the PTAGDP coefficient should only be significant if joining a larger market results in increased FDI-i.e. the expansion effect.

The results of estimating the above model are shown in column (6) of Table 6 . The coefficient magnitudes are somewhat different from the reference specification, but all variables are statistically significant and correctly signed. Most importantly, the coefficient on the extended common market variable remains significant at the one percent level. As expected, the implied elasticity value is lower than in the reference specification, although the reduction is not large (from 0.60 to 0.52). This result is a bit puzzling, since, given the large estimate of the threshold effect in specification (3), we would expect a larger decrease in the value of the coefficient. One potential explanation could be that the specification (6) only sterilizes the threshold effect of signing the first PTA for a given country. If a country is a member of two or more PTAs, their threshold effects continue to be indistinguishable from the impact of larger market size of PTA partners (expansion effect). Given this qualification, it is likely that the current specification only partially picks up the expansion

\footnotetext{
${ }^{67}$ Note that "controlling for other factors" here also includes the extended common market variable following the agreement's entry into force.

${ }^{68}$ It is unlikely to be eliminated entirely, since there may be some new FDI in advance of liberalization to create capacity for future production (e.g. building of factories).
} 
effect. However, together with the results of specifications (1) and (3), the model in column (6) supports a hypothesis that joining a PTA and being a part of a larger common market are both important channels linking preferential liberalization and net FDI inflows - but market size is probably more important.

\subsection{Decomposition by income level and time period}

In this section, we attempt various decompositions of our sample by geographic region, income level, and time period to determine whether our aggregate results mask some important sub-trends. In addition, the estimates of this section will serve as extra sensitivity tests to assess the robustness of the aggregate relationship between preferential liberalization and FDI in the smaller sub-samples. We begin with some decompositions by income level, with the results shown in Table 7 . Column (1) of this table repeats the reference estimates for the full sample (the same as column (1) in Table 6) for ease of comparison with alternative specifications.

Table 7: Estimation results by income level: net FDI inflows

\begin{tabular}{|c|c|c|c|}
\hline \multirow[b]{2}{*}{ Variable } & (1) & $(2)$ & $(3)$ \\
\hline & \multicolumn{3}{|c|}{ Coefficient } \\
\hline \multirow[t]{2}{*}{ GDP } & $0.899^{* *}$ & $0.850^{* *}$ & $0.988^{* *}$ \\
\hline & $(0.017)$ & $(0.021)$ & $(0.052)$ \\
\hline \multirow[t]{2}{*}{ OPEN } & $0.941^{* *}$ & $0.946^{* *}$ & $2.596^{* *}$ \\
\hline & $(0.083)$ & $(0.085)$ & $(0.971)$ \\
\hline \multirow[t]{2}{*}{ GDPGRO } & $0.256^{\dagger}$ & $0.311^{*}$ & 0.231 \\
\hline & $(0.142)$ & (0.148) & $(0.995)$ \\
\hline \multirow[t]{2}{*}{ CPIGRO } & $-0.008^{\dagger}$ & -0.008 & 0.460 \\
\hline & $(0.005)$ & $(0.005)$ & $(0.849)$ \\
\hline \multirow[t]{2}{*}{ RERGRO } & $-0.336^{*}$ & $-0.331^{*}$ & -1.045 \\
\hline & $(0.146)$ & $(0.149)$ & $(1.448)$ \\
\hline \multirow[t]{2}{*}{ WLDGRO } & $-0.677^{\dagger}$ & $-0.898^{*}$ & 0.589 \\
\hline & $(0.391)$ & $(0.418)$ & $(1.832)$ \\
\hline \multirow[t]{2}{*}{ WLDFDIadj } & $0.373^{* *}$ & $0.400^{* *}$ & $0.443^{* *}$ \\
\hline & $(0.039)$ & $(0.042)$ & $(0.096)$ \\
\hline \multirow[t]{2}{*}{ PTAGDP } & $0.060^{* *}$ & $0.080^{* *}$ & -0.082 \\
\hline & $(0.018)$ & $(0.019)$ & $(0.068)$ \\
\hline \multirow[t]{2}{*}{ DISTA } & $-0.155^{* *}$ & $-0.233^{* *}$ & 0.331 \\
\hline & $(0.058)$ & $(0.064)$ & $(0.204)$ \\
\hline $\mathrm{N}$ & 1541 & 1320 & 206 \\
\hline Log-lhd & -1716.811 & -1467.937 & -250.77 \\
\hline$\chi^{2}$ & 3146.643 & 2178.762 & 412.184 \\
\hline \multicolumn{4}{|c|}{$\begin{array}{l}\text { Significance levels: } \dagger 10 \% * 5 \% * * 1 \% \\
\text { Note: Standard errors are in parentheses. The depen- } \\
\text { dent variable is expressed in natural logarithms. Col- }- \\
\text { umn (1) shows estimates for all countries, column (2) } \\
\text { limits the sample to low and middle income countries, } \\
\text { and column (3) shows only high income countries. }\end{array}$} \\
\hline
\end{tabular}


The first experiment involves limiting our focus to low and middle income countries, ${ }^{69}$ which results in the reduction of sample size to 1320 observations, representing an unbalanced panel of 76 countries between 1980 and 2004. The FGLS estimates are shown in column (2) of Table 7. Both the coefficient values and their significance levels are not too different from the reference specification, ${ }^{70}$ and a Wald test $(p=0.00)$ indicates that the model coefficients are significant as a group. The coefficients on the extended common market and average distance to PTA partners are somewhat larger than in the reference model, and significant at the one percent level. In contrast, we get vastly different results when we estimate equation (2) for the sample of high income countries only. These estimated coefficients are shown in column (3), and their values differ dramatically from both the full sample and the developing countries model. Only the GDP, openness, and world FDI variables are significantly different from zero, indicating that neither the size of the extended common market nor the average distance from PTA partners are important determinants of net FDI inflows for the high income countries in our sample. Therefore, our results suggest that the estimated link between preferential liberalization and net FDI inflows is primarily driven by NorthSouth and/or South-South FDI. ${ }^{71}$ Since most of the variance in the value of PTAGDP is accounted for by PTAs with high income partners (by definition most Southern countries do not have large GDP) and since the positive effect of PTAGDP is driven mainly by PTAs between small and large partners, North-South PTAs are probably more important than South-South agreements in generating additional net FDI inflows. One important qualification to this finding is the fact that the fifteen member European Union is treated as a single country in our sample, which limits the cross-sectional dimension of the panel to ten members. Most importantly, this approach prevents us from capturing the FDI stimulus experienced by late entrants to the EU such as Ireland, Greece, Portugal, and Spain. ${ }^{72}$ Since North-North PTAs in our sample are few (they are EFTA, the EEA, and USA-Canada as a part of NAFTA) and South-North FDI is relatively small, it is perhaps not surprising that we cannot identify a robust relationship between, on the one hand, PTAGDP and DIST $A$ and, on the other hand, net FDI inflows for high income countries. In addition, the relatively small size of the high income sample may not provide enough data points to accurately capture the relationship even if it exists, especially considering the fact that we have to use up additional degrees of freedom to estimate the autocorrelation coefficient and the parameters of the variance-covariance matrix. ${ }^{73}$

Next, we turn to decomposing the full country sample into separate time periods. Medvedev (2006) showed that the mid-1990s witnessed an explosive growth in the number of PTAs, which increased by 130 percent from 1995 to 2004. Many of these new agreements were of the "third wave" kind, putting much more emphasis on "deep integration" provisions than the earlier PTAs. Therefore, we would like to test whether the PTA-FDI link that we have established in the course of earlier analysis is larger or more significant in the sample limited to the later PTAs. The results of these experiments are summarized in Table 8, where column (1) again repeats the reference

\footnotetext{
${ }^{69}$ We define high income countries as twenty four members of the OECD plus Liechtenstein.

${ }^{70}$ Inflation becomes insignificant at the ten percent level only because the $p$-value changes 0.099 to 0.10 .

${ }^{71}$ We have also estimated the model in equation (2) separately for developing countries in Latin America, East and South Asia, Eastern Europe, Middle East, and Africa. The estimates are shown in Appendix B. Since the relevant sample sizes are quite small, the results are not very robust and most coefficient estimates are insignificantly different from zero. For these reasons, any conclusions drawn from the estimates in Table 15 are tentative and must be interpreted with a large degree of caution.

${ }^{72}$ See section 3 for references to the literature that has studied the FDI consequences of the early rounds of EU accession.

${ }^{73}$ In the case of small sample sizes, it is quite important that we impose a common autocorrelation parameter, since this results in substantial savings in degrees of freedom used and therefore increased efficiency.
} 
between preferential liberalization and net FDI inflows during the 1980s and early 1990s.

Focusing instead on the later part of the 1990s and the early years of the new millennium changes the PTA-related results dramatically. Due to improved data coverage, the cross-sectional dimension of our panel increases to 85 countries (this is the full sample less Netherlands Antilles and Equatorial Guinea). The estimated coefficients for this sample are shown in column (3) of Table 8. The model coefficients are significant as a group (Wald $p=0.00$ ), but, in addition to GDP growth and inflation, the REER variable is not significantly different from zero (the $p$-values are $0.315,0.108$, and 0.214 , respectively). On the other hand, both of the PTA variables are significant at the one percent level and have the expected signs. The estimated elasticities of PTAGDP and $D I S T A$ are somewhat larger than the results in the reference specification. Thus, Table 8 suggests that the estimated link between preferential liberalization and net FDI is mainly driven by the effects of PTAs that have come into force during the late 1990s and early 2000s.

There are several reasons why we may expect this result. First, as mentioned earlier, PTAs signed over the course of the last decade have generally focused on "deep integration" provisions much more heavily than the earlier agreements. In addition, the "third wave' of PTAs featured many agreements that were signed between countries that are not each other's major trading partners, therefore making other aspects of integration relatively more important. A particularly important link between the new PTAs and FDI is the vast expansion in trade in services, to which FDI is a natural complement. As an example, consider the recent US-Singapore FTA, which is unlikely to have a significant effect on merchandise trade flows between the two partners (especially taking into account Singapore's very liberal MFN tariff schedule) but is expected to have a much larger impact on the already substantial trade in services between the two economies. Finally, studies such as World Bank (2002) have documented the tremendous expansion in the role of FDI as a source financing (especially in developing countries) during the late 1990s and early 2000s, and at least part of this expansion is potentially linked to the increased global integration brought about by the "third wave" PTAs.

Despite these arguments, there also several reasons to be cautious when interpreting the above results. First, causality is much more difficult to establish than correlation. Therefore, even though both the number and scope of PTAs were increasing dramatically at the same time as average country net FDI inflows were surging, it is impossible to know for certain that the latter were directly caused by the former. It may even be the case that, as FDI increased globally in the late 1990s, many countries actively pursued PTAs as a strategy to attract additional net FDI inflows. At the same time, the hope of attracting additional FDI is only one of the many reasons to join PTAs and, since only one-quarter of all PTAs signed during the 1995-2004 period were NorthSouth, it was probably not the main driver of the growth in the number of PTAs during that time. Second, the results of Table 8 do not necessarily imply that the "deep integration" provisions of later PTAs are responsible for the empirical PTA-FDI link, since the "deep integration" provisions are not the only feature differentiating the later PTAs and some of the earlier ones also contained chapters dealing with the liberalization of investment flows (e.g. EFTA, MERCOSUR, US-Israel FTA). Finally, there are also some qualifications on econometric grounds. It is difficult to compare results across various samples because they generate different estimates of the AR(1) parameters and the structure of the variance-covariance matrix. In some cases, the very small sample sizes preclude all but the most general of inferences, since the properties of the FGLS estimators are only known asymptotically. Therefore, only broad-based conclusions are likely to be valid based on the results found in this section, since direct comparisons of individual coefficients from different models are generally inappropriate. 


\section{Conclusion}

A large and growing body of literature has been devoted to understanding the trade creation and diversion effects of preferential trade agreements. On the other hand, the investment consequences of preferential liberalization have received relatively little theoretical and empirical attention. This paper adds to the small but growing literature on the links between PTAs and FDI by establishing a robust positive relationship between preferential trade liberalization and net FDI inflows for a large panel of countries and preferential agreements. There are four main messages emerging from our work. First, our results show that the FDI benefits of preferential liberalization are increasing with the size of PTA partners and their proximity to the host country. Second, we establish both a threshold (membership) and a market size component to the PTA-FDI relationship, although the latter seems more important. Third, we find that this relationship is mainly driven by the developing countries in our sample, which implies that the effect is due mostly to North-South PTAs. Finally, we show that the link between preferential liberalization and FDI is strongest in the late 1990s and early 2000s - a period when most "deep integration" agreements have been signed.

We identify five major channels through which preferential liberalization may affect FDI. The direct effect, observable in many but not all preferential agreements, is the influence of investment liberalization provisions on both incoming and outgoing FDI. The indirect effects include overall strengthening of the investment climate, access to larger markets, and the response of investment to changes in trade flows. In particular, "deep integration" provisions other than investment clauses, such as service sector liberalization and mechanisms for dispute settlement, are likely to result in greater FDI. Similarly, closer integration of PTA partners following preferential liberalization creates a larger common market which may bring in additional FDI due to economies of scale. On the other hand, the relationship between changes in trade flows and FDI is much more complicated. While some models point to a negative association (e.g. tariff-jumping FDI), others maintain it to be positive, and yet other models link the sign of the effect to the type of production structure of the MNE undertaking the investment. Finally, to the extent that preferential liberalization may stimulate additional growth which requires and attracts more investment, one may also expect to see a dynamic relationship between PTAs and FDI. However, the direction of causation is not clear, and PTAs are unlikely to be a major determinant of economic growth.

Since the theory behind the interactions between preferential liberalization and investment does not clearly determine the magnitude or sign of the relationship, we examine the effects of PTAs on net FDI inflows in a panel of 87 countries over the 1980-2004 period. Our pooled estimates take explicit account of both the time-series and cross-sectional correlations in the data, and rely on a comprehensive database of PTAs, which includes both WTO-notified and unnotified agreements. We find evidence that entering into PTAs with more and/or larger partners has a positive effect on an average country's net FDI inflows, while being located further away from these PTA partners tends to dampen the FDI stimulus effect. The former is captured by an extended market size variable, which is the sum of GDP of all PTA partners of a given country. The estimated elasticity of this effect in the baseline model is 0.06 , which implies that a country like Costa Rica can expect its net FDI inflows to rise by 11.5 percent after signing a preferential agreement with a high income partner like the United States. On the other hand, signing a PTA with Ecuador, whose GDP is only 60 percent larger than Costa Rica's, results in almost no change in the latter's FDI. The proximity effect is captured by average distance to all of the country's PTA partners and carries an estimated elasticity of -0.16. This implies, for example, that Costa Rica's FDI increase would be reduced to 9.6 percent if the USA were as far away from it as Germany. 
Due to the limitations of our dataset, it is difficult to establish the relative contributions of each of the above theoretical channels to net FDI inflows. We are able to test for both a threshold effect (i.e. the act of signing a PTA) and a market expansion effect (i.e. the increase in the size of the extended market following the PTA's entry into force), both of which turn out to be important determinants of FDI but the latter is statistically stronger. This finding confirms the importance of scale economies in attracting net FDI inflows. The large size of the threshold effect indicates that our results are to a large extent determined by PTAs with big and/or multiple partners. On the other hand, contrary to some of the earlier studies, we cannot find a significant effect of the expectation of joining a PTA. This result offers some support for the importance of PTA investment provisions, since the barriers to entry are not dismantled until after the agreement is implemented.

Decomposing the results by income level reveals that a positive and significant PTA-FDI relationship is only found among low and middle income countries, and therefore the aggregate results appear driven mainly by North-South agreements. We reach this conclusion by combining the former finding with the greater relative importance of market size (vis-á-vis the threshold effect) and the fact that the PTA-FDI link appears to be determined by agreements between large and small partners. We also show that while the empirical link between preferential trade liberalization and net FDI inflows is insignificant during the 1980s and early 1990s, the relationship is highly significant during the late 1990s and early 2000s. The latter is also the period when the number of PTAs has grown dramatically and many of the new agreements began featuring various "deep integration" provisions. Therefore, we find evidence of correlation between the growing number of "deep integration" agreements and increases in net FDI inflows. Overall, our results offer at least partial support for the investment provisions, investment climate, and market size hypotheses of the relationship between preferential trade liberalization and FDI. However, these decomposition results must be treated with a large degree of caution, since small sample sizes adversely affect the reliability of test statistics and limit the variation in dependent and independent variables, therefore preventing efficient estimation. Finally, combining the estimates of this paper with the results of Medvedev (2006), we have some evidence that, following preferential trade liberalization, FDI and trade may be complements. This is because Medvedev (2006), using a similar sample of PTAs, found a positive effect of preferential liberalization on trade between PTA member countries. Since the same set of PTAs results in greater trade and more net FDI inflows, the relationship between trade and FDI is likely to be positive. However, this statement must be taken with a large degree of caution because our results do not provide any information on the source of FDI, which could come from countries that have experienced trade diversion.

Overall, our results support the hypothesis that PTAs (and "deep integration" PTAs in particular) are associated with significant increases in the net FDI inflows of their participants. Our estimates of the FDI elasticity of a PTA extended common market are roughly similar to Lederman et al. (2005) and Levy Yeyati et al. (2003), who obtain an elasticity of approximately 0.1. We also identify significant proximity effects, although our estimates of the FDI-distance elasticity are much lower than those obtained under bilateral gravity specifications of Levy Yeyati et al. (2003) and Adams et al. (2003). Our estimates are particularly interesting since we consider a very wide sample of PTAs, many of which are small and/or poorly implemented. At the same time, there are a number of questions that our work does not address. For example, we do not consider the source of net FDI inflows and therefore cannot identify any PTA-induced investment creation or diversion effects. We also do not distinguish between types of PTAs-North-South vs. South-South, bilateral vs. regional, etc. - although different kinds of agreements are likely to have varying investment effects. Finally, we do not differentiate between PTAs that include explicit investment provisions and 
those that do not. Answers to these questions are likely to shed additional light on the empirical relationship between preferential trade liberalization and FDI and therefore represent promising directions for future research on the subject. 


\section{A Data details}

\section{A.1 List of sample countries}

Table 9: Regional definitions and country membership

\begin{tabular}{|c|c|c|c|}
\hline Latin America, Caribbean & East Asia, Pacific & Europe, Central Asia & "Sub-Saharan Africa \\
\hline Argentina & China & Armenia & Burundi \\
\hline Bahamas, The & Fiji & Bulgaria & Cameroon \\
\hline Belize & Hong Kong, China & Croatia & Central African Republic \\
\hline Bolivia & Indonesia & Cyprus & Congo, Dem. Rep. \\
\hline Brazil & Malaysia & Czech Republic & Cote d'Ivoire \\
\hline Chile & Papua New Guinea & Georgia & Equatorial Guinea \\
\hline Colombia & Philippines & Hungary & Gabon \\
\hline Costa Rica & Samoa & Macedonia, FYR & Gambia, The \\
\hline Dominica & Singapore & Moldova & Ghana \\
\hline Dominican Republic & Solomon Islands & Poland & Lesotho \\
\hline Ecuador & Thailand & Romania & Malawi \\
\hline Grenada & Tonga & Russian Federation & Nigeria \\
\hline Guyana & & Slovak Republic & Sierra Leone \\
\hline Mexico & & Turkey & South Africa \\
\hline Netherlands Antilles & & Ukraine & Uganda \\
\hline Nicaragua & & & Zambia \\
\hline \multicolumn{4}{|l|}{ Paraguay } \\
\hline \multicolumn{4}{|l|}{ Peru } \\
\hline \multicolumn{4}{|l|}{ St. Kitts and Nevis } \\
\hline \multicolumn{4}{|l|}{ St. Lucia } \\
\hline \multicolumn{4}{|c|}{ St. Vincent and the Grenadines } \\
\hline \multicolumn{4}{|l|}{ Togo } \\
\hline \multicolumn{4}{|l|}{ Trinidad and Tobago } \\
\hline \multicolumn{4}{|l|}{ Uruguay } \\
\hline \multicolumn{4}{|l|}{ Venezuela, RB } \\
\hline South Asia & Middle East & North Africa & High income \\
\hline India & Iran, Islamic Rep. & Algeria & Australia \\
\hline \multirow[t]{9}{*}{ Pakistan } & Israel & Egypt, Arab Rep. & Canada \\
\hline & Kuwait & Morocco & European Union \\
\hline & & Tunisia & Iceland \\
\hline & & & Japan \\
\hline & & & Korea, Rep. \\
\hline & & & New Zealand \\
\hline & & & Norway \\
\hline & & & Switzerland \\
\hline & & & United States \\
\hline
\end{tabular}

\section{A.2 Data sources}

With the exception of the PTA database, all variables used in the analysis can be easily obtained from the World Bank's World Development Indicators (WDI) database and from Centre d'Etudes Prospectives et d'Informations Internationales (CEPII ). The WDI database was accessed by the author through an internal World Bank server, but the data are also available on CD-ROM at subscribing libraries. In addition, the CD-ROM can be purchased from the World Bank bookstore, either in person or on-line. The CEPII distance data (dist_cepii.xls) may be freely downloaded 
online at http://www.cepii.fr/anglaisgraph/bdd/distances.htm. The details on PTA names and membership are provided in Appendix E of Medvedev (2006). Table 10 lists the names and codes of the WDI and CEPII data series that were used in the analysis.

Table 10: Variable names and codes

\begin{tabular}{lll}
\hline \hline Variable & Name in source data & Code \\
\hline GDP & GDP (current US\$) & NY.GDP.MKTP.CD \\
Exports & Merchandise exports (current US\$) & TX.VAL.MRCH.CD.WT \\
Imports & Merchandise imports (current US\$) & TM.VAL.MRCH.CD.WT \\
CPI & Consumer price index $(2000=100)$ & FP.CPI.TOTL \\
FDI & Foreign direct investment, net inflows $(B o P$, current US\$) & BX.KLT.DINV.CD.WD \\
REER & Real effective exchange rate index $(2000=100)$ & PX.REX.REER \\
Distance & & dist \\
\hline
\end{tabular}

\section{A.3 Data transformation}

This section provides the STATA code used to construct the dataset and conduct the analysis.

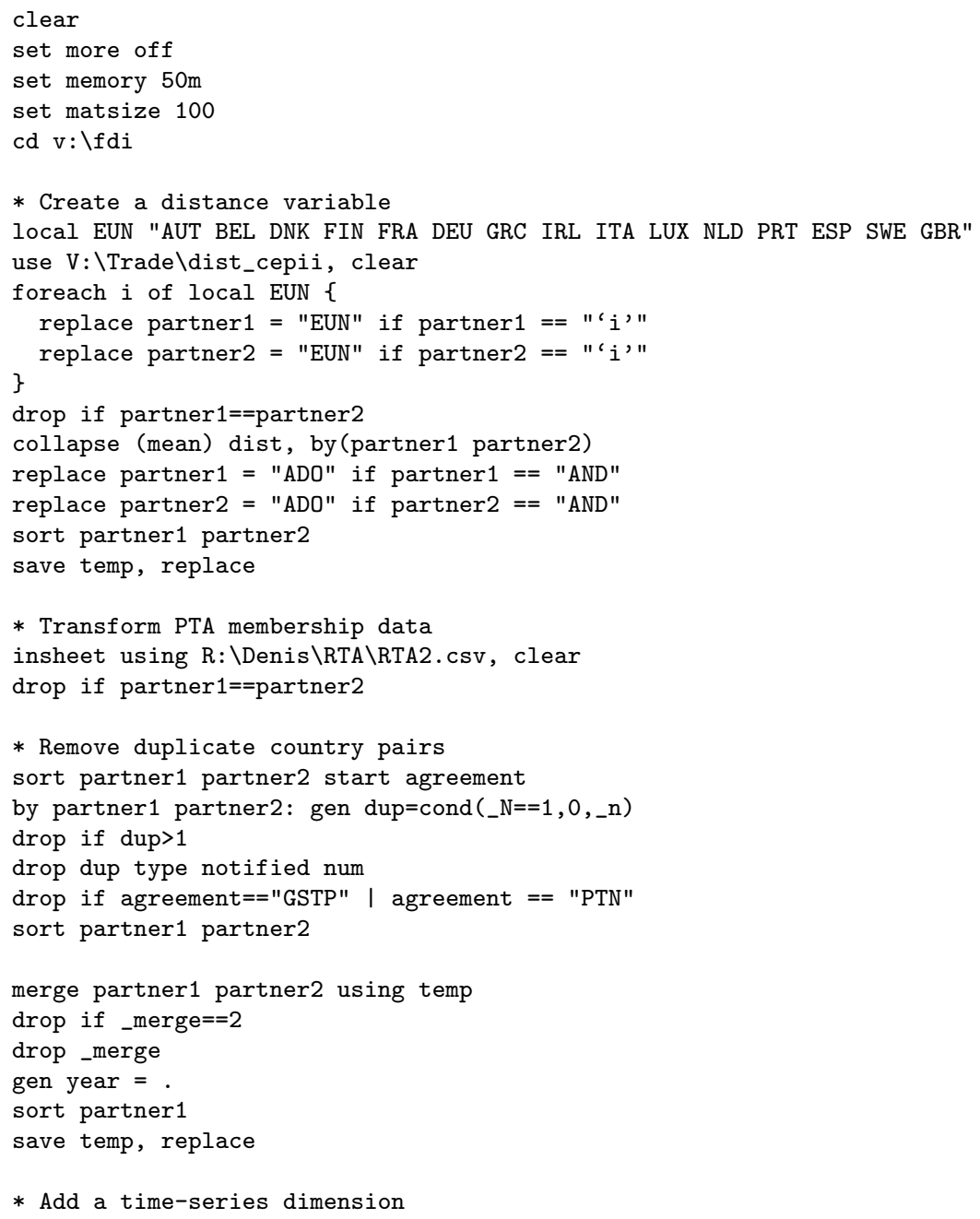




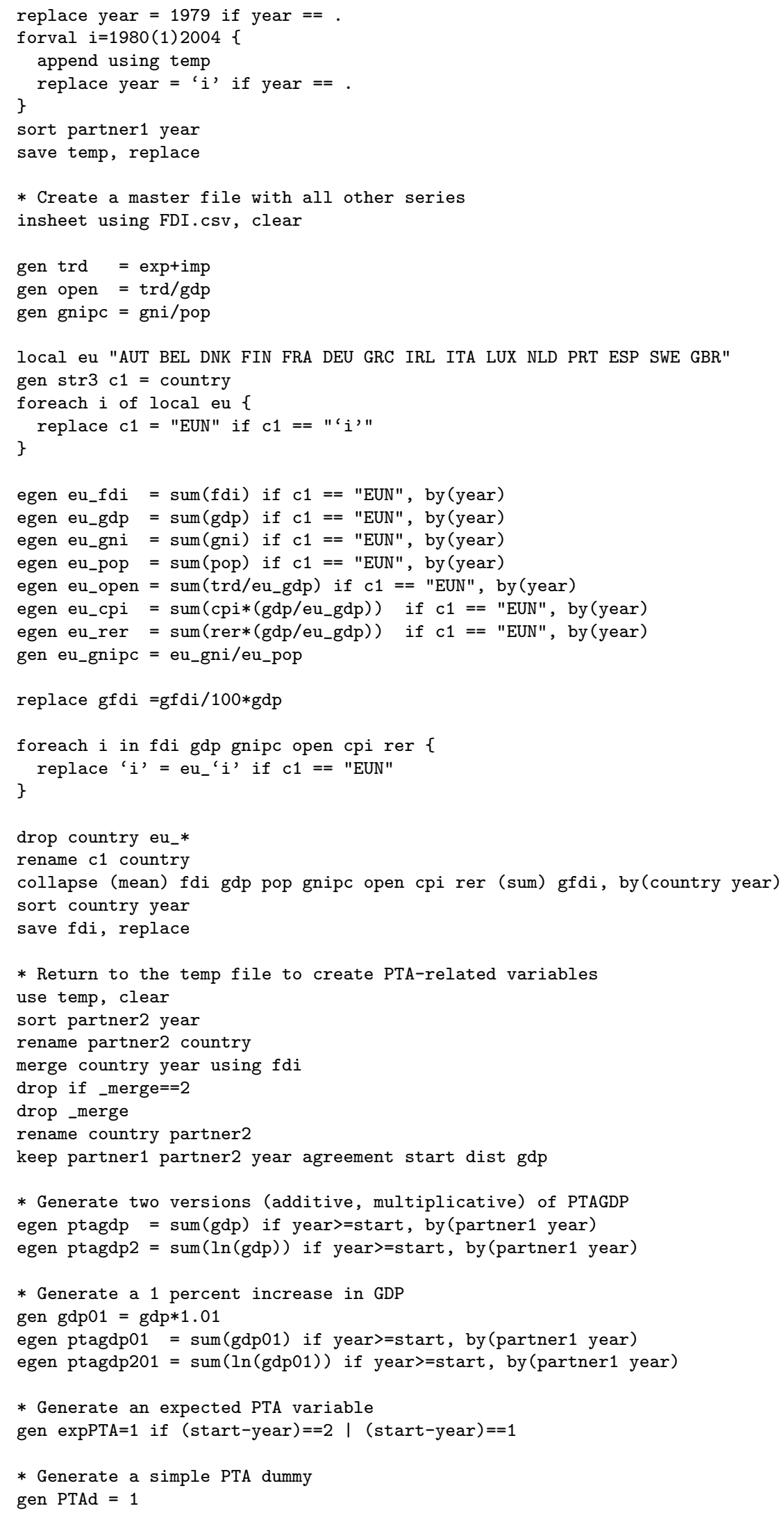




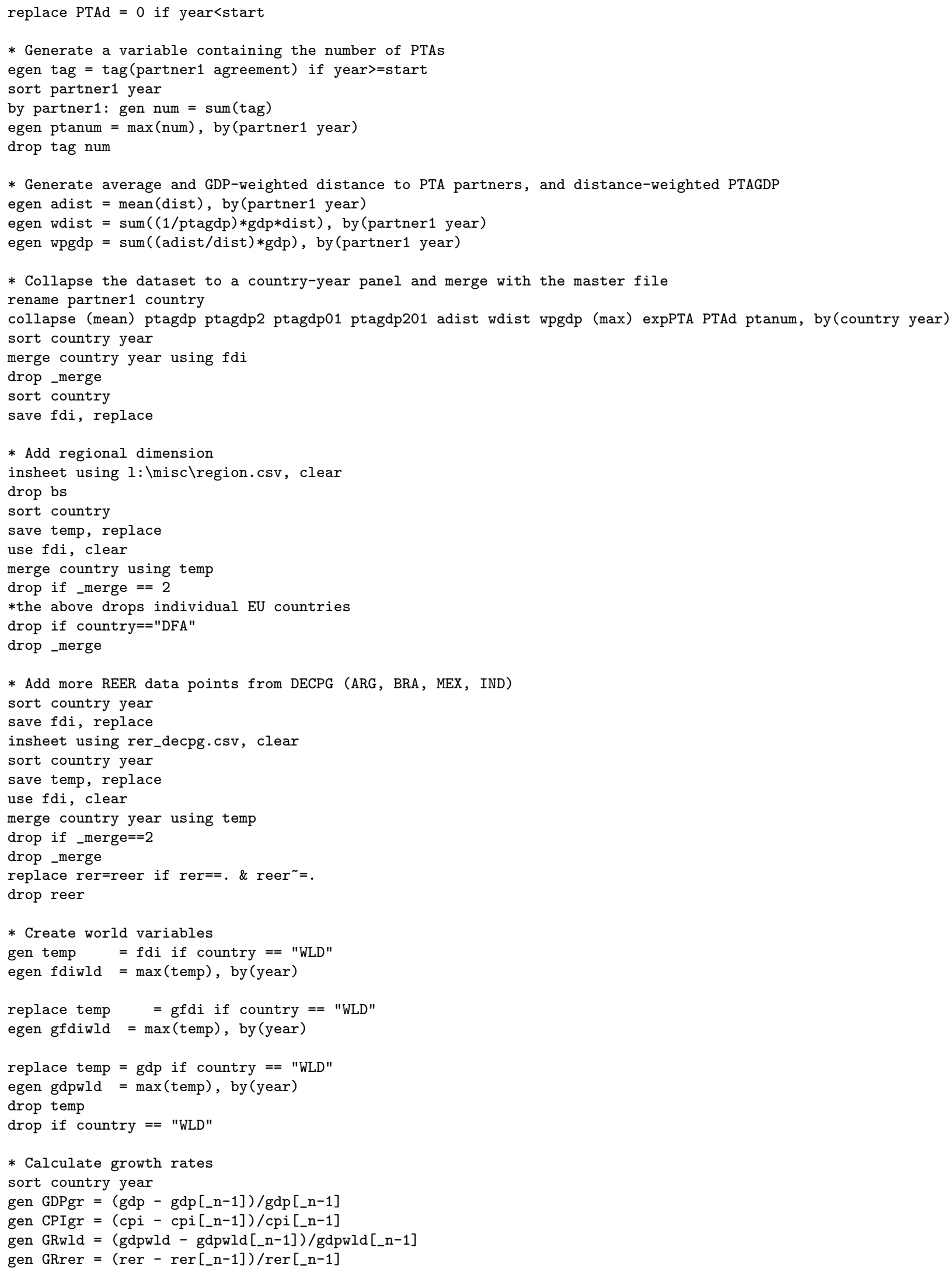




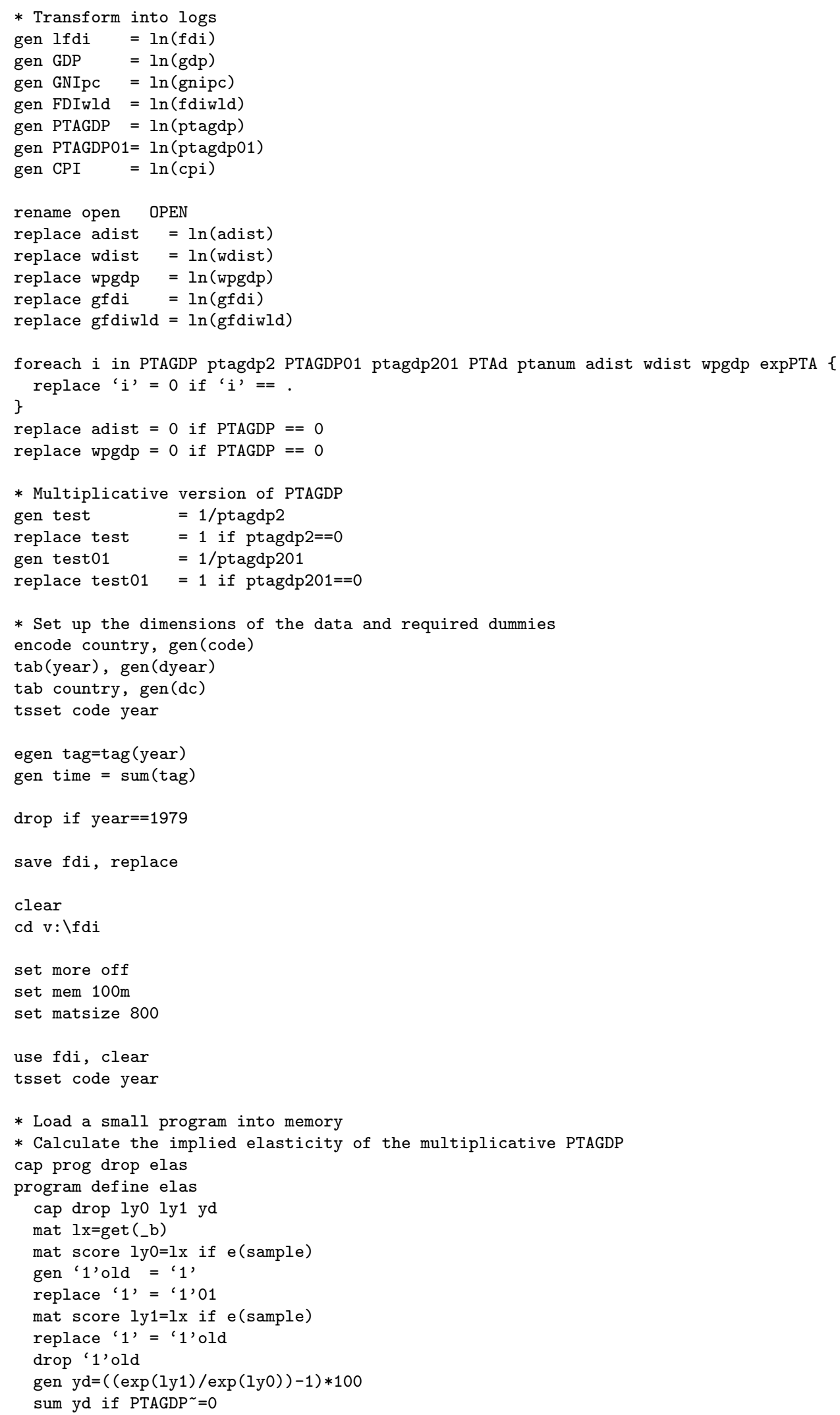


end

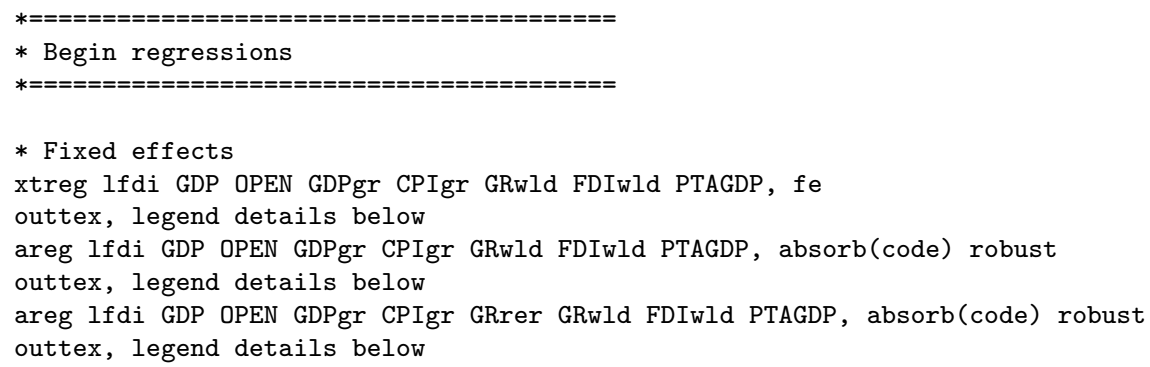


* iFGLS with distance

xtgls lfdi GDP OPEN GDPgr CPIgr GRrer iFDIwld PTAGDP adist, igls panels(heteroskedastic)

$i$ (code) corr (ar1) t (year) force

outtex, legend details below

xtgls lfdi GDP OPEN GDPgr CPIgr GRrer iFDIwld PTAGDP wdist, igls panels(heteroskedastic)

$i$ (code) corr (ar1) t (year) force

outtex, legend details below

xtgls lfdi GDP OPEN GDPgr CPIgr GRrer iFDIwld wpgdp, igls panels(heteroskedastic)

$i$ (code) corr $(\operatorname{ar} 1) t$ (year) force

outtex, legend details below

* FGLS with other checks

xtgls lfdi GDP OPEN GDPgr CPIgr GRrer iFDIwld test adist, igls panels(heteroskedastic)

$i$ (code) corr (ar1) t (year) force

outtex, legend details below

elas test

xtgls lfdi GDP OPEN GDPgr CPIgr GRrer iFDIwld PTAd adist, igls panels(heteroskedastic)

$i$ (code) corr (ar1) t (year) force

outtex, legend details below

rename ptanum PTAnum

xtgls lfdi GDP OPEN GDPgr CPIgr GRrer iFDIwld PTAnum adist, igls panels(heteroskedastic)

$i$ (code) corr (ar1) t (year) force

outtex, legend details below

gen PTAnum2 = PTAnum²

xtgls lfdi GDP OPEN GDPgr CPIgr GRrer iFDIwld PTAnum PTAnum2 adist, igls panels(heteroskedastic)

$i$ (code) corr (ar1) t (year) force

outtex, legend details below

xtgls lfdi GDP OPEN GDPgr CPIgr GRrer iFDIwld expPTA PTAGDP adist, igls panels(heteroskedastic)

$i$ (code) $\operatorname{corr}(\operatorname{ar} 1) \mathrm{t}$ (year) force

outtex, legend details below

* Regressions by region and time period

xtgls Ifdi GDP OPEN GDPgr CPIgr GRrer iFDIwld PTAGDP adist if region ${ }^{2}$ "North",

igls panels (heteroskedastic) $i$ (code) $\operatorname{corr}(\operatorname{ar} 1) t(y e a r)$ force

outtex, legend details below

xtgls lfdi GDP OPEN GDPgr CPIgr GRrer iFDIwld PTAGDP adist if region=="North",

igls panels (heteroskedastic) i(code) corr(ar1) t(year) force

outtex, legend details below

xtgls lfdi GDP OPEN GDPgr CPIgr GRrer iFDIwld PTAGDP adist if region=="LAC",

igls panels (heteroskedastic) i(code) corr (ar1) $t$ (year) force

outtex, legend details below

xtgls lfdi GDP OPEN GDPgr CPIgr GRrer iFDIwld PTAGDP adist if region=="EAP",

igls panels (heteroskedastic) i(code) corr (ar1) t(year) force

outtex, legend details below

xtgls lfdi GDP OPEN GDPgr CPIgr GRrer iFDIwld PTAGDP adist if region=="EAP"|region=="SAS",

igls panels(heteroskedastic) $i$ (code) $\operatorname{corr}(\operatorname{ar} 1) t$ (year) force

outtex, legend details below

xtgls lfdi GDP OPEN GDPgr CPIgr GRrer iFDIwld PTAGDP adist if region=="ECA",

igls panels (heteroskedastic) i(code) corr(ar1) t(year) force

outtex, legend details below

xtgls lfdi GDP OPEN GDPgr CPIgr GRrer iFDIwld PTAGDP adist if region=="MNA"|region=="SSA",

igls panels(heteroskedastic) i(code) corr(ar1) t(year) force

outtex, legend details below

xtgls lfdi GDP OPEN GDPgr CPIgr GRrer iFDIwld PTAGDP adist if region=="MNA" ,

igls panels (heteroskedastic) $i$ (code) $\operatorname{corr}(\operatorname{ar} 1)$ t(year) force

outtex, legend details below

xtgls lfdi GDP OPEN GDPgr CPIgr GRrer iFDIwld PTAGDP adist if year<1995,

igls panels (heteroskedastic) $i$ (code) $\operatorname{corr}(\operatorname{ar} 1) t$ (year) force

outtex, legend details below

xtgls lfdi GDP OPEN GDPgr CPIgr GRrer iFDIwld PTAGDP adist if year>1994,

igls panels (heteroskedastic) $i$ (code) $\operatorname{corr}(\operatorname{ar} 1) t$ (year) force

outtex, legend details below

$*$ Using i2FDIwld as an instrument

$*$ 
* iFGLS with distance

xtgls lfdi GDP OPEN GDPgr CPIgr GRrer GRwld i2FDIwld PTAGDP adist, igls panels (heteroskedastic) i(code) corr (ar1) t(year) force outtex, legend details below

xtgls lfdi GDP OPEN GDPgr CPIgr GRrer GRwld i2FDIwld PTAGDP wdist, igls panels (heteroskedastic) i(code) corr(ar1) t(year) force outtex, legend details below

xtgls lfdi GDP OPEN GDPgr CPIgr GRrer GRwld i2FDIwld wpgdp, igls panels(heteroskedastic) i(code) corr(ar1) $t$ (year) force outtex, legend details below

* FGLS with other checks

xtgls lfdi GDP OPEN GDPgr CPIgr GRrer GRwld i2FDIwld test adist, igls panels(heteroskedastic) i(code) corr (ar1) t(year) force outtex, legend details below

elas test

xtgls lfdi GDP OPEN GDPgr CPIgr GRrer GRwld i2FDIwld PTAd adist, igls panels (heteroskedastic) i(code) corr (ar1) t(year) force

outtex, legend details below

rename ptanum PTAnum

xtgls lfdi GDP OPEN GDPgr CPIgr GRrer GRwld i2FDIwld PTAnum adist, igls panels (heteroskedastic) i(code) corr (ar1) t(year) force

outtex, legend details below

gen PTAnum2 = PTAnum²

xtgls lfdi GDP OPEN GDPgr CPIgr GRrer GRwld i2FDIwld PTAnum PTAnum2 adist, igls panels(heteroskedastic) i(code) corr(ar1) t(year) force

outtex, legend details below

xtgls lfdi GDP OPEN GDPgr CPIgr GRrer GRwld i2FDIwld expPTA PTAGDP adist, igls panels (heteroskedastic) i(code) corr (ar1) t(year) force

outtex, legend details below

* Regressions by region and time period xtgls Ifdi GDP OPEN GDPgr CPIgr GRrer GRwld i2FDIwld PTAGDP adist if region ${ }^{=}$"North", igls panels(heteroskedastic) i(code) corr(ar1) t(year) force outtex, legend details below

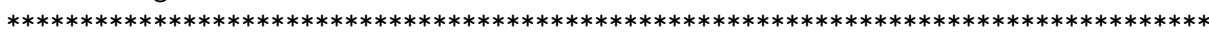

* Count countries and PTAs in the sample (for PTAs, keep if e(sample),

* save temp1, merge with temp from RTA.csv) 


\section{B Additional estimation results}

\section{B.1 Specification tests of the replication model}

Table 11 provides a summary of some simple specification tests of equation (1). The first column of the table reproduces the fixed effects estimates shown in Table 3 for ease of comparison. Column (2) applies the Huber-White "sandwich" procedure to the fixed effects estimates to obtain robust standard errors. The robust standard errors of most model coefficients are 15 to 30 larger than the unadjusted standard errors, although the standard error of openness more than doubles, indicating that this variable may be the main cause of heteroscedasticity in the model. Despite the marked increase in the absolute value of standard errors, however, the coefficient significance levels (and therefore inference) remain largely unchanged from the baseline model.

Table 11: Fixed effects and FGLS estimation results: net FDI inflows

\begin{tabular}{|c|c|c|c|c|c|}
\hline \multirow[b]{2}{*}{ Variable } & (1) & $(2)$ & $(3)$ & $(4)$ & $(5)$ \\
\hline & \multicolumn{5}{|c|}{ Coefficient } \\
\hline \multirow[t]{2}{*}{ GDP } & $1.209^{* *}$ & $1.209^{* *}$ & $0.896^{* *}$ & $1.508^{* *}$ & $0.878^{* *}$ \\
\hline & $(0.094)$ & $(0.127)$ & $(0.016)$ & $(0.120)$ & $(0.020)$ \\
\hline \multirow[t]{2}{*}{ OPEN } & $0.651^{* *}$ & $0.651^{*}$ & $0.879^{* *}$ & $0.601^{* *}$ & $0.875^{* *}$ \\
\hline & $(0.118)$ & $(0.261)$ & $(0.059)$ & $(0.161)$ & $(0.081)$ \\
\hline \multirow[t]{2}{*}{ GNIREL } & $-1.904^{* *}$ & $-1.904^{* *}$ & $0.412^{* *}$ & $-2.571^{* *}$ & $0.321^{\dagger}$ \\
\hline & $(0.472)$ & $(0.495)$ & $(0.152)$ & $(0.489)$ & $(0.173)$ \\
\hline \multirow[t]{2}{*}{ GDPGRO } & $0.444^{*}$ & $0.444^{*}$ & 0.041 & $0.448^{\dagger}$ & 0.154 \\
\hline & $(0.177)$ & $(0.185)$ & $(0.094)$ & $(0.241)$ & $(0.126)$ \\
\hline \multirow[t]{2}{*}{ CPIGRO } & $-0.028^{* *}$ & $-0.028^{* *}$ & $-0.015^{* *}$ & $-0.024^{* *}$ & $-0.011^{*}$ \\
\hline & $(0.006)$ & $(0.009)$ & $(0.004)$ & $(0.007)$ & $(0.005)$ \\
\hline \multirow[t]{2}{*}{ WLDGRO } & $-1.235^{* *}$ & $-1.235^{* *}$ & $-0.596^{*}$ & $-1.535^{*}$ & -0.454 \\
\hline & $(0.467)$ & $(0.455)$ & $(0.284)$ & $(0.597)$ & $(0.371)$ \\
\hline \multirow[t]{2}{*}{ WLDFDI } & $0.376^{* *}$ & $0.376^{* *}$ & $0.410^{* *}$ & $0.336^{* *}$ & $0.455^{* *}$ \\
\hline & $(0.037)$ & $(0.050)$ & $(0.029)$ & $(0.046)$ & $(0.038)$ \\
\hline \multirow[t]{2}{*}{ PTAGDP } & 0.002 & 0.002 & $0.007^{*}$ & -0.006 & $0.012^{* *}$ \\
\hline & $(0.004)$ & $(0.006)$ & $(0.003)$ & $(0.005)$ & $(0.004)$ \\
\hline \multirow[t]{2}{*}{ PTAEXP } & -0.031 & -0.031 & 0.043 & -0.010 & 0.032 \\
\hline & $(0.061)$ & $(0.057)$ & $(0.038)$ & $(0.078)$ & $(0.051)$ \\
\hline $\mathrm{N}$ & 2561 & 2561 & 2561 & 1528 & 1528 \\
\hline $\mathrm{R}^{2}($ Log-lhd $)$ & 0.645 & 0.645 & -3029.078 & 0.685 & -1688.7 \\
\hline $\mathrm{F}\left(\chi^{2}\right)$ & 161.21 & 178.402 & 6198.195 & 105.624 & 3486.39 \\
\hline \multicolumn{6}{|c|}{$\begin{array}{l}\text { Significance levels : } \dagger 10 \% * 5 \% * * * 1 \% \\
\text { Note: Standard errors are in parentheses. The dependent variable is expressed } \\
\text { in natural logarithms. Column (1) shows fixed effects estimates of equation } \\
\text { (1), column (2) shows the same estimates with Huber-White robust stan- } \\
\text { dard errors, column (3) estimates the same equation using three-step FGLS, } \\
\text { column(4) applies fixed effects to the sample of Table 4, column(5) applies } \\
\text { three-step FGLS to the same sample. }\end{array}$} \\
\hline
\end{tabular}

Column (3) estimates equation (1) using the three-step FGLS approach (the same one used for the baseline model in section 4.2). As mentioned in the main text, the heteroscedasticity- and 
autocorrelation-consistent FGLS estimates are not easily comparable to the results produced by the fixed effects estimator. For example, since the desirable properties of the FGLS estimator can only be shown to hold asymptotically, hypothesis testing is based on the normal distribution) rather than its small sample counterparts (i.e. inference is made on the basis of $z$ and $\chi^{2}$ statistics rather than $t$ and $F$ ). Nonetheless, the fact that point estimates of several control variables change by a large amount and the relative GNI variable changes sign while remaining highly significant indicates that serial correlation is a considerable problem and that fixed effects estimator of equation (1) is not appropriate in our data.

Column (4) of Table 11 returns to the fixed effects estimator, but applies it to the limited sample of countries considered in the baseline model. The sample size is reduced to 1528 observations, which is smaller than 1541 observations shown in Table 4. The 13 excluded observations correspond to several data points for Bahamas, Grenada, Kuwait, and Poland where we do not have the data on GNI per capita. The point estimates differ by as much as 50 percent from those shown in column (1), but coefficient signs, orders of magnitude, and significance levels remain unchanged. ${ }^{74}$ Therefore, we can conclude that the large reduction in the sample size when moving from equation (1) to equation (2) does not qualitatively change the model results.

Column (5) applies the three-step FGLS estimator to the sample that was considered in column (4). The point estimates are very different from the previous column, and quite close to those shown in column (3). As before, when moving from the fixed effects within estimator to FGLS the relative GNI per capita switches sign while remaining significant at the ten percent level, while GDP growth becomes insignificantly different from zero. Furthermore, global growth also becomes insignificant. Finally, similar to the estimates in column (3), the PTA extended common makret variable has the expected positive sign and is significant at the one percent level. Therefore, these results show that the choice of estimator has a large effect on the point estimates of coefficients, their signs, and qualitative conclusions drawn from these. On the other hand, reducing the sample size by 40 percent (moving from the sample of Table 3 to the sample of Table 4) has much more modest effects on the point estimates and does not affect coefficient signs or model inference.

\section{B.2 Multicollinearity tests}

Table 12 conducts some simple tests for multicollinearity between GDP and openness, and GDP and relative GNI by regressing one of the independent variables against the other. In addition to the variables shown, each regression also included an intercept term and a set of country fixed effects (dropping the last one to avoid the dummy variable trap). For each regression, the $F$ statistic is significant at the one percent level, indicating that the model variables are significant as a group.

\section{B.3 Granger causality tests}

A variable $x$ is said to Granger-cause $y$ if, in a regression of $y$ on its lagged values, lagged values of $x$ contribute significantly to the explanatory power of the model (see Granger, 1969). Table 13 summarizes the results of regressing several of the model variables on their own lags, lags of other variables, an intercept term, and a set of country fixed effects (the last two are not shown). "L", "L2", and "L3" refer to the first, second, and third lags respectively. The lag lengths shown were chosen as the "best" specification after testing several alternative lag structures.

\footnotetext{
${ }^{74}$ The point estimate of $P T A G D P$ becomes negative, but in either case it is not significantly different from zero.
} 
Table 12: Fixed effects estimation results: GDP

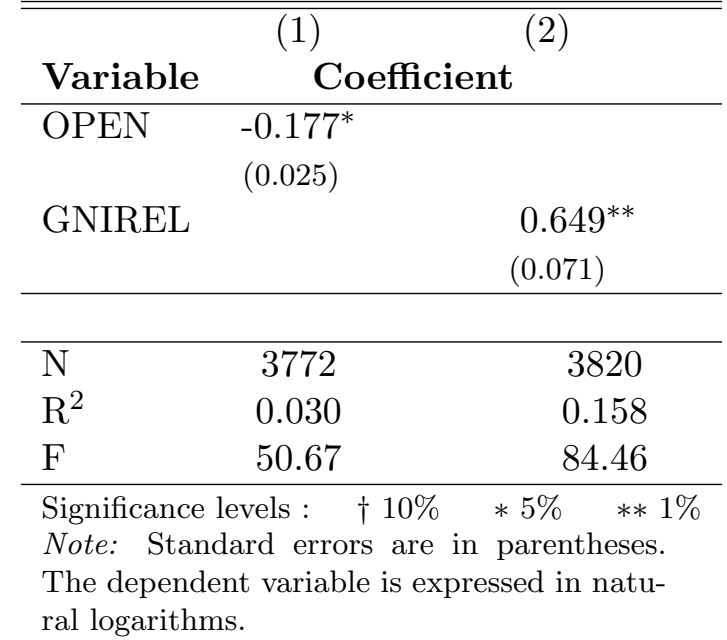

Table 13: Granger causality estimation results

\begin{tabular}{|c|c|c|c|c|}
\hline "Variable: & $\overline{\overline{\text { FDI }}}$ & 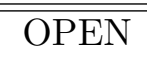 & $\overline{\text { FDI }}$ & 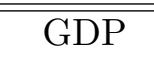 \\
\hline \multirow[t]{2}{*}{ L.FDI } & $0.497^{* *}$ & $0.004^{\dagger}$ & $0.435^{* *}$ & $0.016^{* *}$ \\
\hline & $(0.022)$ & $(0.002)$ & $(0.022)$ & $(0.003)$ \\
\hline \multirow[t]{2}{*}{ L2.FDI } & $0.129^{* *}$ & 0.000 & $0.094^{* *}$ & 0.001 \\
\hline & $(0.024)$ & $(0.002)$ & $(0.023)$ & $(0.003)$ \\
\hline \multirow[t]{2}{*}{ L3.FDI } & $0.099^{* *}$ & $0.004^{\dagger}$ & $0.052^{* *}$ & $0.007^{*}$ \\
\hline & $(0.020)$ & $(0.002)$ & $(0.020)$ & $(0.003)$ \\
\hline \multirow[t]{2}{*}{ L.OPEN } & $0.517^{*}$ & $0.781^{* *}$ & & \\
\hline & $(0.241)$ & $(0.023)$ & & \\
\hline \multirow[t]{2}{*}{ L2.OPEN } & -0.151 & -0.021 & & \\
\hline & $(0.293)$ & $(0.028)$ & & \\
\hline \multirow[t]{2}{*}{ L3.OPEN } & -0.083 & $0.038^{*}$ & & \\
\hline & $(0.221)$ & $(0.017)$ & & \\
\hline \multirow[t]{2}{*}{ L.GDP } & & & $0.886^{* *}$ & $1.080^{* *}$ \\
\hline & & & $(0.150)$ & $(0.023)$ \\
\hline \multirow[t]{2}{*}{ L2.GDP } & & & -0.086 & $-0.224^{* *}$ \\
\hline & & & $(0.212)$ & $(0.031)$ \\
\hline \multirow[t]{2}{*}{ L3.GDP } & & & -0.116 & $0.048^{*}$ \\
\hline & & & $(0.147)$ & $(0.021)$ \\
\hline $\mathrm{N}$ & 2100 & 2176 & 2112 & 2188 \\
\hline $\mathrm{R}^{2}$ & 0.895 & 0.959 & 0.901 & 0.997 \\
\hline $\mathrm{F}$ & 107.206 & 305.264 & 115.034 & 4849.023 \\
\hline
\end{tabular}

\section{B.4 Specification tests of the baseline model}

Table 14 provides a summary of some simple specification tests of the baseline model. For ease of comparison, column (1) repeats the results of estimating equation (2) with three-step FGLS (shown 
Table 14: Fixed effects and FGLS estimation results: net FDI inflows

\begin{tabular}{|c|c|c|c|c|}
\hline \multirow[b]{2}{*}{ Variable } & (1) & $(2)$ & (3) & (4) \\
\hline & \multicolumn{4}{|c|}{ Coefficient } \\
\hline \multirow[t]{2}{*}{ GDP } & $0.899^{* *}$ & $1.208^{* *}$ & $0.899^{* *}$ & $0.899^{* *}$ \\
\hline & $(0.017)$ & $(0.107)$ & $(0.017)$ & $(0.017)$ \\
\hline \multirow[t]{2}{*}{ OPEN } & $0.941^{* *}$ & $0.705^{* *}$ & $0.920^{* *}$ & $0.943^{* *}$ \\
\hline & $(0.083)$ & $(0.162)$ & $(0.081)$ & $(0.083)$ \\
\hline \multirow[t]{2}{*}{ GDPGRO } & $0.256^{\dagger}$ & $0.452^{\dagger}$ & $0.260^{\dagger}$ & 0.111 \\
\hline & $(0.142)$ & $(0.260)$ & $(0.143)$ & $(0.127)$ \\
\hline \multirow[t]{2}{*}{ CPIGRO } & $-0.008^{\dagger}$ & $-0.022^{* *}$ & $-0.008^{\dagger}$ & $-0.011^{*}$ \\
\hline & $(0.005)$ & $(0.008)$ & $(0.005)$ & $(0.005)$ \\
\hline \multirow[t]{2}{*}{ RERGRO } & $-0.336^{*}$ & -0.243 & $-0.319^{*}$ & \\
\hline & $(0.146)$ & $(0.238)$ & $(0.147)$ & \\
\hline \multirow[t]{2}{*}{ WLDGRO } & $-0.677^{\dagger}$ & $-1.711^{* *}$ & -0.643 & -0.386 \\
\hline & $(0.391)$ & $(0.620)$ & $(0.393)$ & $(0.371)$ \\
\hline \multirow[t]{2}{*}{ WLDFDIadj } & $0.373^{* *}$ & $0.317^{* *}$ & $0.400^{* *}$ & $0.377^{* *}$ \\
\hline & $(0.039)$ & $(0.045)$ & $(0.038)$ & $(0.039)$ \\
\hline \multirow[t]{2}{*}{ PTAGDP } & $0.060^{* *}$ & $0.148^{* *}$ & $0.013^{* *}$ & $0.058^{* *}$ \\
\hline & $(0.018)$ & $(0.024)$ & $(0.004)$ & $(0.018)$ \\
\hline \multirow[t]{2}{*}{ DISTA } & $-0.155^{* *}$ & $-0.488^{* *}$ & & $-0.151^{* *}$ \\
\hline & $(0.058)$ & $(0.079)$ & & $(0.058)$ \\
\hline $\mathrm{N}$ & 1541 & 1541 & 1541 & 1541 \\
\hline Log-lhd $\left(R^{2}\right)$ & -1716.811 & 0.721 & -1719.664 & -1719.765 \\
\hline$\chi^{2}(\mathrm{~F})$ & 3146.643 & 110.522 & 3172.543 & 3138.254 \\
\hline \multicolumn{5}{|c|}{$\begin{array}{l}\text { Significance levels: } \dagger 10 \% * 5 \% * * 1 \% \\
\text { Note: Standard errors are in parentheses. The dependent variable } \\
\text { is expressed in natural logarithms. Column (1) reproduces the esti- } \\
\text { mates of Table 4, column (2) estimates equation (2) using fixed ef- } \\
\text { fects, columns (3) and (4) apply the three-step FGLS estimator while } \\
\text { omitting the distance and REER growth variables, respectively. }\end{array}$} \\
\hline
\end{tabular}

in Table 4). For equation (1), section B.1 has shown that the choice of estimator has a significant impact on the model results, while sample size is much less important and does not qualitatively change the conclusions. In order to test whether is the former is true for equation (2), column (2) shows the results of estimating this equation with a fixed effects approach. The point estimates vary widely across specifications: for example, the coefficients on inflation, global growth, and PTA extended common market are approximately three times larger when using fixed effects. At the same time, all variables with the exception of REER growth rate have the expected signs and are significant at the ten percent level, and both PTA-related variables are significant at the one percent threshold. This suggests that it is the choice of variables (i.e. model specification) rather than the estimation approach that renders PTAGDP and DIST A statistically significant. In other words, once we account for multicollinearity and endogeneity problems by dropping the GNIREL variable and replacing $W L D F D I$ with $W L D F D I a d j$, the choice of estimation approach becomes 
less important for drawing broad conclusions from the model. ${ }^{75}$ The exception to this statement is the $R E R G R O$ variable, which is not statistically significant under any approaches that do not specifically control for serial correlation.

Columns (3) and (4) investigate the sensitivity of results to the two new variables in equation (2): average distance to PTA partners and the REER growth rate. Excluding the distance variable has a very small impact on the coefficient estimates and significance levels of the control variables. Global growth becomes insignificant at the ten percent level, but in fact the $p$-value increases from 0.083 to 0.102 , which is not a large change. Consistent with intuition, the coefficient on PT AGDP is much smaller with the distance variable excluded. This is because the former now controls for both the positive effects of joining a PTA and belonging to a larger common market and the negative effect of being located farther away from PTA partners.

Excluding the REER growth variable has a much stronger effect on the estimates. While the coefficients and significance levels of the PTA-related variables remain largely unchanged, both GDP growth and global growth become insignificant. ${ }^{76}$ This suggests that REER dynamics play an important role in determining the distribution of net FDI inflows across countries, and ignoring this channel can lead to unexpected behavior of other model variables.

\section{B.5 Decomposing model results by geographic region and income level}

The set of experiments in this section concerns further disaggregating the developing country results into geographic regions. The first region we consider is Latin America and the Caribbean. The sample consists of 24 countries and 465 observations, and the results are shown in column (1) of Table 15. Our model does not do well in explaining the variation in the dependent variable, since only GDP and world FDI are significantly different from zero at conventional confidence levels. On the other hand, PTAGDP, CPIGRO, and RERGRO barely miss the ten percent significance threshold with $p$-values of $0.109,0.113$, and 0.131 , respectively. These results indicate that our model may still be applicable to the Latin American data, but that the relatively small size of the sample does not allow for efficient estimation with FGLS.

Next, we focus on East and South Asia. Here, we consider 14 countries which results in the sample size of 236 observations. The estimation results are shown in column (2). The only statistically significant variables are GDP, openness, world FDI, and the growth in the real effective exchange rate. Most importantly, neither of the PTA-related variables are significantly different from zero at any accepted confidence intervals (the relevant $p$-values are 0.449 and 0.452 for PTAGDP and $D I S T A$, respectively). Therefore, preferential liberalization does not appear to be an important determinant of net FDI for the low and middle income countries in East and South Asia, although the the sample size disclaimer mentioned while discussing the high income model is also applicable here. We also estimate a separate model for East Asian countries only, with the results shown in column (3) of Table 15. This sample contains 12 countries, which limits the number of available observations to 198. The results are roughly similar to the previous estimates, with three important differences. First, the coefficient on openness is much lower when we restrict the sample to East Asian countries only. One explanation for this could be that while the East Asian economies have traditionally been more open to trade, the same cannot be said of their South Asian counterparts.

\footnotetext{
${ }^{75}$ Recall that OLS, and by extension the fixed effects estimator, remains unbiased in the presence of heteroscedasticity and autocorrelation, but is no longer efficient. Therefore, if moving from equation (1) to equation (2) addresses most of the problems save for serial correlation and heteroscedasticity, we expect the differences between the FGLS and fixed effects to diminish.

${ }^{76}$ The $p$-values increase to 0.382 and 0.297 , respectively.
} 
Table 15: Estimation results by income level and region: net FDI inflows

\begin{tabular}{|c|c|c|c|c|c|c|}
\hline \multirow[b]{2}{*}{ Variable } & $\overline{(1)}$ & $\overline{(2)}$ & $\overline{(3)}$ & $\overline{(4)}$ & $\overline{(5)}$ & $\overline{(6)}$ \\
\hline & \multicolumn{6}{|c|}{ Coefficient } \\
\hline \multirow[t]{2}{*}{ GDP } & $0.784^{* *}$ & $1.073^{* *}$ & $1.107^{* *}$ & $0.783^{* *}$ & $0.857^{* *}$ & 0.336 \\
\hline & $(0.024)$ & $(0.048)$ & $(0.044)$ & $(0.052)$ & $(0.067)$ & $(0.417)$ \\
\hline \multirow[t]{2}{*}{ OPEN } & 0.097 & $0.999^{* *}$ & $0.816^{* *}$ & 0.541 & $1.961^{* *}$ & -0.139 \\
\hline & $(0.112)$ & $(0.079)$ & $(0.085)$ & $(0.345)$ & $(0.355)$ & $(1.251)$ \\
\hline \multirow[t]{2}{*}{ GDPGRO } & 0.241 & 0.532 & 1.081 & $1.151^{* *}$ & 0.294 & -0.640 \\
\hline & $(0.221)$ & $(0.588)$ & $(0.664)$ & $(0.339)$ & $(0.314)$ & $(0.930)$ \\
\hline \multirow[t]{2}{*}{ CPIGRO } & -0.009 & 0.004 & 0.370 & 0.020 & -0.037 & 0.118 \\
\hline & $(0.006)$ & $(1.164)$ & (1.198) & $(0.025)$ & $(0.043)$ & $(0.200)$ \\
\hline \multirow[t]{2}{*}{ RERGRO } & -0.372 & $-1.555^{\dagger}$ & $-2.794^{* *}$ & $-1.243^{* *}$ & 0.083 & $3.200^{* *}$ \\
\hline & $(0.246)$ & $(0.883)$ & $(1.002)$ & $(0.328)$ & $(0.245)$ & $(1.030)$ \\
\hline \multirow[t]{2}{*}{ WLDGRO } & -0.691 & -1.293 & $-2.640^{*}$ & $-2.465^{*}$ & -1.436 & 1.713 \\
\hline & $(0.582)$ & $(1.135)$ & (1.307) & $(1.070)$ & (1.008) & $(2.062)$ \\
\hline \multirow[t]{2}{*}{ WLDFDIadj } & $0.496^{* *}$ & $0.175^{\dagger}$ & 0.127 & $0.580^{* *}$ & $0.560^{* *}$ & $0.704^{* *}$ \\
\hline & $(0.053)$ & $(0.090)$ & $(0.091)$ & $(0.102)$ & $(0.099)$ & $(0.220)$ \\
\hline \multirow[t]{2}{*}{ PTAGDP } & 0.053 & 0.024 & 0.018 & $0.105^{* *}$ & 0.015 & 0.134 \\
\hline & $(0.033)$ & $(0.032)$ & $(0.032)$ & $(0.033)$ & $(0.066)$ & $(0.121)$ \\
\hline \multirow[t]{2}{*}{ DISTA } & -0.121 & -0.074 & -0.072 & $-0.241^{\dagger}$ & -0.076 & -0.446 \\
\hline & $(0.110)$ & $(0.098)$ & $(0.096)$ & $(0.126)$ & $(0.213)$ & $(0.405)$ \\
\hline $\mathrm{N}$ & 465 & 236 & 198 & 191 & 428 & 123 \\
\hline Log-lhd & -403.153 & -250.073 & -212.783 & -183.456 & -599.971 & -162.488 \\
\hline$\chi^{2}$ & 1817.553 & 851.215 & 948.444 & 412.818 & 294.012 & 37.187 \\
\hline
\end{tabular}

Therefore, the variation in the openness variable is smaller in the East Asia sample, where it also explains a smaller share of the variation in the dependent variable. The second important difference is that the coefficient on the REER variable is now significant at the one percent level (as opposed to the eight percent level in specification (2)) and much larger in absolute value. This could be capturing the particular importance of currency fluctuations for FDI in East Asia, such as the sharp fall in investment in the aftermath of the East Asian financial crisis. However, both the PT AGDP and the adist variables remain insignificantly different from zero. Therefore, the FDI results for East Asia largely parallel our conclusions based on the trade gravity model of Medvedev (2006) preferential liberalization does not seem to be an important channel for the region's integration with the rest of the world. Although it is possible to estimate the model for only South Asian countries, it is doubtful that the results are robust since there are barely enough observations to invoke the Central Limit Theorem (there are only two countries in this sample: India and Pakistan, for a total of 38 observations). Therefore, these estimates are not shown.

The next region we consider is Eastern Europe and the former Soviet Union. There are 15 countries in this sample (including the recent EU entrants) for a total of 191 observations. The relatively small number of observations (when compared with other regions) is due to the fact that little data are available for these countries prior to the 1990s. The estimation results are shown 
in column (4) of Table 15. The outcome is quite unlike the previous models, since all estimated coefficients with the exception of openness inflation are significantly different from zero and are correctly signed. The elasticities of the extended market variable and the average distance to PTA partners are somewhat larger than the reference specification (column (1) of Table 7), which shows that joining larger (and closer) markets through conclusion of various PTAs is an important mechanism of attracting additional FDI in this region.

The final set of regions to be examined include Middle Eastern and African countries. This is the largest group we have considered yet, with 24 countries and 428 observations. The estimated coefficients are shown in column (5) of Table 15. Only three variables are significantly different from zero: GDP, openness, and world FDI. While the coefficient on market size (GDP) is close to the estimate in the reference specification, trade openness is more than double its full sample estimate, suggesting that this is a particularly important determinant of FDI for these countries. However, neither the size of the extended common market nor the distance to PTA partners have significant influence on net FDI inflows. We get different results when we limit our sample to countries in the Middle East and North Africa, many of which have signed or are in the process of negotiating preferential agreements with the EU as a part of the future Euro-Mediterranean Free Trade Area. These estimates are shown in column (6), and cover 7 countries for a total of 123 observations. Given the very small sample size for this specification, we must be particularly careful with interpretation and inference - therefore the following comments should be taken with a special degree of caution. Despite the relatively low value of the Wald $\chi^{2}$ statistic, the model coefficients are significant as a group at the one percent level. Only two variables are significantly different from zero, and the REER variable is incorrectly signed. The latter could be due to the fact that most of the sample countries are major oil exporters (including Iran, Kuwait, Tunisia, and Algeria), which have experienced significant REER appreciation through the Dutch disease channel but have still attracted large quantities of FDI aimed at taking advantage of their natural resources. Shifting our focus to the PTA-related variables, neither the extended common market variable nor the average distance to PTA partners are significantly different from zero. Therefore, preferential liberalization does not appear to affect net FDI inflows for countries in the Middle East and North Africa, although these results must be heavily qualified due to the extremely small size of the sample. 


\section{References}

Adams, Richard, Philippa Dee, Jyothi Gali, and Greg McGuire (2003, May). "The trade and investment effects of preferential trading arrangements - old and new evidence." Working paper, Productivity Commission, Canberra.

Addison, Tony and Almas Heshmati (2003, May). "The new global determinants of FDI flows to developing countries." Discussion Paper 2003/45, UNU/WIDER (World Institute for Development Economics Research).

Asiedu, Elizabeth (2002, January). "On the determinants of foreign direct investment to developing countries: Is Africa different?" World Development 30(1), 107-119.

Balasubramanyam, V.N. (2001). "Foreign direct investment in developing countries: Determinants and impact." In New Horizons for Foreign Direct Investment. Paris: Organisation for Economic Co-operation and Development (OECD).

Baltagi, Badi H. (2001). Econometric Analysis of Panel Data (2 ed.). West Sussex, England: John Wiley \& Sons.

Berthelon, Matias (2004). "Growth effects of regional integration agreements." Working Paper 278, Central Bank of Chile.

Blomström, Magnus and Ari Kokko (1997, April). "Regional integration and foreign direct investment." Working Paper 6019, National Bureau of Economic Research (NBER).

Blonigen, Bruce (1997, June). "Firm-specific assets and the link between exchange rates and foreign direct investment." The American Economic Review 87(3), 447-465.

Blonigen, Bruce A. (2005, May). "A review of the empirical literature on FDI determinants." Working Paper 11299, National Bureau of Economic Research (NBER).

Brash, D. T. (1966). American Investment in Australian Industry. Canberra: Australian National University Press.

Buckley, Peter, Jeremy Clegg, Nicholas Forsans, and Kevin Reilly (2000). "United States foreign direct investment into Canada: An empirical analysis with emphasis on the free trade hypothesis." Mimeo, University of Leeds.

Burfisher, Mary, Sherman Robinson, and Karen Thierfelder (2001). "The impact of NAFTA on the United States." Journal of Economic Perspectives 15(1), 125-144.

Caves, Richard (1996). Multinational Enterprise and Economic Analysis. New York: Cambridge University Press.

Chakrabarti, Avik (2001). "The determinants of foreign direct investment: Sensitivity analyses of cross-country regressions." Kyklos 54(1), 89-114.

Chudnovsky, Daniel and Andrés López (2001). "La inversion extranjera directa en el Mercosur: Un análisis comparativo." In Daniel Chudnovsky and Andrés López, eds., El Boom de Inversión Extranjera Directa en el Mercosur. Buenos Aires: Siglo Veintiuno de Argentina Editores. 
Coughlin, Cletus and Eran Segev (2000). "Foreign direct investment in China: a spatial econometric study." World Economy 23(1), 1-23.

Cushman, David O. (1985, May). "Real exchange rate risk, expectations, and the level of direct investment." The Review of Economics and Statistics 67(2), 297-308.

Dollar, David (1992, April). "Outward-oriented developing economies really do grow more rapidly: Evidence from 95 LDCs, 1976-85." Economic Development and Cultural Change 40(3), 523-544.

Dollar, David and Aart Kraay (2003, March). "Institutions, trade, and growth: Revisiting the evidence." Policy Research Working Paper 3004, World Bank.

Dunning, John H. (1958). American Investment in British Manufacturing Industry. London: George Allen and Unwin.

Dunning, John H (1977). "Trade, location of economic activity and MNE: A search for an eclectic approach." In B. Ohlin, P. O. Hesselborn, and P.M. Wijkman, eds., The International Allocation of Economic Activity. London: Macmillan.

Dunning, John H (2000). "The impact of the completion of the European internal market on FDI." In John H Dunning, ed., Regions, Globalization and the Knowledge-Based Economy. Oxford: Oxford University Press.

Frankel, Jeffrey and Andrew Rose (2002, May). "An estimate of the effect of common currencies on trade and growth." The Quarterly Journal of Economics 117(2), 437-466.

Froot, Kenneth and Jeremy Stein (1991, November). "Exchange rates and foreign direct investment: An imperfect capital markets approach." The Quarterly Journal of Economics 106(4), 1191-1217.

Globerman, Steven (2002, August). "Trade, FDI and regional economic integration: Cases of North America and Europe." Paper presented at "Enhancing Investment Cooperation in Northeast Asia", Honolulu.

Globerman, Steven and Daniel Shapiro (1999). "The impact of government policies on foreign direct investment: The Canadian experience." Journal of International Business Studies 30(3), $513-532$.

Globerman, Steven and Daniel Shapiro (2002, December). "National political infrastructure and foreign direct investment." Working Paper 37, Industry Canada Research Publications Program.

Graham, Edward and Erika Wada (2000). "Domestic reform, trade and investment liberalization, financial crisis, and foreign direct investment into Mexico." World Economy 23(6), 777-797.

Granger, Clive W. J. (1969, July). "Investigating causal relations by econometric models and cross-spectral methods." Econometrica 37(3), 24-36.

Greene, William H. (2000). Econometric Analysis (4 ed.). Upper Saddle River, New Jersey: Prentice Hall.

Horst, T. (1972). "Firm and industry determinants of the decision to invest abroad." The Review of Economics and Statistics 54, 37-45. 
Jaumotte, Florence (2004, November). "Foreign direct investment and regional trade agreements: The market size effect revisited." Working Paper 04/206, International Monetary Fund (IMF).

Kolstad, Ivar and Line Tondel (2002). "Social development and foreign direct investments in developing countries." Report 11, Chr. Michelsen Institute, Bergen, Norway.

Krueger, Anne O. (1999). "Are preferential trading agreements trade-liberalizing or protectionist?" Journal of Economic Perspectives 13(4), 105-124.

Lederman, Daniel, William Maloney, and Luis Serven (2005). Lessons from NAFTA for Latin America and Caribbean Countries: A Summary of Research Findings. Washington, DC: World Bank.

Lee, J.-Y. and Edwin Mansfield (1996). "Intellectual property protection and US foreign direct investment." The Review of Economics and Statistics 78, 181-186.

Levy Yeyati, Eduardo, Ernesto Stein, and Christian Daude (2003). "Regional integration and the location of FDI." Working Paper 492, Inter-American Development Bank(IADB).

Lim, Ewe-Ghee (2001, November). "Determinants of, and the relation between, foreign direct investment and growth: A summary of the recent literature." Working Paper 01/175, International Monetary Fund (IMF).

Mansfield, Edwin (1993). "Unauthorized use of intellectual property: Effects on investment, technology transfer, and innovation." In M. Wallerstein, M. Mogee, and R. Schoen, eds., Global Dimensions of Intellectual Property Rights in Science and Technology. Washington, DC: National Academy Press.

Markusen, James R. (2002). "Foreign direct investment and trade." In Bijit Bora, ed., Research Issues in Foreign Direct Investment. London: Routledge.

Maskus, Keith (1998). "The international regulation of intellectual property." Weltwirtschaftliches Archiv 134, 186-208.

Maskus, Keith (2000). Intellectual Property Rights in the Global Economy. Washington, DC: Institute for International Economics.

Maskus, Keith and Denise Eby-Konan (1994). "Trade-related intellectual property rights: Issues and exploratory results." In Alan Deardoff and Robert Stern, eds., Analytical and Negotiating Issues in the Global Trading System. Ann Arbor: University of Michigan Press.

Medvedev, Denis (2006, October). "Preferential trade agreements and their role in world trade." Policy Research Working Paper 4038, World Bank.

Monge-Naranjo, Alexander (2002, August). "The impact of NAFTA on foreign direct investment flows in Mexico and the excluded countries." Department of Economics, Northwestern Unweversity.

Pain, Nigel (1997). "Continental drift: European integration and the location of uk foreign direct investment." The Manchester School Supplement 65, 94-117. 
Pain, Nigel and Melanie Lansbury (1997). "Regional economic integration and foreign direct investment: The case of German investment in Europe." National Institute Economic Review 160, $87-99$.

Primo Braga, Carlos and Carsten Fink (1998). "The relationship between intellectual property rights and foreign direct investment." Duke Journal of Comparative and International Law 9, $163-188$.

Rodriguez, Francisco and Dani Rodrik (2001). "Trade policy and economic growth: A skeptic's guide to the cross-national literature." In B. Bernanke and K. S. Rogoff, eds., Macroeconomics Annual 2000. Cambridge, MA: MIT Press for NBER.

Rodrik, Dani (1999). "The new global economy and developing countries: Making openness work." Policy Essay 24, Overseas Development Council, Washington, DC.

Rodrik, Dani, Arvind Subramanian, and Francesco Trebbi (2004). "Institutions rule: the primacy of institutions over geography and integration in economic development." Journal of Economic Growth 9(2), 131-165.

Rose, Andrew and Eric van Wincoop (2001). "National money as a barrier to international trade: The real case for currency union." The American Economic Review 91(2).

Sachs, Jeffrey and Andrew Warner (1995). "Economic reform and the process of global integration." Brookings Papers on Economic Activity 1, 1-118.

Soloaga, Isidro and L. Alan Winters (2001). "Regionalism in the nineties: What effect on trade?" North American Journal of Economics and Finance 12(1), 1-29.

UNCTAD (1998). World Investment Report: Trends and Determinants. New York: United Nations Conference on Trade and Development.

Winters, L. Alan (2004). "Trade liberalisation and economic performance: An overview." The Economic Journal 114(493), F4-F21.

World Bank (2000). Trade Blocs. Oxford University Press.

World Bank (2001). Global Development Finance 2001: Coalition Building for Effective Development Finance. Washington, DC: World Bank.

World Bank (2002). Global Economic Prospects 2003: Investing to Unlock Global Opportunities. Washington, DC: World Bank.

World Bank (2004). Global Economic Prospects 2005: Trade, Regionalism, and Development. Washington, DC: World Bank.

Yanikkaya, Halit (2003). "Trade openness and economic growth: a cross-country empirical investigation." Journal of Development Economics 72, 57-89. 